Pacific Northwest

National Laboratory

Operated by Battelle for the

U.S. Department of Energy

\section{Mineralogical and Bulk-Rock Geochemical Signatures of Ringold and Hanford Formation Sediments}
Y. Xie
G.V. Last
C.J. Murray
R. Mackley

February 2003

Prepared for the U.S. Department of Energy under Contract DE-AC06-76RL01830 


\title{
DISCLAIMER
}

This report was prepared as an account of work sponsored by an agency of the United States Government. Neither the United States Government nor any agency thereof, nor Battelle Memorial Institute, nor any of their employees, makes any warranty, express or implied, or assumes any legal liability or responsibility for the accuracy, completeness, or usefulness of any information, apparatus, product, or process disclosed, or represents that its use would not infringe privately owned rights. Reference herein to any specific commercial product, process, or service by trade name, trademark, manufacturer, or otherwise does not necessarily constitute or imply its endorsement, recommendation, or favoring by the United States Government or any agency thereof, or Battelle Memorial Institute. The views and opinions of authors expressed herein do not necessarily state or reflect those of the United States Government or any agency thereof.

\author{
PACIFIC NORTHWEST NATIONAL LABORATORY \\ operated by \\ BATTELLE \\ for the \\ UNITED STATES DEPARTMENT OF ENERGY \\ under Contract DE-AC06-76RL01830
}

This document was printed on recycled paper. 


\section{Mineralogical and Bulk-Rock \\ Geochemical Signatures of Ringold and Hanford Formation Sediments}
Y. Xie
G. V. Last
C. J. Murray
R. Mackley

February 2003

Prepared for

the Groundwater Protection Project

Managed by Fluor Hanford, Inc., and

the U.S. Department of Energy

under Contract DE-AC06-76RLO 1830

Pacific Northwest National Laboratory

Richland, Washington 99352 


\section{Summary}

Pacific Northwest National Laboratory (PNNL) conducted this study for the Groundwater Protection Project managed by Fluor Hanford, Inc., and the U.S. Department of Energy (DOE). The purpose of the study was to explore the possibility of using statistical methods to classify sediment samples belonging to the Hanford and Ringold formations using mineralogy and geochemistry data. Visual examinations of the sediment do not always conclusively identify the geologic formation to which a sample belongs.

The Hanford and Ringold formations constitute the majority of the vadose zone sediments within DOE's Hanford Site. They are particularly important because of the control they exert on contaminant transport in the subsurface environment. Although much is known about the formations from geologists' studies, quantitative methods for distinguishing between them had not been developed.

In this study, PNNL constructed a database consisting of existing mineralogy measurements made using electron microprobe (EM) and petrographic (Petro) techniques and geochemical compositions measured by x-ray fluorescence (XRF). Data were concentrated in the 200 West and 200 East Areas of the Hanford Site. Statistical techniques were used to examine the distributions of the variables. Principal component analysis was used to examine the multivariate structure of the data. In addition, several classification methods were used to identify classification functions that could be used to distinguish between the two formations.

Based on the results of this study, we concluded that principal component analysis, discriminant function analysis, and machine learning methods were valuable additions to the standard toolbox in quantifying the explanatory value of mineral and chemical variables and determining which are most effective in distinguishing between the Ringold and Hanford stratigraphic units.

Several recommendations are appropriate:

- To test the power of the study's approach, it would be beneficial to conduct a future field sampling campaign where common mineralogical and geochemical analyses could be conducted on the same samples. This would allow the use of joint information from the two kinds of measurements to determine the best variables for distinguishing between the two formations. This sampling campaign should include representative samples from all post-basalt units and facies, including the Cold Creek unit.

- To address concerns with grain size variation, Petro and XRF measurements should be performed on just the fine sample fraction of the samples. An alternative possibility would be to include grain size statistics (e.g., mean grain size, sorting, and skew ness) as additional variables in the multivariate analysis.

- Future work should build on the datasets developed for this study with new data from a broader geographic area and all suprabasalt sediments, making it possible to classify samples taken from uncertain stratigraphic units with a high level of confidence. 
- Preliminary work by Pacific Northwest National Laboratory staff, and conclusions reached in the scientific literature, both indicate that the routine measurement of trace element data would be a valuable addition to the suite of data that could be used to distinguish between suprabasalt sediments at the Hanford Site.

Given the differences in chemical and mineral composition for the Hanford and Ringold formations identified in this study, and the control that compositional differences often exert on $\mathrm{K}_{\mathrm{d}}$ 's for different contaminants, it appears that routine measurement of chemical and mineralogical composition from new Hanford boreholes would make it easier to classify Hanford and Ringold sediments and also provide data that would be useful for predicting the $\mathrm{K}_{\mathrm{d}}$ values for the sediments. 


\section{Contents}

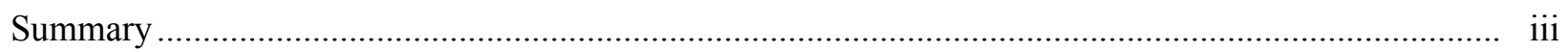

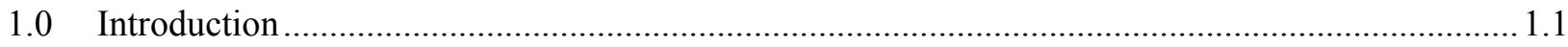

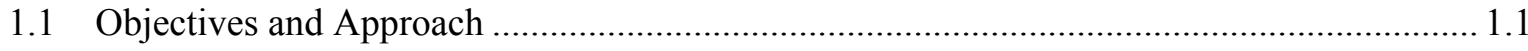

1.2 Geological Background ........................................................................................... 1.1

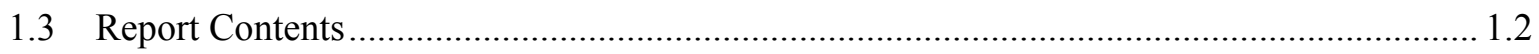

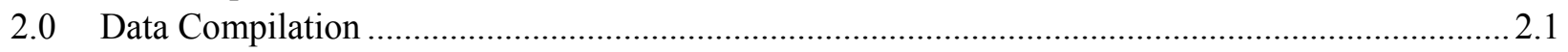

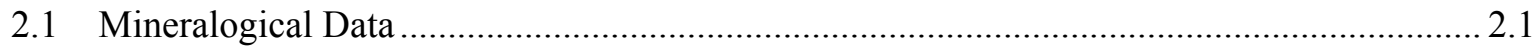

2.2 Bulk Rock Chemistry - X-Ray Fluorescence Spectrometry …………………………….... 2.3

3.0 Statistical Analysis Approaches …………………………........................................................

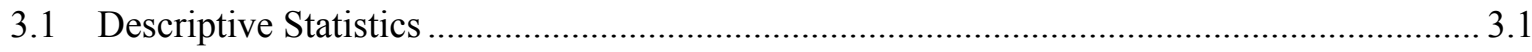

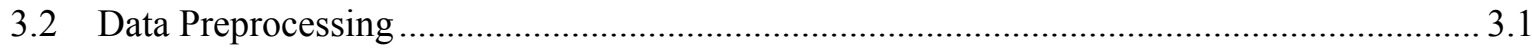

3.3 Statistical Tests of Differences in Variable Distributions ………………………………...... 3.2

3.4 Principal Component Analysis .............................................................................. 3.2

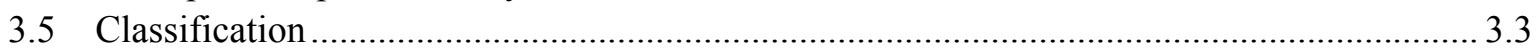

3.5.1 Linear Discriminant Analysis.............................................................................. 3.3

3.5.2 OneR

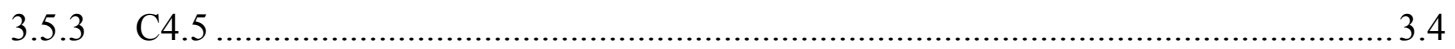

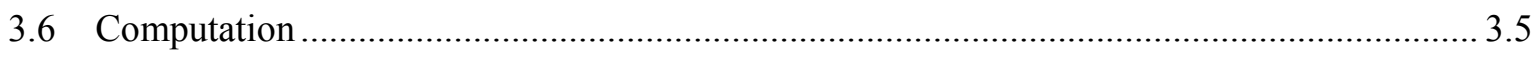

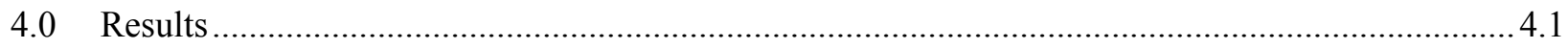

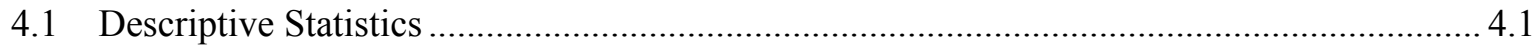

4.2 Tests of Differences Between Data from the 200 East and 200 West Areas ......................... 4.5

4.3 Tests of Differences in Geochemical and Mineralogical Variables Between Hanford and Ringold Formations .................................................................................................. 4.8

4.4 Principal Component Analysis ........................................................................................ 4.11

4.5 Classification of Samples from Hanford and Ringold Formations ……………………...... 4.16

4.6 Classification Rules from Machine Learning Algorithms................................................... 4.18

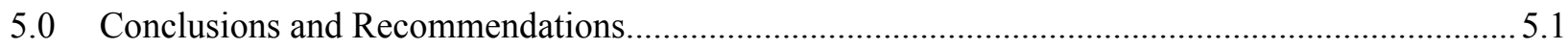

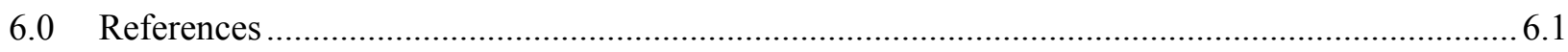

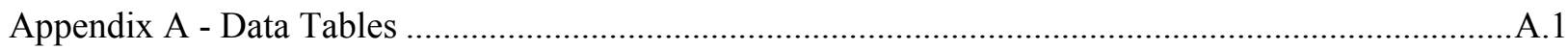

Appendix B - Supporting Data Analysis and Figures .......................................................................... 


\section{Figures}

4.1a Histograms of 35 EM Samples From 200 West Area ................................................................... 4.2

4.2 Histograms of 22 Petro Samples From 200 West Area.............................................................. 4.4

4.3 Box Plots Showing the Strong Control on Chemical Composition Related to Particle Size for Hanford Formation Samples from the 200 West Area ................................................................. 4.5

4.4a Histograms of 68 XRF Samples From 200 West Area ................................................................ 4.6

4.4b Histograms of all 99 XRF Samples From 200 West and 200 East Areas .................................... 4.6

4.5 Variable Loadings on the First Two PCs for 35 EM Samples from the 200 West Area and

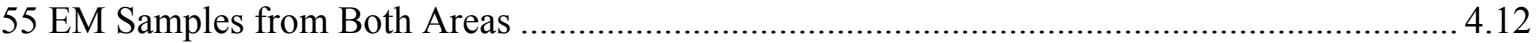

4.6 Scatter Plot of Data On PC1-PC2 Space for 35 EM Samples From the 200 West Area .............. 4.12

4.7 Variable Loadings for the First Two PCs of 22 Petro Samples from the 200 West Area............. 4.13

4.8 Scatter Plot of Data on PC1-PC2 space of 22 Petro Samples from the 200 West Area................ 4.14 


\section{Tables}

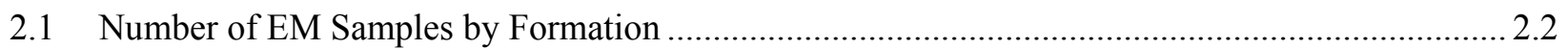

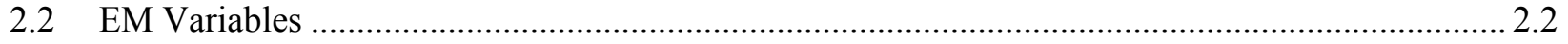

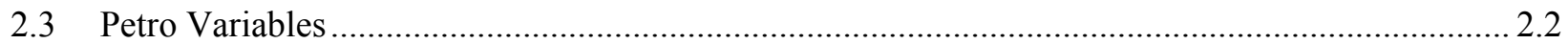

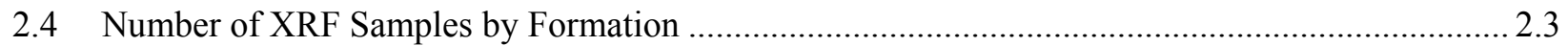

4.1 Significance Test on the Distribution Difference between EM Samples from the 200 West and 200 East Areas Based on Mann-Whitney (M-W), Two-Sample Kolmogorov-Smirnov (K-S), and Analysis Of Variance (ANOVA) Tests.

4.2 Significance Test on the Distribution Differences between Hanford Formation XRF Data from the 200 West and 200 East Areas Based on Mann-Whitney (M-W), Two-Sample Kolmogorov-Smirnov (K-S), and Analysis Of Variance (ANOVA) Tests

4.3 Significance Tests of EM Variables in Terms of the Differences Between Hanford and Ringold Formation Samples (200 West Area)

4.4 Significance Tests of EM Variables in Terms of the Differences Between Hanford and Ringold Formation Samples (both 200 West and 200 East) ....

4.5 Significance Tests of Petro Variables in Terms of the Differences Between Hanford and Ringold Formation Samples (200 West Area)

4.6 Significance Tests of XRF Variables in Terms of the Differences Between Hanford and Ringold Formation Samples (200 West Area)

4.7 Significance Tests of XRF Variables in Terms of the Differences Between Hanford and Ringold Formation Samples (both 200 West and East Areas)

4.8 Validation of Classification Results for 200 West Area EM Samples......................................... 4.16

4.9 Validation of Classification Results for 200 West Area Petro Samples ...................................... 4.17

4.10 Validation of Classification Results for 200 West XRF Samples .............................................. 4.18

4.11 Classification Rules from Machine Learning Methods for EM, Petro, and XRF Data................. 4.19 


\subsection{Introduction}

The Hanford and Ringold formations are two important geological formations at the U.S. Department of Energy (DOE) Hanford Site because they constitute the main controls on contaminant transport. Although much is known about the two formations from geologists' studies, quantitative methods for distinguishing between them have not been developed. This report documents a preliminary study of statistical methods that can be used for that purpose. The report describes recent efforts on the 1) compilation of an electronic database of mineralogical and bulk-rock geochemical data collected during the last 30 years, 2) calculation of descriptive statistics to summarize the distribution characteristics of the two geological formations, 3) exploration of possible natural patterns of the data and potential important variables for distinguishing between the Hanford and Ringold formations, and 4) building quantitative classifiers based on a variety of statistical and machine learning methods and checking the classification capability for distinguishing samples from the two geological formations. Informative variables are identified and recommendations for future well drilling and data collection are provided.

\subsection{Objectives and Approach}

The objective of this study was to explore quantitative approaches to distinguish between the two important geological units at the Hanford Site: the Hanford and Ringold formations. To achieve this objective, mineralogical and bulk-rock geochemical data collected over more than 30 years by different research groups were compiled into a central, digital database. The data were concentrated in the 200 West Area and 200 East Area. Although the 200 West Area was the primary focus of this study, statistical analyses were also conducted on data pooled from the two areas. Variable distributions were investigated when the data were treated as a whole as well as for subgroups comprised of samples from the two formations and for subsamples from the two sampling areas. Natural patterns within the data and the identity of variables with the potential to distinguish between the two geological formations also were investigated. Statistical techniques and machine learning approaches were applied to build classifiers based on multivariate measurements from the 200 West Area. The classification performance was evaluated by cross validation.

\subsection{Geological Background}

The 200 West and 200 East Areas are located near the center of the Hanford Site. The Site lies within the Pasco Basin, a topographic depression and structural basin located within the center of the Columbia Plateau Physiographic Province. Bedrock geology consists mainly of the Miocene age Columbia River Basalt Group. Thick packages of coarse-grained to fine-grained sediments overlie the basalt. These suprabasalt sediments include the Neogene fluvial deposits of the Ringold Formation; colluvial, alluvial, eolian, and pedogenic deposits of Cold Creek Unit (formerly the Plio-Pleistocene unit); and Pleistocene flood deposits associated with cataclysmic ice-age flooding referred to as the Hanford formation (Tallman et al. 1979; Baker 1973; Bjornstad 1990; and DOE, 2002). Most of the Ringold formation was eroded from the 200 East Area. 
Of particular interest to this study were the similarities and differences of the Ringold and Hanford formations, as they constitute the majority of the vadose zone sediments within the Hanford Site. Finegrained facies of the two formations are usually easy to distinguish. However, coarse-grained facies of these formations can be difficult to distinguish from each other in drill cuttings. Generally, distinction between the coarse-grained facies of the two formations has been based on the following observations:

- the Ringold formation 1) contains an abundance of lighter colored, rounded granite and quartzite cobbles; 2) often has a bimodal grain size distribution; and 3) is often weathered to a reddish, orange color from iron oxide staining associated with its diagenesis and partial cementation.

- The coarse-grained Hanford formation sediments occasionally have an open framework of dark, subangular to subrounded basaltic gravels with a poorly sorted matrix of silt and sand, lacking any significant weathering alteration as a result of its rapid burial during cataclysmic floods and its younger age (Tallman et al. 1979; Bjornstad 1990; G. Last, Pacific Northwest National Laboratory, personal comm.).

Hanford formation depositional structures often reflect their high-energy depositional environment in the form of steep, foreset bedding, but this is normally difficult to detect in core samples. Significant variations exist in both units, sometimes making clear, confident assignments to either unit difficult. Complicating things further is that, in at least some locales, sediments originally deposited as Ringold were subsequently reworked during later, Pleistocene proglacial flooding and then re-deposited. These sediments show depositional structures common to the Hanford formation but still retain Ringold-like composition. In the 200 West Area the complications associated with reworking are minimal (G. Last, Pacific Northwest National Laboratory, personal comm.).

\subsection{Report Contents}

Section 2.0 of this document describes the data compilation process for this study. Section 3.0 outlines the statistical analytical approaches. Results of our analyses are presented in Section 4.0. Section 5.0 presents conclusions and recommendations. Supporting data are presented in Appendix A, with supporting analyses in Appendix B. 


\subsection{Data Compilation}

More than 30 years of data, located in many separate locations within the Applied Geology and Geochemistry Group at PNNL, were gathered for this study and manually entered into an electronic database. A recently published data catalog (Horton et al. 2001) was used to identify reports containing data pertinent to the study. Scientists familiar with previous studies of the Site also were consulted. Data were collected on mineralogy and bulk rock geochemistry. No subjective, "second generation loss" of the data in terms of its integrity, was intentionally introduced during the process of entering the data, other than unit conversions where necessary to maintain homogeneity within the database. In instances where the exact data were reported in more than one report, the earliest publication was cited. Microsoft Excel was used to store and organize the data. In the future, this Excel spreadsheet will be incorporated into a more robust database structure to manage and maintain configuration control of the data.

It is not the purpose of this study to detail each analytical method or laboratory technique used in the various reports from which the data were derived. However, it is important in such a quantitative study to be alert to certain biases or strong statistical tendencies that arise out of similarities and differences between analytical methods.

The data compiled for the study are tabulated in Tables A.1 to A.3 in Appendix A.

\subsection{Mineralogical Data}

The mineralogical data collected and compiled in the database came from two different analytical methods: electron microprobe (EM) and petrography (Petro). Although many recent reports use X-ray diffraction (XRD) to analyze mineralogy, XRD data are semi-quantitative, which makes direct comparison of results difficult. Thus, the study did not include mineralogical XRD data. The EM and Petro techniques are based on two different approaches, and analysis of the mineralogical data from the two techniques (not shown) suggests that they provide significantly different results, e.g., for the concentration of a single mineral like quartz. Mineralogical data obtained from the two techniques should be analyzed separately and should not be combined into a single dataset.

Fifty-nine samples with EM data were collected on 13 measured variables. A total of 35 samples from the 200 West Area and 20 samples from the 200 East Area were labeled by the geological formation. Table A.1 presents the EM data. Geological formation designations for each sample were taken from the data sources given in Appendix A. Samples for which the geologic formation designations were not available in the original sources were not included for this or other datasets assembled for the study. It is possible that some samples designated as belonging to the Hanford formation may actually belong to the Cold Creek unit as recently defined in DOE (2002). The formation designations should be reevaluated in future studies.

Table 2.1 summarizes the sample split between locations and formations for the EM data. The 13 variables measured on the samples are tabulated in Table 2.2. As shown in Table 2.1, the number of samples from the two formations are well balanced. For example, there were 17 Hanford samples and 18 
Table 2.1. Number of EM Samples by Formation

\begin{tabular}{|c|cc|c|}
\hline Location & Hanford & Ringold & Total \\
\hline 200 West & 17 & 18 & 35 \\
200 East & 14 & 6 & 20 \\
\hline Overall & 31 & 24 & 55 \\
\hline
\end{tabular}

Table 2.2. EM Variables

\begin{tabular}{||lll||}
\hline \multicolumn{3}{|c||}{ Name of Measured Variables } \\
\hline QUARTZ & MAGNETITE & SPHENE \\
MICROCLINE & AMPHIBOLES & APATITE \\
PLAGIOCLASE & ALBITE & MICA \\
PYROXENES & ILMENITE & \\
CALCITE & EPIDOTE & \\
\hline
\end{tabular}

Ringold samples from the 200 West Area and 14 Hanford samples and 6 Ringold samples from the 200 East Area. The summations of the measured variables were $100 \%$ for the 35 samples from the 200 West Area, and for several samples from the 200 East Area. However, there were 14 samples from the 200 East Area for which the variable summations are not $100 \%$. Five out of the 14 samples have minor absolute deviations of $0.1 \%$ that might be due to rounding error, but the absolute deviations of the other 9 samples range from $9 \%$ to $30 \%$, indicating possible errors in the EM data for those 9 samples.

A total of 22 samples with petrographic measurements of mineralogy were analyzed from the 200 West Area. Petro variables include the percentages of both monomineralic grains and rock fragments that contain more than a single mineral. Some samples classified by geologists as Hanford formation may actually be from the gravel facies of the Cold Creek unit (DOE 2002). There were five samples for which the mineralogical variables do not sum to $100 \%$, but the largest absolute deviation is smaller than $2.5 \%$. Of the 22 Petro samples, 6 were from the Hanford formation, and 16 were from the Ringold Formation. The measured Petro variables are shown in Table 2.3.

Table 2.3. Petro Variables

\begin{tabular}{||l|l||}
\hline \multicolumn{2}{|c|}{ Name of Measured Variable } \\
\hline QUARTZ & MUSCOVITE \\
PLAGFELDSPAR & OPAQUES \\
MAFIC $^{(a)}$ & GARNET \\
SEDAGGREGATE $^{(a)}$ & EPIDOTE \\
K_FELDSPAR $_{\text {PYROXENE }}$ & GRANITIC $^{(a)}$ \\
HORNBLENDE & METAMORPHIC $^{(a)}$ \\
BIOTITE & CARBONATE \\
\hline (a) rock fragments. & OTHER \\
\hline
\end{tabular}




\subsection{Bulk Rock Chemistry - X-Ray Fluorescence Spectrometry}

X-ray fluorescence spectrometry (XRF) commonly has been used to measure elemental composition at the Hanford Site. The rock chemistry dataset consists of 68 samples (including 5 composite samples) from the 200 West Area and 21 samples from the 200 East Area. The composite samples contain sediment from more than a single well. The measurements include 7 oxides, $\mathrm{Al}_{2} \mathrm{O}_{3}, \mathrm{SiO}_{2}, \mathrm{FeO}, \mathrm{CaO}, \mathrm{K}_{2} \mathrm{O}$, $\mathrm{TiO}_{2}$, and $\mathrm{MnO}$. Unfortunately, sodium, which is another key indicator of mobility and degree of weathering, was not analyzed in the existing data because the capability to measure it by XRF did not exist in the 1980s when most of the samples were analyzed (R. J. Serne, Pacific Northwest National Laboratory, personal comm., 2002).

The bulk-rock chemistry data can be found in Table A.3. Table 2.4 shows the split in the data by geological formation and sampling area. Among the 68 samples from the 200 West Area, 27 are Hanford sediment samples, and 41 are Ringold sediment samples. The 31 samples from the 200 East Area are all Hanford formation sediment samples. Some samples classified by geologists in the source reports as Hanford formation may actually be from the Cold Creek unit (DOE 2002). The oxide summations of all 68 samples from the 200 West Area are $100 \%$.

Because the major oxides are relatively common in all sedimentary rocks, major oxide differences don't always uniquely set formations apart. Unfortunately, not all the original sources for the data included trace element data, so assembling a dataset for examination of the value of trace element data for distinguishing between Hanford and Ringold sediments was not performed for this study. However, preliminary studies by Bjornstad (1990) indicate that the trace elements $\mathrm{Rb}, \mathrm{Zn}, \mathrm{Zr}$, and Ba can be used to differentiate between the Hanford and Ringold formations. A recent study on the value of chemical and mineralogical data for differentiating between clastic sediments from different formations found that trace elements were the most valuable data (von Eynatten et al. 2003). The use of trace element data to distinguish between suprabasalt formations at the Hanford Site should be pursued in future studies.

Table 2.4. Number of XRF Samples by Formation

\begin{tabular}{||l|cc|c|}
\hline \multicolumn{1}{|c|}{ Location } & Hanford & Ringold & Total \\
\hline 200 West & 27 & 41 & 68 \\
200 East & 31 & 0 & 31 \\
\hline Overall & 58 & 41 & 99 \\
\hline
\end{tabular}




\subsection{Statistical Analysis Approaches}

\subsection{Descriptive Statistics}

Descriptive statistics such as the mean, median, minimum, maximum, etc., were calculated to provide a brief summary of the data available for each variable. In addition, histograms and box and whisker plots were plotted for each variable as visual supplements to the descriptive statistics.

\subsection{Data Preprocessing}

Most statistical methods assume that observations are from a normally distributed population, but most geological data do not exhibit a normal distribution. Many geologic variables are positively skewed: lognormal or "fuzzy" distributions are often the norm in geological data (Chapman 1976; Rock 1988); data assembled for this study are no exception. A logarithmic transformation is widely used to transform the positively skewed geological data into a more symmetrical form. The logarithmic transformation also tends to stabilize the variance of the data (Davis 2002).

In addition to being positively skewed, the data assembled for this study also suffer from a closure problem. The measurements in the mineralogy and geochemistry datasets consist of proportional measurements in which the sum of the proportions for all variables for a given sample are expected to sum to $100 \%$. This kind of data is referred to as compositional data or closed data (Aitchison 1986; Davis 2002). For closed data, an increase in the proportion of one variable can only occur at the expense of the proportions of other variables, which causes a spurious negative correlation among variables. Therefore, it may be unclear if a correlation observed between a pair of variables is due to a real correlation between the variables or from the mathematical constraint of closure.

Studies on the statistical implications of non-normality and the closure problem by Pearson (1897), Aitchison (1981), and Rietjens (1995), to name a few, have resulted in various suggested methods and transformational solutions to their effects. Although no universal consensus currently exists within the literature, Aitchison's log-ratio transformation is applied to geochemical datasets more frequently than any other and has been shown to reliably account for non-normality and closure (Verrucchi and Minissale 1995; Reyment and Savazzi 1999; Cullers 2000). Because the absolute magnitudes of compositional variables are ratios to a common sum, Aitchison proposed to use relative magnitudes by calculating the ratio of each compositional variable compared to a single variable that functions as a constant divisor. Further, by taking the logarithm of the ratios, the transformed values can vary over the entire real number range, rather than being restricted to the range from zero to $100 \%$. Thus, this transformation makes the application of conventional statistical techniques more justifiable.

Because of the existence of large numbers of zero values in the EM and Petro datasets, it was not possible to apply either a logarithmic transformation to handle the skewed distributions or a logratio transformation to deal with the closure problem. Therefore, the EM and Petro mineralogical datasets were not transformed for this study. A recently published paper discusses a method for replacement of zero values (von Eynatten et al. 2003) so that a logratio transform can be applied to mineralogical data. 
That approach should be adopted in future studies. A logratio transformation was applied to the XRF data, and $\mathrm{Al}_{2} \mathrm{O}_{3}$ was chosen as the common divisor because of its immobility during weathering and its common occurrence in both the Ringold and Hanford formations.

\subsection{Statistical Tests of Differences in Variable Distributions}

The histogram and box and whisker plots are good visualization tools for examining data distributions. When box-whisker plots are plotted in parallel for different subgroups of samples (e.g., different formations or geographic areas) the difference and/or consistency in the distributions of the variables can be easily visualized in a qualitative way.

Statistical tests were applied to provide a quantitative assessment of the significance of the differences. Analysis of Variance (ANOVA) was used to test the equality of the means of groups of samples. Non-parametric tests were also applied to supplement the ANOVA because ANOVA assumes a normal distribution, and a number of the variables used in this study are very skewed and depart significantly from a normal distribution. To supplement the ANOVA, we applied two non-parametric methods that are more resistant to departures from normality. The Kruskal-Wallis test was used to test the equality of the non-parametric counterpart of the means (i.e., the medians) of the subgroups. The test statistic is constructed by sorting the data based on their ranks and calculating the sum of the ranks for each subgroup. For situations with only two subgroups, the Kruskal-Wallis test is identical to the Mann-Whitney test. We used an additional non-parametric test, the two-sided Kolmogorov-Smirnov test, to determine whether two independent subgroups of samples came from the same distribution by comparing their cumulative distributions.

\subsection{Principal Component Analysis}

In this study, principal component analysis was used to investigate the data patterns and variable relationships of the mineralogical and geochemical measurements. Principal component analysis (Johnson and Wichern 1988; Davis 2002) is aimed at finding and interpreting hidden, complex, and possibly causally determined relationships between variables in a dataset by studying the correlations between multiple variables. Normally, data with many correlated variables can be represented by a smaller number of principal components. This allows the study of data in the high-dimensional variable space through its projection onto a lower-dimensional principal component space. Principal component analysis has been used in other studies for identifying the multivariate structure of mineralogy and geochemistry data from clastic sedimentary formations (von Eynatten et al. 2003).

A multivariate data vector, $x=\left(x_{1}, x_{2}, \ldots, x_{n}\right)$, can be viewed as a point in the high-dimensional space where each of the $n$ measured variables represents an axis. A set of multivariate data, $X_{m \times n}$, therefore forms a cloud of $m$ data points in the $n$-dimensional variable space. Principal component analysis can be viewed as a coordinate rotation process of the data cloud. The data in the original measured variable coordinate system are transformed (rotated) into a new coordinate system where the axes are the orthogonal principal components, and each principal component axis is a linear combination of the original measured variables. The orthogonality of the principal components means that they are independent, i.e., uncorrelated. The principal components are derived in a descending order in terms of the amount of 
variance accounted for by each principal component. In other words, the first principal component axis is the direction along which the maximum data variance exists and so on. The principal component analysis of a dataset can thus be expressed as: $X_{m \times n}=S_{m \times p} \times L_{p \times n}^{\prime}$. The coefficients (weights) of the original variables in the principal components are called the loadings, $L$, which describe the relative importance of the $n$ variables in each principal component and also reveal the common influence of variables to certain principal components, indicating some important variable relationships. The projections of data onto the new principal component axes are called the principal component scores, $S$, which are the coordinates of the data on the new axes. Because each principal component maximizes the variance remaining in the data, the full data variance can often be expressed with fewer principal components $(p)$ than the number of original variables $(n)$. This occurs when the original variables are highly correlated, so that several of them may be regarded as partially redundant. Natural patterns embedded in a high-dimensional variable space can thus be visualized in a lower dimensional (e.g., 2-, or 3-dimensional) principal component space.

Several different algorithms can be used to conduct principal component analysis. Eigenanalysis (Rencher 1995) and singular value decomposition (Golub and Van Loan 1983) are two popular methods. From eigenanalysis, loadings of the principal component, $L$, are given directly by the eigenvectors, which are orthogonal vectors with unit norm. In literature and commercial software packages, the term loadings sometimes refers to the multiplication of the orthonormal eigenvectors with the eigenvalues. An eigenvalue represents the amount of variance expressed by the principal component associated with it. Nevertheless, the relative values (coefficients, weights) of the variables in a principal component remain the same. Principal component scores can be obtained through manipulation of the original data matrix and loading matrix. Both scores and loadings are orthogonal. Scatter plots of the principal component scores are often used to visualize patterns of data in the lower-dimensional principal component space.

\subsection{Classification}

Classification represents another type of multivariate data analysis where the aim is to build classifiers based on data with multiple measured variables and a known designation of classes. Classification is a particular type of pattern recognition, and there are numerous statistical and machine learning methods that can be used for classification. In this study, linear discriminant function analysis and two machine learning methods were applied to develop mathematical functions that could be used to classify samples into the proper formations using mineralogical or geochemical data. Linear discriminant analysis is a well-known classification technique that has been applied by other researchers to the classification of data from different sedimentary formations (von Eynatten et al. 2003). The goal of the classification analysis was to develop an approach that could be used to provide estimates of the probability that unknown samples belong to either the Hanford or the Ringold formations based on their mineralogy or geochemistry, using relationships developed from samples where the identity of the formation was known.

\subsubsection{Linear Discriminant Analysis}

Linear discriminant analysis (Johnson and Wichern 1988) is a classical multivariate statistical approach for classification where the discriminant hyperplane is found by maximizing the variance between classes and minimizing the variance within classes. Similar to principal component analysis, 
linear discriminant analysis seeks to identify new axes known as discriminant functions that are the linear combination of the original measured variables that best serve to differentiate between the classes:

$$
s_{k}=w_{k}{ }^{\prime} \times x=w_{k 1} \times x_{1}+w_{k 2} \times x_{2}+\ldots+w_{k n} \times x_{n}
$$

The weights $w$ of the linear discriminant function are usually found as the eigenvectors of the following eigen function:

$$
\left(B \times W^{1}\right) w=\lambda w
$$

where $B$ expresses the variance between the means of the classes, and matrix $W$ expresses the pooled within-class variance of all the classes.

For the discriminant function, a discriminant score can be calculated for a sample that is the location of the object along the axis represented by the discriminant function. Because we can also compute the scores (locations along the axis) of the means of each class and their variance, we can easily classify each object based on the distance between its discriminant score and the scores of the class means.

\subsubsection{OneR}

OneR (Holte 1993; Witten and Frank 1999) is a machine learning method used to find very simple classification rules from a training dataset. It makes classification rules that test on a single variable and branch accordingly for each value of a variable. Rules from each variable are evaluated by determining the number of correct and incorrect classifications, and the variable that generates the best rules is chosen. Thus, the single variable that is most important to the classification of samples can be identified by the OneR method. Although it is simple, OneR generally does well in comparison with more sophisticated classification schemes.

\subsection{3 $\quad$ C4.5}

C4.5 (Quinlan 1992) is a state-of-the-art decision tree induction method constructed by a divide-andconquer approach. At the root node of the decision tree, the variable that provides the most information is chosen to split on. The split separates training objects into subsets and makes branches of the tree, one branch for every value of the variable. The process is repeated recursively for each branch using only those training data that actually reach the branch. If at any time all data at a node have the same classifycation, the tree development is stopped for that part of the tree, and a leaf is formed. To classify a test object, it is routed down the tree according to the values of the variables tested at successive nodes, and when a leaf is reached, the object is classified according to the class assigned to the leaf. The decision rules can be obtained by reading directly off a decision tree. One rule is generated for each leaf consisting of the test conditions at the nodes as antecedent of the rule together with the class designation. 


\subsection{Computation}

Most of the statistical analyses were conducted using the commercial statistical software package SYSTAT 10.0 (SYSTAT 2000), while the machine learning approaches were conducted using the Weka public domain software package (Witten and Frank 1999). 


\subsection{Results}

\subsection{Descriptive Statistics}

Descriptive statistics were calculated for variables of the EM, Petro, and XRF datasets and are tabulated in Tables B. 1 to B.3 in the Appendix. Correlation coefficients of XRF variable pairs are summarized in Tables B.4 and B.5 of Appendix B. The statistics show considerable variability for all variables of the three datasets.

Figure 4.1 shows quartz has the highest proportion in the sediment for the EM dataset, followed by microcline, plagioclase, and magnetite. Most EM variables, except quartz, microcline, and plagioclase, are distributed asymmetrically with long positive tails (i.e., most values are low, but there are small numbers of values that are much higher than the majority of samples). Most variables have the same ranges and histogram shape for the pooled data from the 200 West and 200 East Areas, except for a noticeable increase in the range of sphene. Most samples do not contain sphene in either the Hanford or Ringold formations; however, there is a Ringold sample from the 200 East Area that contains 2.8\% sphene, the highest in the dataset. The consistency in the ranges and histogram shapes between the 200 West and East Areas indicates the two areas have similar mineralogy as measured by the electron microprobe.

Quartz, plagioclase feldspar, mafic rock fragments, granitic rock fragments and sedimentary aggregates are among the most common components in the Petro measurements, as shown in Figure 4.2. A consistent set of Petro data from the 200 East Area were not available, so the variability of Petro data from the two areas cannot be established at this time.

The XRF database contains compositional data for a wide range of size-fractions. Analysis of the XRF data confirmed that grain-size variation of composition, which has been found in other studies (e.g., Zhang et al. 2002), was very strong. For example, when bulk samples were compared to sieved samples containing only the $<2.0-\mu \mathrm{m}$ size-fractions, we found a consistent difference between the chemical composition of the bulk fraction and the sieved samples (Figure 4.3). Since the majority of the chemistry data in the database were bulk samples, the very fine $(<2.0 \mu \mathrm{m})$ samples were left out to eliminate variability due primarily to grain size fractionation.

The XRF measurements for the bulk rock samples (Figure 4.3) show that $\mathrm{SiO}_{2}$ content is much higher than the other oxides, as is common for most geologic environments. Figure $4.4 \mathrm{a}$ and $4.4 \mathrm{~b}$ also show that, compared to the raw XRF data, the logratio-transformed XRF data exhibit more symmetrical distributions, and there is more consistency between the transformed data from the two locations. 

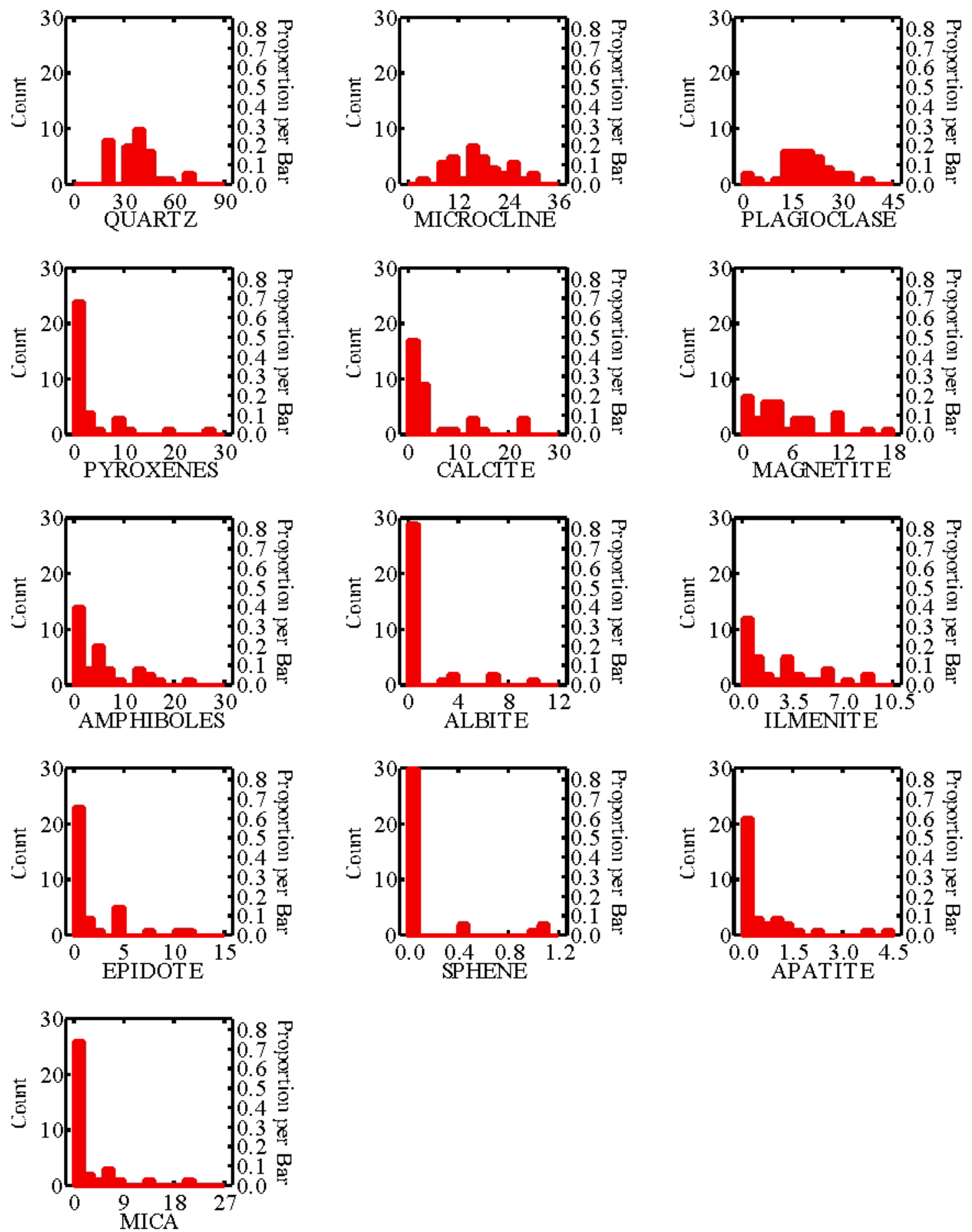

Figure 4.1a. Histograms of 35 EM Samples From 200 West Area. All variables have the same unit of percentage. 

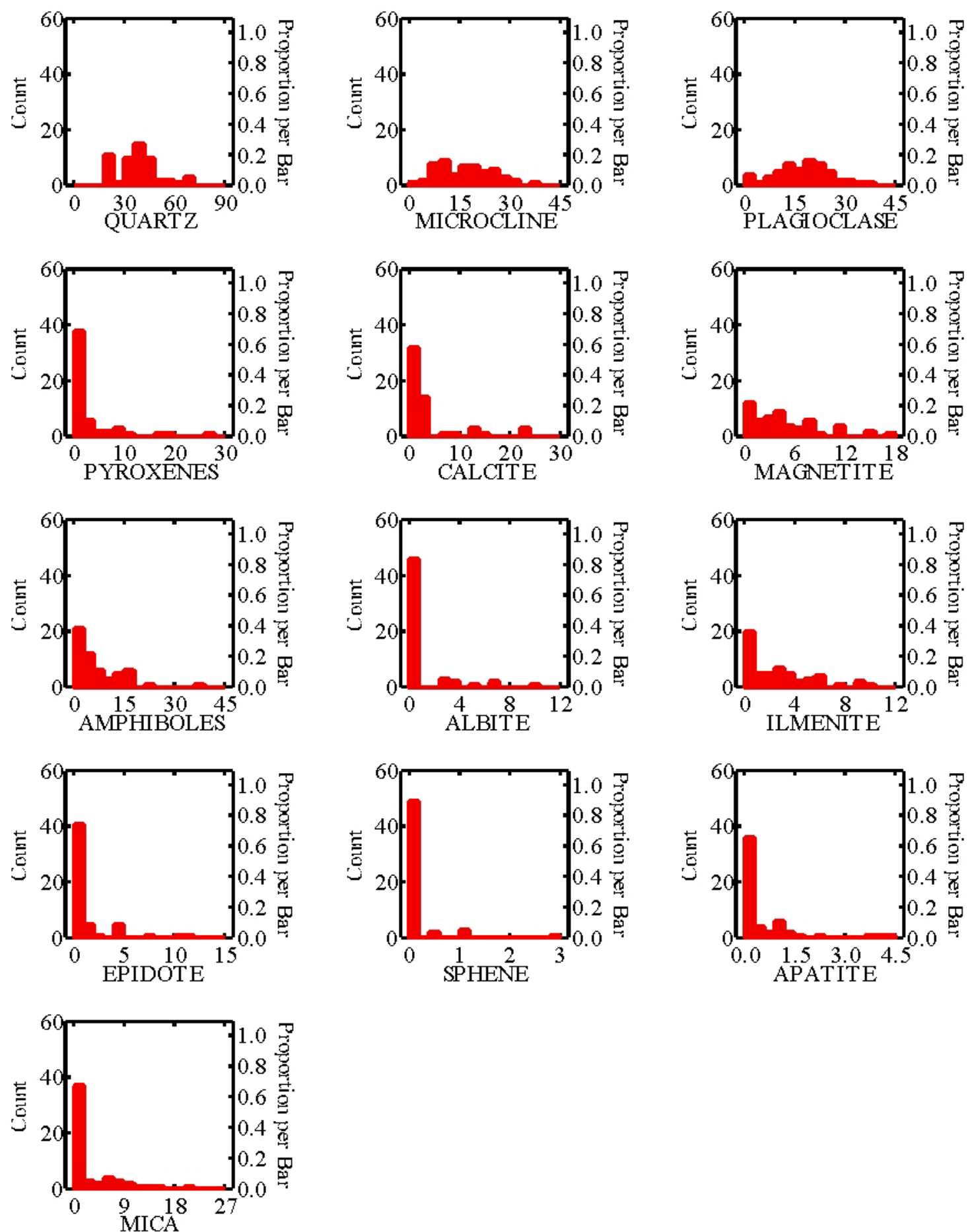

Figure 4.1b. Histograms of all 55 EM Samples From Both 200 West and 200 East Areas. All variables have the same unit of percentage. 

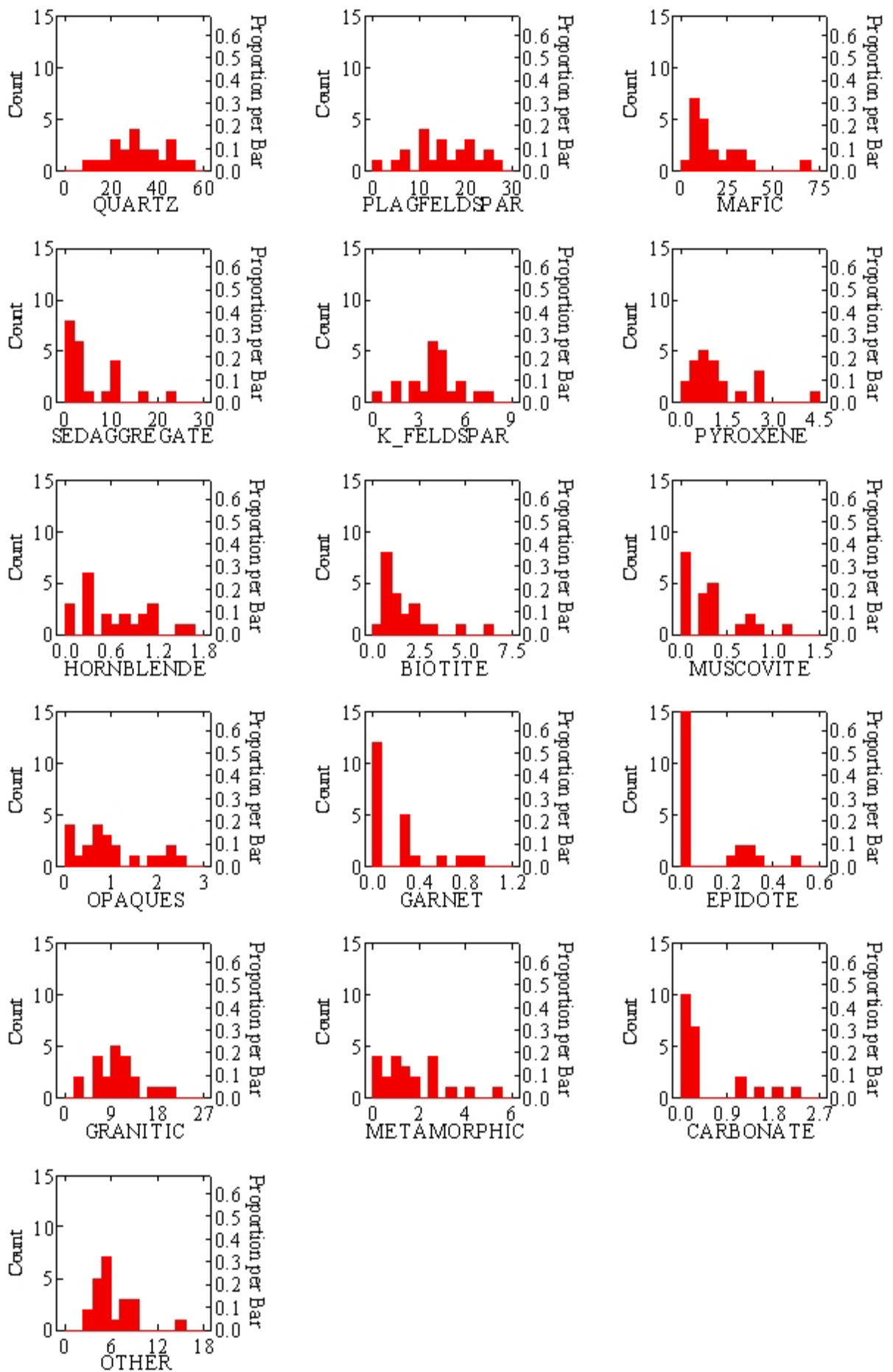

Figure 4.2. Histograms of 22 Petro Samples From 200 West Area. All variables have the same unit of percentage. 

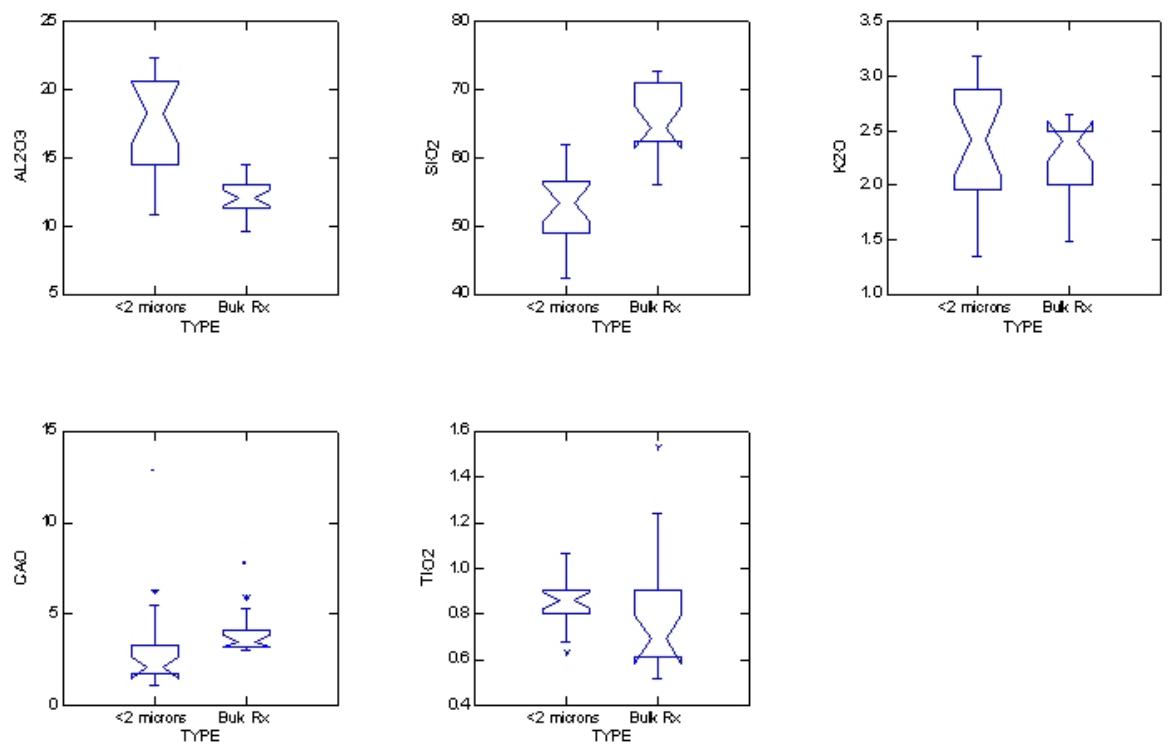

Figure 4.3. Box Plots Showing the Strong Control on Chemical Composition Related to Particle Size for Hanford Formation Samples from the 200 West Area. Vertical axes for each variable are in percent.

In summary:

- Considerable data variability exists for mineralogical and geochemical data from the Hanford and Ringold formations and for data from different spatial locations.

- The numbers of samples are balanced for the EM measurements, both in terms of geological formations and spatial locations, but they are not balanced for the Petro and XRF measurements. No Ringold formation samples were measured in the 200 East Area for either the Petro or the XRF measurements.

\subsection{Tests of Differences Between Data from the 200 East and 200 West Areas}

We used ANOVA to determine if significant differences existed in the mean values of the variables from the 200 West and 200 East Areas. We also used the Mann-Whitney test to check the median differences and applied a two-sample Kolmogorov-Smirnov test to determine if a significant difference existed between the cumulative distributions of data from the two areas. Box plots comparing the EM and XRF datasets for the 200 East and 200 West Areas are provided in Appendix B as Figures B.1 and B.2.

Table 4.1 lists the results of significance tests of the EM variable distributions. It can be seen that the EM variables measured on samples of Hanford formation are consistent between the 200 West and 200 East Areas. Only calcite and ilmenite show any significant differences between the two areas. For samples from the Ringold formation, however, many more variables show significant differences between 

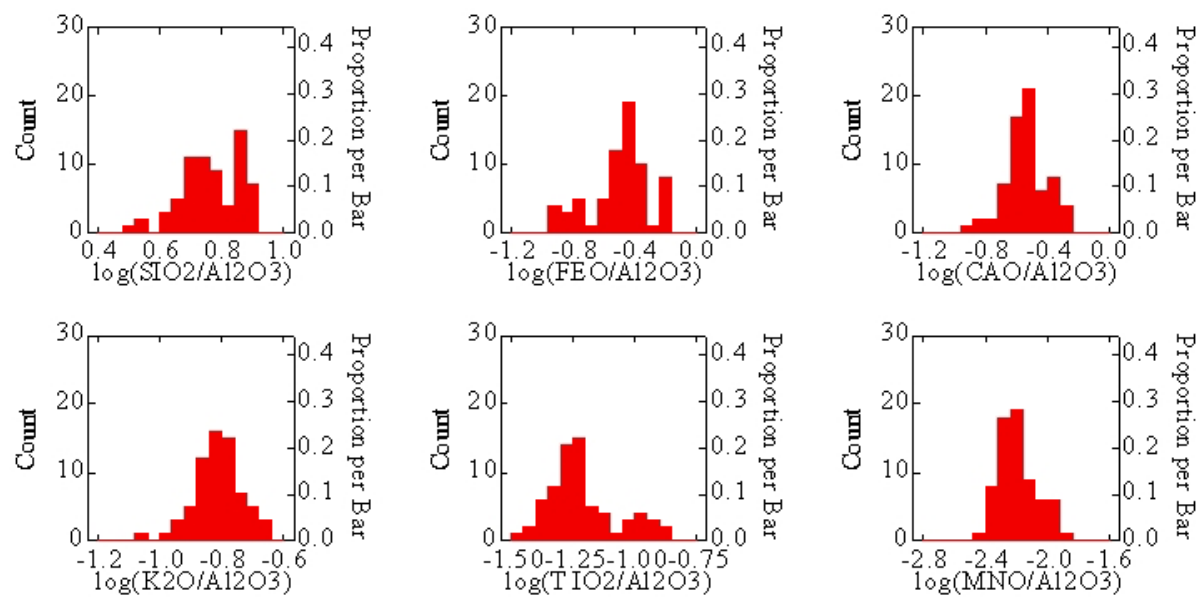

Figure 4.4a. Histograms of 68 XRF Samples From 200 West Area
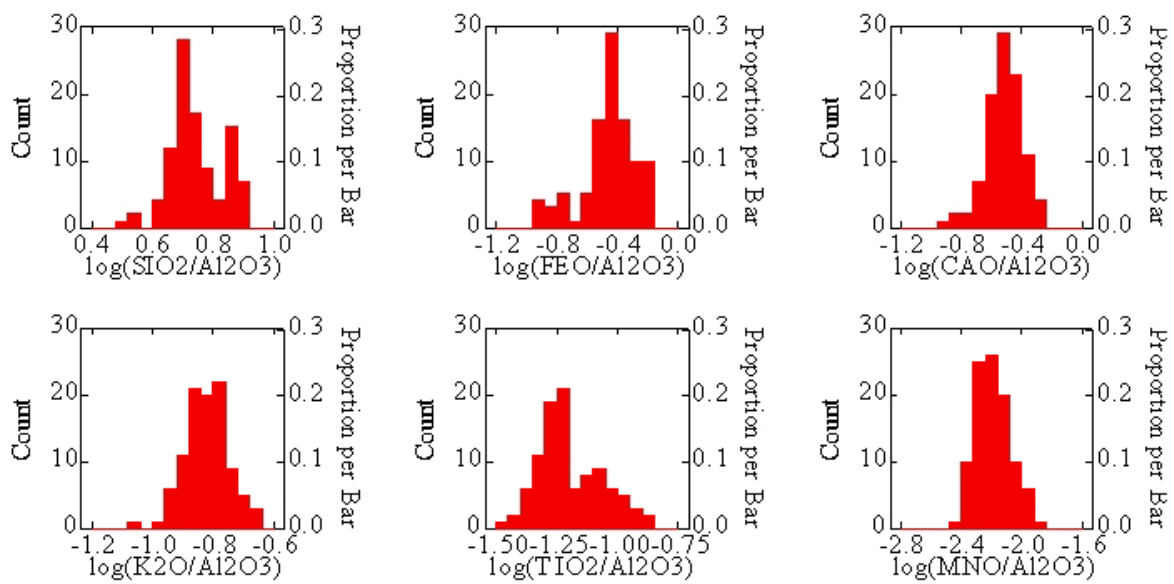

Figure 4.3b. Histograms of all 99 XRF Samples From 200 West and 200 East Areas

the two areas. Specifically, quartz is higher, and plagioclase is lower in the 200 East Area (see Appendix B). Pyroxene, albite, epidote, and apatite did not show up in the six Ringold samples from the 200 East Area. There were 6 Ringold samples in the 200 East Area compared to 18 in the 200 West Area, so the samples from the 200 East Area might not represent the full variability in the Ringold Formation.

All 31 XRF samples in the 200 East Area were from the Hanford formation. The comparison of the variable distributions for the 200 East and 200 West Area was thus conducted only for Hanford samples. Table 4.2 lists results from the ANOVA and non-parametric tests. These results show no significant difference of most XRF variables from Hanford samples between the two areas.

Overall, for the Hanford formation samples, the EM and the XRF measurements are most consistent between the two sampling areas. For the Ringold Formation samples, the EM measurements show inconsistency in the data distributions of more variables. Because both the EM and Petro data provide information on the mineralogy of the samples, further study may be necessary to determine which method 
Table 4.1. Significance Test on the Distribution Difference between EM Samples from the 200 West and 200 East Areas Based on Mann-Whitney (M-W), Two-Sample Kolmogorov-Smirnov (K-S), and Analysis Of Variance (ANOVA) Tests. Green denotes no significant difference while red indicates a significant difference.

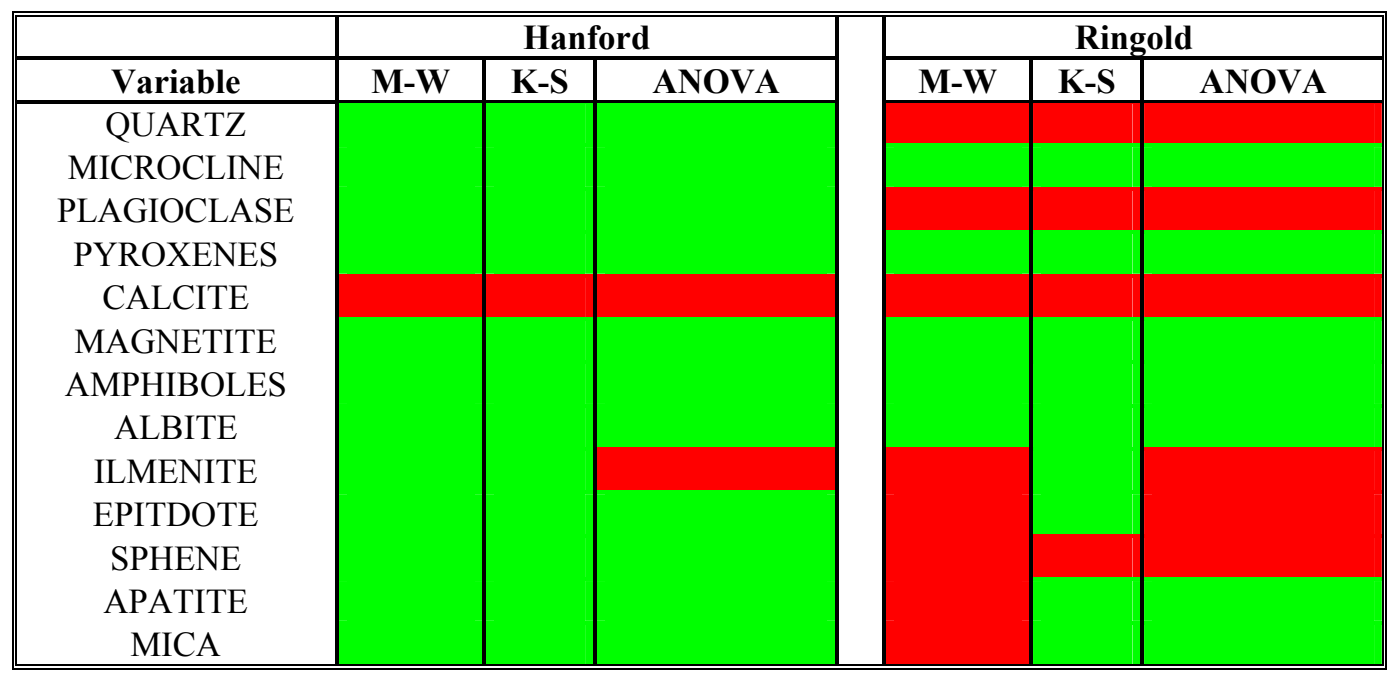

Table 4.2. Significance Test on the Distribution Differences between Hanford Formation XRF Data from the 200 West and 200 East Areas Based on Mann-Whitney (M-W), TwoSample Kolmogorov-Smirnov (K-S), and Analysis Of Variance (ANOVA) Tests. Green denotes no significant difference while red indicates significant difference.

\begin{tabular}{||c|c|c|c|}
\hline Variable & M-W & K-S & ANOVA \\
\hline $\log \left(\mathrm{SiO}_{2} / \mathrm{Al}_{2} \mathrm{O}_{3}\right)$ & & & \\
$\log \left(\mathrm{FeO} / \mathrm{Al}_{2} \mathrm{O}_{3}\right)$ & & & \\
$\log \left(\mathrm{CaO} / \mathrm{Al}_{2} \mathrm{O}_{3}\right)$ & & & \\
$\log \left(\mathrm{K}_{2} \mathrm{O} / \mathrm{Al}_{2} \mathrm{O}_{3}\right)$ & & & \\
$\log \left(\mathrm{TiO}_{2} / \mathrm{Al}_{2} \mathrm{O}_{3}\right)$ & & & \\
$\log \left(\mathrm{MnO} / \mathrm{Al}_{2} \mathrm{O}_{3}\right)$ & & & \\
\hline
\end{tabular}

provides the most consistent and correct results. The lack of Ringold formation samples in the 200 East Area for the XRF measurement prevents us from obtaining similar information for these two measurement methods. However, the apparent existence of spatial variability of the variables measured on samples from the same geological formations suggest that it might be difficult to establish a uniform generalpurpose quantitative method for classification of samples based on mineralogical and geochemical measurements that could be applied uniformly across the Site.

In summary:

- The distributions of EM variables are consistent for the Hanford formation samples from the two different areas, but more variables show spatial variability for the Ringold Formation samples. 
- For XRF measurements, the spatial consistency was only tested on Hanford formation samples due to the lack of Ringold Formation samples in the 200 East Area, and most XRF variables have similar distributions in the two areas.

\subsection{Tests of Differences in Geochemical and Mineralogical Variables Between Hanford and Ringold Formations}

Tables 4.3 and 4.4 show the test results for the distribution differences of the EM data from the two geological formations, and Figure B.3 shows box plots that visualize the differences. Tests included the Mann-Whitney test on the medians, mean comparisons performed using ANOVA, and the two-sided Kolmogorov-Smirnov test of cumulative distributions. These tests were performed for the 200 West Area (Table 4.3) and for data pooled from both the $200 \mathrm{West}$ and 200 East Areas (Table 4.4). The tables are slightly different from the tables for the significance tests in Section 4.2. Here, the variables with significant differences in central values are denoted by either red (variables have higher mean/median) or blue (variables have lower mean/median) entries for the two formations. For the Kolmogorov-Smirnov test, the results only indicate if the differences between the distributions are significant. Table 4.3 shows that the distributions for more than half the EM variables cannot be distinguished for Hanford and Ringold samples. The differences that seem significant are that Hanford formation samples contains higher percentages of plagioclase, pyroxenes, sphene, and mica and lower percentages of calcite and ilmenite. Fewer variables have significant differences between the two formations when 200 East samples are pooled with the 200 West samples (Table 4.4).

Table 4.5 shows results for Petro variables for the 200 West Area samples from median comparisons using a Mann-Whitney test, the comparison of means using ANOVA, and the difference in distributions

Table 4.3. Significance Tests of EM Variables in Terms of the Differences Between Hanford and Ringold Formation Samples (200 West Area). White blocks = not significantly different; colors indicate significantly higher (red) or lower (blue) mean/median differences.

\begin{tabular}{|c|l|l|l|l|l|}
\hline \multirow{2}{*}{ Variable } & \multicolumn{2}{|c|}{ Mann-Whitney } & \multicolumn{2}{c|}{ ANOVA } & \multirow{2}{*}{ Kolmogorov-Smirnov } \\
\hline & Hanford & Ringold & Hanford & Ringold & \\
\hline QUARTZ & & & & & \\
\hline MICROCLINE & & & & & \\
\hline PLAGIOCLASE & & & & & \\
\hline PYROXENES & & & & & \\
\hline CALCITE & & & & & \\
\hline MAGNETITE & & & & & \\
\hline AMPHIBOLES & & & & & \\
\hline ALBITE & & & & & \\
\hline ILMENITE & & & & & \\
\hline EPIDOTE & & & & & \\
\hline SPHENE & & & & & \\
\hline APATITE & & & & & \\
\hline MICA & & & & & \\
\hline
\end{tabular}


Table 4.4. Significance Tests of EM Variables in Terms of the Differences Between Hanford and Ringold Formation Samples (both 200 West and 200 East). White blocks = not significantly different; colors indicate significantly higher (red) or lower (blue) mean/median differences.

\begin{tabular}{|c|c|c|c|c|c||}
\hline \multirow{2}{*}{ Variable } & \multicolumn{2}{|c|}{ Mann-Whitney } & \multicolumn{2}{c|}{ ANOVA } & \multirow{2}{*}{ Kolmogorov-Smirnov } \\
\hline & Hanford & Ringold & Hanford & Ringold & \multirow{2}{*}{} \\
\hline QUARTZ & & & & & \\
\hline MICROCLINE & & & & & \\
\hline PLAGIOCLASE & & & & & \\
\hline PYROXENES & & & & & \\
\hline CALCITE & & & & & \\
\hline MAGNETITE & & & & & \\
\hline AMPHIBOLES & & & & & \\
\hline ALBITE & & & & & \\
\hline ILMENITE & & & & & \\
\hline EPIDOTE & & & & & \\
\hline SPHENE & & & & & \\
\hline APATITE & & & & & \\
\hline MICA & & & & & \\
\hline
\end{tabular}

Table 4.5. Significance Tests of Petro Variables in Terms of the Differences Between Hanford and Ringold Formation Samples (200 West Area). White blocks = not significantly different; colors indicate significantly higher (red) or lower (blue) mean/median differences.

\begin{tabular}{|c|l|l|l|l|l||}
\hline \multirow{2}{*}{ Variable } & \multicolumn{2}{|c|}{ Mann-Whitney } & \multicolumn{2}{c|}{ ANOVA } & \multirow{2}{*}{ Kolmogorov-Smirnov } \\
\hline & Hanford & Ringold & Hanford & Ringold & \multirow{2}{*}{} \\
\hline QUARTZ & & & & & \\
\hline PLAGFELDSPAR & & & & & \\
\hline MAFIC & & & & & \\
\hline SEDAGGREGATE & & & & & \\
\hline K_FELDSPAR & & & & & \\
\hline PYROXENE & & & & & \\
\hline HORNBLENDE & & & & & \\
\hline BIOTITE & & & & & \\
\hline MUSCOVITE & & & & & \\
\hline OPAQUES & & & & & \\
\hline GARNET & & & & & \\
\hline EPIDOTE & & & & & \\
\hline GRANITIC & & & & & \\
\hline METAMORPHIC & & & & & \\
\hline CARBONATE & & & & & \\
\hline OTHER & & & & & \\
\hline \hline
\end{tabular}


using a Kolmogorov-Smirnov test. Box plots comparing the Petro variables measured on samples of the two formations are shown in Figure B.4. Most Petro variables have significantly different central values between Hanford and Ringold samples. These results suggest that it might be possible to construct a good classifier for identifying the two formations based on the Petro data; however, data aren't available from outside the 200 West Area to determine how consistent the differences might be across the Hanford Site.

Tables 4.6 and 4.7 show the significance test results for the XRF samples from median comparisons using Mann-Whitney tests and mean comparisons using ANOVA for the 200 West Area samples and for pooled samples. Box plots are shown in Figure B.5. The significance tests and box plots indicate that pooling Hanford formation samples from the 200 East Area does not change the relative content of the variables in the two geological formations. This suggests the Hanford samples in the two areas have fairly consistent chemical compositions. Thus, the box plots and significance tests indicate that significant differences exist for most XRF variables between the Hanford and Ringold formations, and that those differences are fairly consistent between the two study areas.

In summary:

- EM variables measured on the 200 West Area samples show significant differences between the Hanford and Ringold formation. Pooling the 200 East and 200 West samples weakens the distinguishability of the EM variables because of spatial variability, especially for the Ringold samples.

- Petro variables measured on 200 West Area samples show significant differences between the Hanford and Ringold formations.

- XRF variables measured on 200 West Area samples also show significant differences between the two geological formations; such differences do not change much when pooling samples from the 200 East Area because of the greater consistency of the XRF data from the two locations. This suggests that the XRF data might be useful in developing classification algorithms to identify Hanford and Ringold formation samples that apply over wider geographic areas.

Table 4.6. Significance Tests of XRF Variables in Terms of the Differences Between Hanford and Ringold Formation Samples (200 West Area). White blocks $=$ not significantly different; colors indicate significantly higher (red) or lower (blue) mean/median differences.

\begin{tabular}{||c|c|c|c|c|c||}
\hline \multirow{2}{*}{ Variable } & \multicolumn{2}{|c|}{ Mann-Whitney } & \multicolumn{2}{c|}{ ANOVA } & \multirow{2}{*}{ Kolmogorov-Smirnov } \\
\hline & Hanford & Ringold & Hanford & Ringold & \\
\hline $\log \left(\mathrm{SiO}_{2} / \mathrm{Al}_{2} \mathrm{O}_{3}\right)$ & & & & & \\
\hline $\log \left(\mathrm{FeO} / \mathrm{Al}_{2} \mathrm{O}_{3}\right)$ & & & & & \\
\hline $\log \left(\mathrm{CaO} / \mathrm{Al}_{2} \mathrm{O}_{3}\right)$ & & & & & \\
\hline $\log \left(\mathrm{K}_{2} \mathrm{O} / \mathrm{Al}_{2} \mathrm{O}_{3}\right)$ & & & & & \\
\hline $\log \left(\mathrm{TiO}_{2} / \mathrm{Al}_{2} \mathrm{O}_{3}\right)$ & & & & & \\
\hline $\log \left(\mathrm{MnO} / \mathrm{Al}_{2} \mathrm{O}_{3}\right)$ & & & & & \\
\hline
\end{tabular}


Table 4.7. Significance Tests of XRF Variables in Terms of the Differences Between Hanford and Ringold Formation Samples (both 200 West and East Areas). White blocks $=$ not significantly different; colors indicate significantly higher (red) or lower (blue) mean/median differences.

\begin{tabular}{|c|c|c|c|c|c|}
\hline \multirow[b]{2}{*}{ Variable } & \multicolumn{2}{|c|}{ Mann-Whitney } & \multicolumn{2}{|c|}{ ANOVA } & \multirow[b]{2}{*}{ Kolmogorov-Smirnov } \\
\hline & Hanford & Ringold & Hanford & Ringold & \\
\hline $\log \left(\mathrm{SiO}_{2} / \mathrm{Al}_{2} \mathrm{O}_{3}\right)$ & & & & & \\
\hline $\log \left(\mathrm{FeO} / \mathrm{Al}_{2} \mathrm{O}_{3}\right)$ & & & & & \\
\hline $\log \left(\mathrm{CaO} / \mathrm{Al}_{2} \mathrm{O}_{3}\right)$ & & & & & \\
\hline $\log \left(\mathrm{K}_{2} \mathrm{O} / \mathrm{Al}_{2} \mathrm{O}_{3}\right)$ & & & & & \\
\hline $\log \left(\mathrm{TiO}_{2} / \mathrm{Al}_{2} \mathrm{O}_{3}\right)$ & & & & & \\
\hline $\log \left(\mathrm{MnO} / \mathrm{Al}_{2} \mathrm{O}_{3}\right)$ & & & & & \\
\hline
\end{tabular}

\subsection{Principal Component Analysis}

Principal component analysis was applied to the EM, Petro, and XRF datasets to investigate the data structure and the relationships between variables. Because the variables within each dataset are expressed in the same units (percentages for mineralogical data and logratio transformed units for the XRF data), and the magnitudes of the variable measurements are meaningful, principal component analysis was conducted on the raw data without further standardization. The loadings and the loading plots generated from SYSTAT are the eigenvectors upscaled by their corresponding eigenvalues. Because the difference between loadings calculated in this way and the eigenvectors only differ by a constant ratio, and the relative magnitude of the variables in the loading vectors and eigenvectors remain the same, we use the term loadings to refer to either of them.

The contributions of the EM variables to the first two principal components (PCs) are reflected by the corresponding relative magnitude of the variable loadings. The variable relationships also can be visualized through their positions in the PC space. Figure 4.5 shows the relative magnitude of the variable loadings on the first two PCs. Also in Figure 4.5, the first two loading vectors from the pooled samples are plotted together with those from 200 West Area samples to show the changes of data structure caused by including the 200 East Area samples. Quartz has the largest magnitude on PC1, which indicates quartz dominates the first PC. Plagioclase, amphiboles, calcite, pyroxenes, magnetite and microcline also make large contributions to $\mathrm{PC} 1$ relative to the other variables. Both calcite and plagioclase contribute heavily to PC2 but have the opposite sign relative to their loadings on PC1. Microcline, pyroxenes, magnetite, and amphiboles have smaller contributions on PC2. From Figure 4.5, it can be seen that calcite, amphiboles, and magnetite are clustered in the PC space, indicating similar behaviors. Plagioclase and pyroxenes are also clustered in the PC space. For pooled samples from the two areas, the first PC is still dominated by quartz. In addition, it can be seen that while the loadings on the first PCs are almost identical, the second PC changes a lot. This means the pooling of 200 East and 200 West Area samples changes the data structure significantly. Figure 4.6 shows scatter plots of the 200 West Area samples in the PC1 and PC2 space. No distinct data clusters are revealed and, in particular, no obvious distinction 


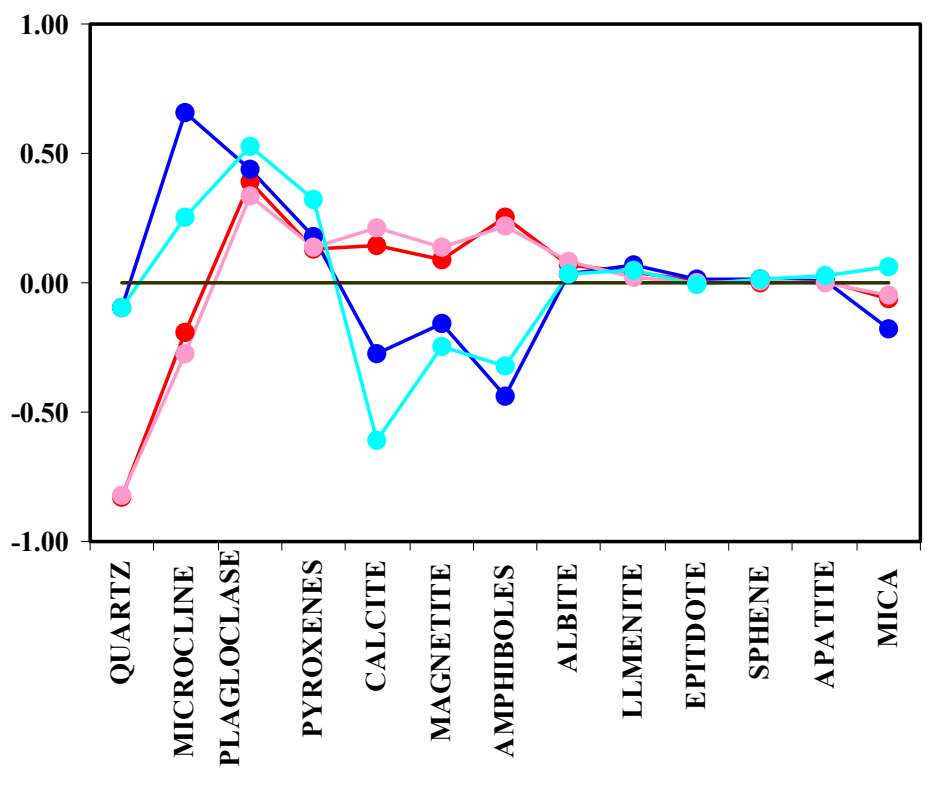

$\multimap$ PC1 (All Data) $\multimap-P C 2$ (All Data) $\multimap-$ PC1 200 West $\multimap-$ PC2 200 West

Figure 4.5. Variable Loadings on the First Two PCs for 35 EM Samples from the 200 West Area and 55 EM Samples from Both Areas

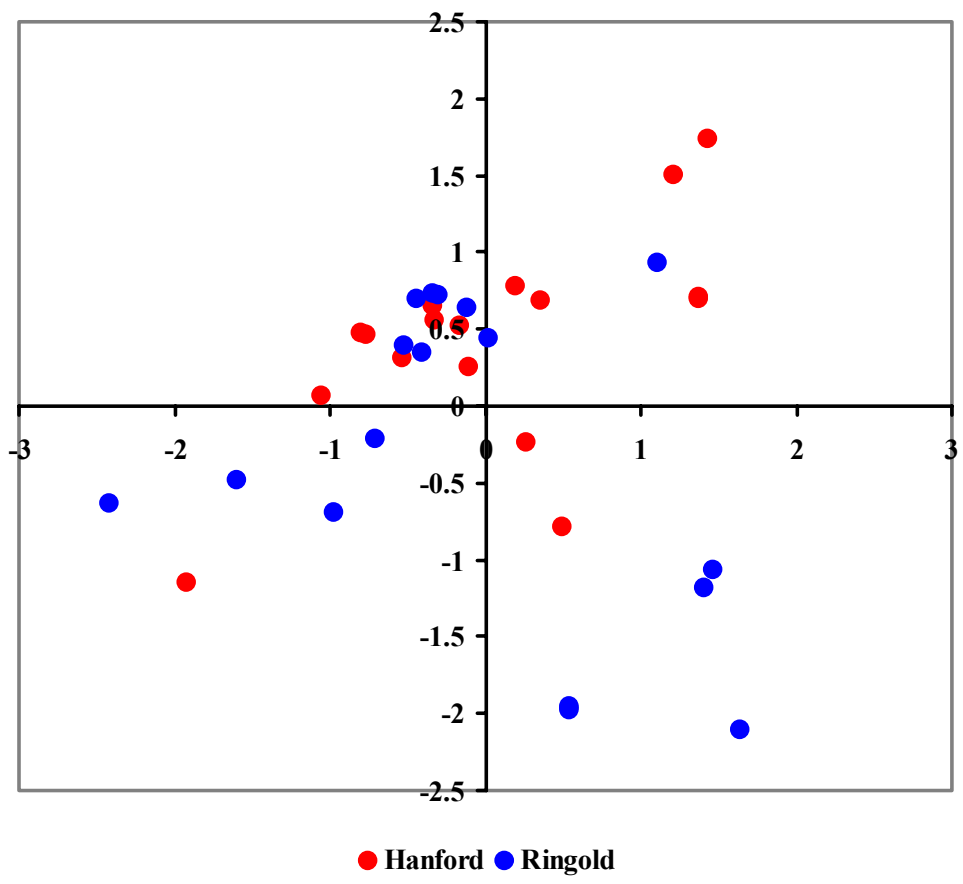

Figure 4.6. Scatter Plot of Data On PC1-PC2 Space for 35 EM Samples From the 200 West Area 
can be seen between the Hanford and Ringold formation samples. It should be noted the first two PCs account for only about $65 \%$ of the data variance, so significant data variability will not be accounted for if only two PCs are used.

Over $90 \%$ of the data variance is accounted for by the first 3 PCs for the Petro data. This suggests that the Petro variables have more collinearity than the EM variables. As shown in Figure 4.7, the first two PCs based on 200 West Area data are mostly dominated by mafic grains, quartz, plagioclase feldspar, and sedimentary aggregates. Quartz and mafic grains have opposite signs in the loadings on the first two PCs as do plagioclase feldspar and sedimentary aggregates. Figure 4.8 shows some separation of Hanford samples from Ringold samples in the PC space, suggesting that a good classifier could be established to distinguish between the two geological formations in the 200 West Area using the Petro data. However, caution should be taken in any attempt to generalize the results, because there are only six Hanford formation samples, which may not cover the full variability of the Hanford formation in that area. In addition, Petro data from the 200 East Area were not available for comparison, so that the spatial variability of the Petro data is not well known.

For the XRF data, the first three PCs account for almost $90 \%$ of the total data variability. All six variables contribute to the first two $\mathrm{PCs}$, with $\mathrm{FeO}$ having relatively high loadings on both $\mathrm{PCs} . \mathrm{K}_{2} \mathrm{O}$ contributes little to both PCs, as shown in Figure 4.9. The first two PCs based on the 200 West Area samples and pooled with the 200 East Area samples are shown in Figure 4.9 and are almost identical. This confirms the consistency of the XRF data measured in the two areas as indicated by the statistical tests in Section 4.2. Figure 4.10 shows that the variability of the Hanford formation samples measured in the 200 West Area also covers the variability of Hanford samples measured in the 200 East Area. Figure 4.10 shows that the samples form two separate groups in the space spanned by PC1 and PC2.

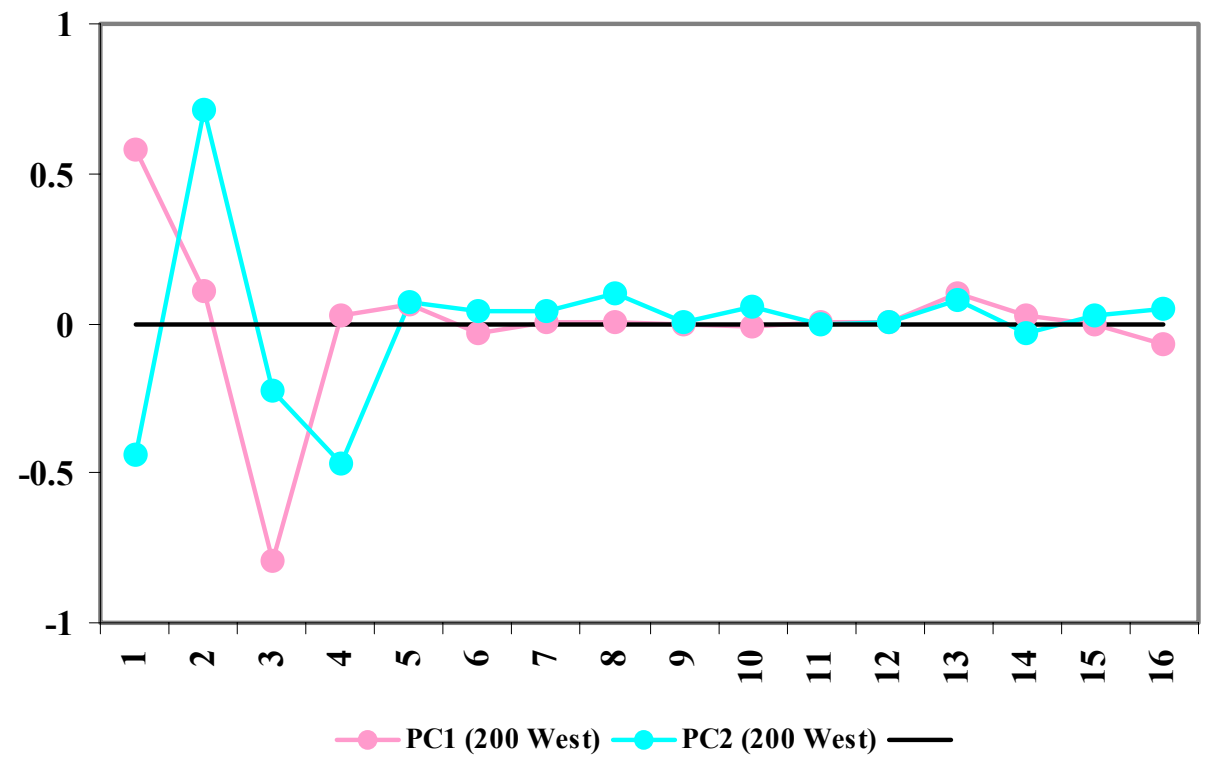

Figure 4.7. Variable Loadings for the First Two PCs of 22 Petro Samples from the 200 West Area 


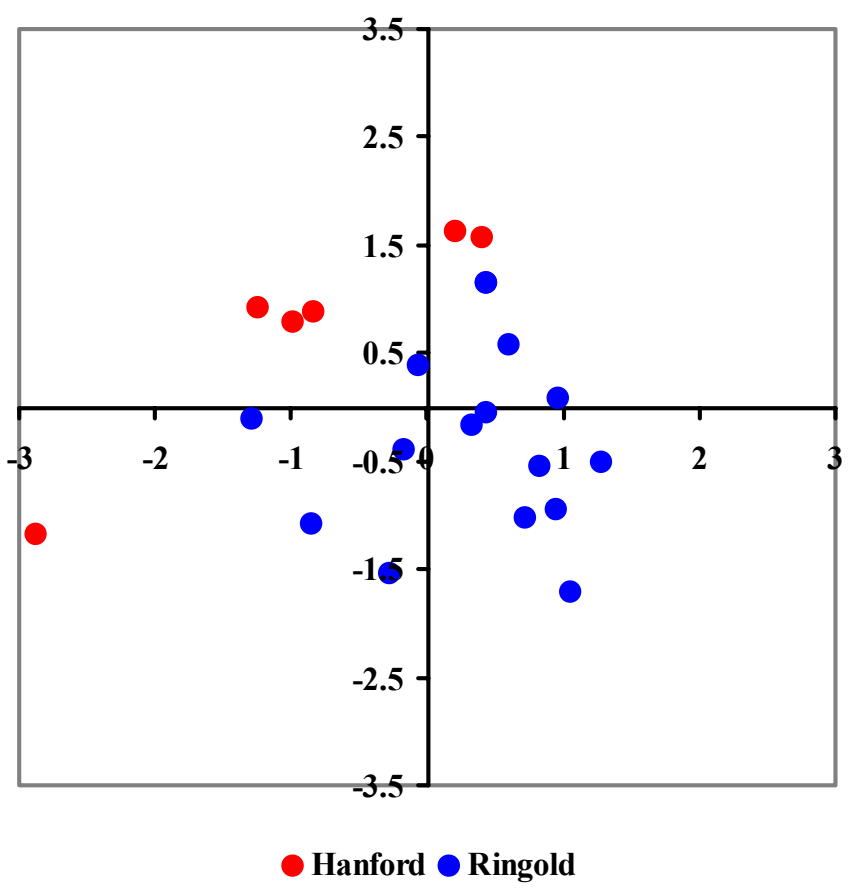

Figure 4.8. Scatter Plot of Data on PC1-PC2 space of 22 Petro Samples from the 200 West Area

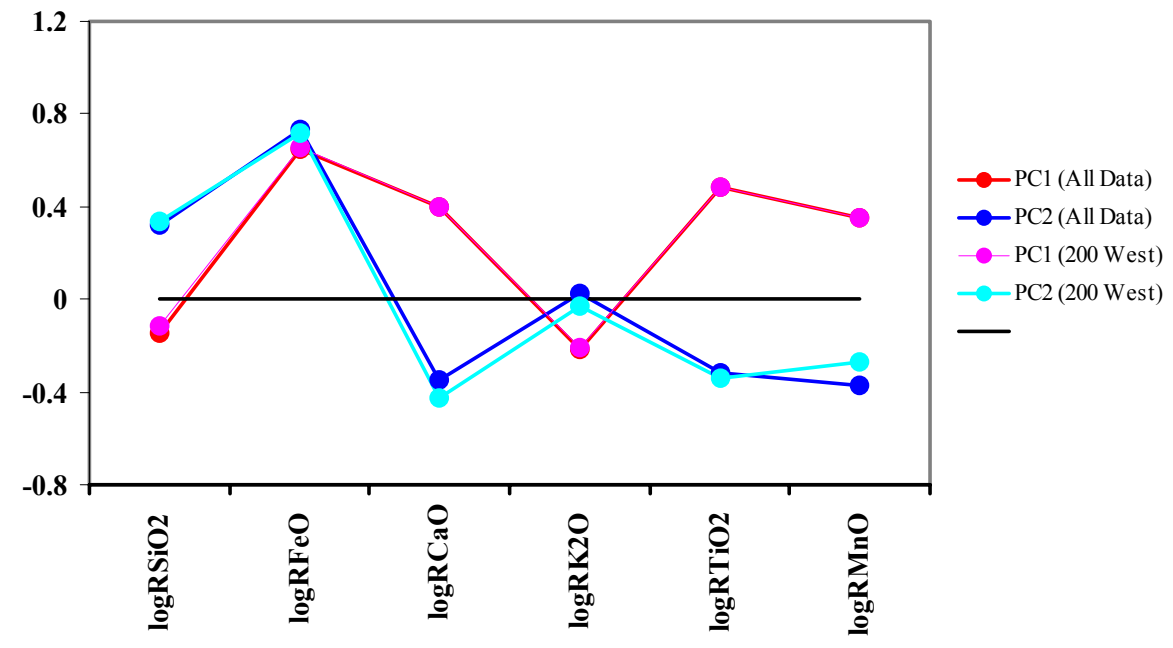

Figure 4.9. Variable Loadings on the First 2 PCs for 68 XRF Samples from the 200 West Area and 99 XRF Samples from Both Areas 


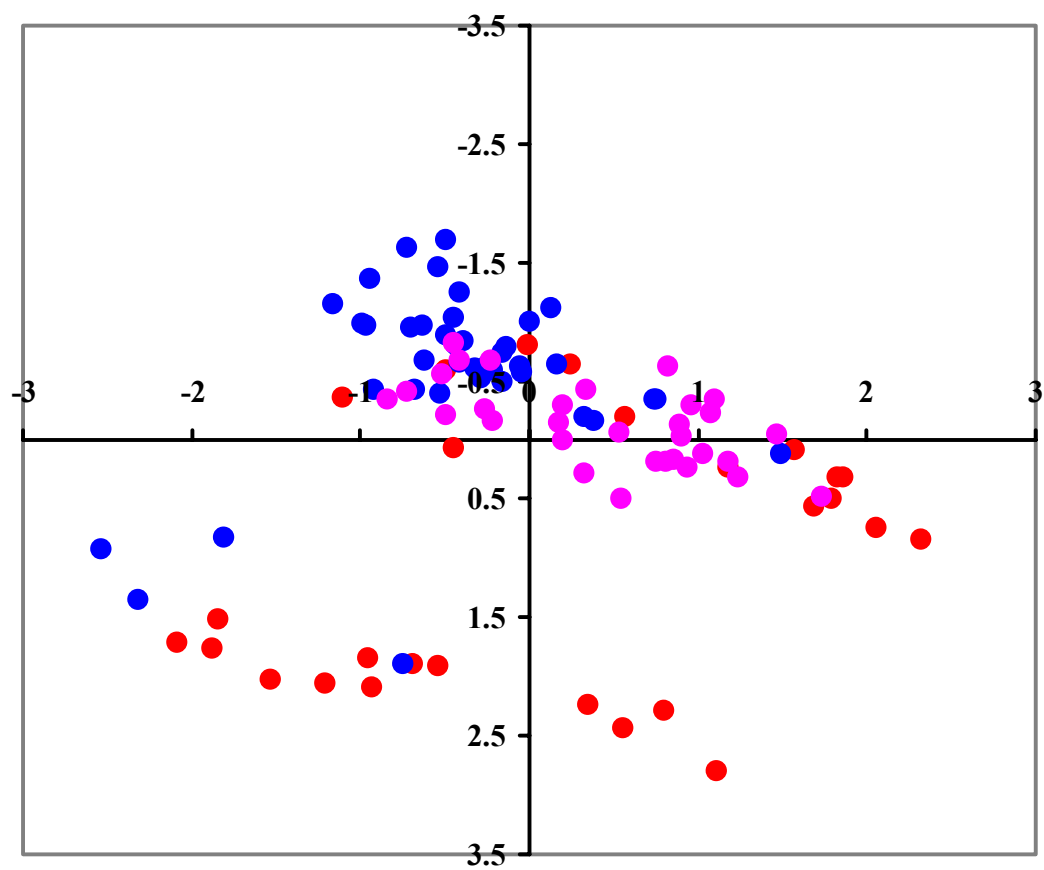

Hanford (200W) ○ Ringold $\odot$ Hanford (200E)

Figure 4.10. Scatter Plot of Data on PC1-PC2 Space of 99 XRF Samples from Both Areas

Despite that separation, a boundary could be drawn between the Hanford formation samples and Ringold Formation samples on the PC space, although there would be some overlap between the two formations. The observation of such a separable boundary and the overlap of the Hanford formation samples from the 200 West Area with those from the 200 East Area suggest that a good classifier between the two geological formations could be derived based on the XRF measurements. However, the lack of Ringold samples from the 200 East Area makes it impossible to validate the generality of any classifier built based on data from the 200 West Area.

In summary:

- The change in PC loading when pooling samples from the two areas suggests the existence of distribution differences for the EM variables. No obvious clusters and distinctions between samples from the two formations suggest those variables contributing most to the data variance might not be good candidates for constructing classifiers for the two formations.

- For the Petro variables, a smaller number of PCs accounts for the same amount of data variance as the EM data, which suggests that a higher correlation exists between several of the Petro variables. Separation of samples from the two formations measured in the 200 West Area seen in the PC space suggests a good classifier could be built for the two formations.

- More separation of samples from the two geological formations appears in the PC space of the XRF data. Pooling 200 East and 200 West Area samples does not significantly change the data structure, 
which confirms the consistency of the XRF measurements from the two locations. This suggests that the XRF data would be most useful in classifying samples from the Hanford and Ringold formations.

\subsection{Classification of Samples from Hanford and Ringold Formations}

We applied stepwise linear discriminant analysis to evaluate classification functions that could be used to discriminate between samples from the Hanford and Ringold formations. This technique was applied separately to the EM, Petro, and XRF datasets. The lack of any samples from the 200 East Area for the Petro measurements and of Ringold Formation samples for the XRF measurements indicated it would be improper to use the 200 East Area data as an external validation set for testing classification rules developed for the 200 West Area. Therefore, the validation of the classifiers was tested only through the cross-validation of the training data (i.e., 200 West Area data) themselves. In cross-validation, samples are removed from the training set one at a time, and the remaining samples are used to build the classifier. The classification function built on the remaining training data is then evaluated with the omitted sample, and the process is repeated until all samples have been left out once. The overall number of correctly classified observations is used to evaluate the performance of the classifier. Cross-validation performed in this fashion often gives too optimistic an evaluation of the performance of the classifier, but is the only option when an external validation dataset is not available, or when sufficient samples don't exist to set aside a portion of the samples in an area as a verification dataset.

Evaluation of the EM data using discriminant analysis indicated that microcline, plagioclase, calcite, ilmenite, and mica were the most important minerals in distinguishing the two formations. This is not surprising because those five variables also had significant differences in the distributions between the two formations in one or more of the statistical tests shown in Table 4.4. Table 4.8 shows the classification results from both reclassifying the training samples directly and from cross-validation. The number within each cell of the table is based on the validation schemes described in the previous paragraph and it indicates the count of samples estimated to belong to each formation compared to the actual formation designations for those samples. Samples are classified correctly if the estimated and actual formation designations are the same. The high correct rate for classifying the training samples and from crossvalidation suggests the discriminant function model describes the training samples in the 200 West Area very well. The discriminant function for the EM data has the form of:

Table 4.8. Validation of Classification Results for 200 West Area EM Samples

\begin{tabular}{|c|c|c|c|c|}
\hline & \multirow[b]{2}{*}{ Training Data Re-Estimated } & \multicolumn{2}{|c|}{ Estimated } & \multirow[b]{2}{*}{ \%correct } \\
\hline & & Hanford & Ringold & \\
\hline \multirow{5}{*}{$\begin{array}{l}\overline{3} \\
\overline{0} \\
\end{array}$} & Hanford & 17 & 0 & 100 \\
\hline & \begin{tabular}{|l|} 
Ringold \\
\end{tabular} & 3 & 15 & 83 \\
\hline & Total & 20 & 15 & 91 \\
\hline & & \multicolumn{2}{|c|}{ Estimated } & \\
\hline & Cross Validation & Hanford & Ringold & \%correct \\
\hline \multirow{3}{*}{\begin{tabular}{l}
$\bar{\Xi}$ \\
\multirow{3}{0}{} \\
$\frac{\pi}{\pi}$
\end{tabular}} & Hanford & 17 & 0 & 100 \\
\hline & Ringold & 3 & 15 & 83 \\
\hline & Total & 20 & 15 & 91 \\
\hline
\end{tabular}




$$
\begin{gathered}
\text { Discriminant Score }=-4.682+0.182 \times[\text { Microcline }]-0.064 \times[\text { Plagioclase }]+0.26 \times[\text { Calcite }]+ \\
0.494 \times[\text { Ilmenite }]+0.122 \times[\text { Mica }]
\end{gathered}
$$

The mean discriminant scores of the discriminant function are -1.892 for Hanford formation samples and 1.787 for Ringold Formation samples. For a future sample, the discriminant score can be calculated by plugging in the value of the selected variables in the equation above. Then the difference between the calculated discriminant score and the mean score of the two formations is calculated and compared. The sample will be assigned to the formation that has a smaller difference between the calculated discriminant score and the mean score for the formation.

Table 4.9 shows the classification results from the use of stepwise linear discriminant function analysis on the 200 West Area Petro data. Mafic grains, hornblende, and biotite were selected as the most distinguishable variables for the discriminant function. Again, the high correct rates that were obtained for the training data and from cross-validation suggest that the two geological formations are easily separable within the 200 West Area, and that a reasonable classification scheme can be built by applying discriminant function analysis to the Petro data. The discriminant function for Petro data is:

Discriminant Score $=-4.314+0.103 \times[$ Mafic rock fragments $]+2.156 \times[$ Hornblende $]+0.565 \times[$ Biotite $]$

and the mean scores for the two formations are 2.89 for Hanford and -1.084 for Ringold. Again the classification of future samples can be done by calculating the discriminant score for the sample, then assigning the sample to the formation with a smaller difference between the score and the mean score of the formations.

Table 4.10 shows the classification results from the use of stepwise linear discriminant function analysis on the 200 West Area XRF data. $\mathrm{SiO}_{2}, \mathrm{FeO}, \mathrm{K}_{2} \mathrm{O}, \mathrm{CaO}$, and $\mathrm{MnO}$ were retained in the discriminant function. The high correlation between $\mathrm{MnO}$ and $\mathrm{TiO}_{2}$ reflects the redundancy of those variables, and either one of them can adequately represent the variation in the other, so only one of the variables was retained in the discriminant function by the stepwise variable selection procedure. Again, high correct rates, $94 \%$ and $88 \%$ of the observations correctly classified as either Hanford or Ringold formation, are obtained when the discriminant function is tested on the training data directly and using cross-validation, respectively. The discriminant function for the XRF measurements is:

\begin{tabular}{|c|c|c|c|c|}
\hline & \multirow[b]{2}{*}{ Training Data Re-Estimated } & \multicolumn{2}{|c|}{ Estimated } & \multirow[b]{2}{*}{ \%correct } \\
\hline & & Hanford & Ringold & \\
\hline \multirow{5}{*}{ 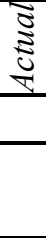 } & Hanford & 5 & 1 & 83 \\
\hline & Ringold & 0 & 16 & 100 \\
\hline & Total & 5 & 17 & 95 \\
\hline & & \multicolumn{2}{|c|}{ Estimated } & \\
\hline & Cross Validation & Hanford & Ringold & \%correct \\
\hline \multirow{3}{*}{ 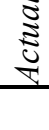 } & Hanford & 5 & 1 & 83 \\
\hline & Ringold & 1 & 15 & 94 \\
\hline & Total & 6 & 16 & 91 \\
\hline
\end{tabular}

Table 4.9. Validation of Classification Results for 200 West Area Petro Samples 
Table 4.10. Validation of Classification Results for 200 West XRF Samples

\begin{tabular}{|c|c|c|c|c|}
\hline & \multirow[b]{2}{*}{ Training Data Re-Estimated } & \multicolumn{2}{|c|}{ Estimated } & \multirow[b]{2}{*}{ \%correct } \\
\hline & & Hanford & Ringold & \\
\hline \multirow{5}{*}{ 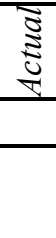 } & Hanford & 26 & 1 & 96 \\
\hline & Ringold & 3 & 38 & 93 \\
\hline & Total & 29 & 39 & 94 \\
\hline & & \multicolumn{2}{|c|}{ Estimated } & \\
\hline & Cross Validation & Hanford & Ringold & $\%$ correct \\
\hline \multirow{3}{*}{ 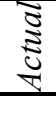 } & Hanford & 24 & 3 & 89 \\
\hline & Ringold & 5 & 36 & 88 \\
\hline & Total & 29 & 39 & 88 \\
\hline
\end{tabular}

Discriminant Score $=-36.316+14.594 \times\left[\log \left(\mathrm{SiO}_{2} / \mathrm{Al}_{2} \mathrm{O}_{3}\right)\right]+2.368 \times\left[\log \left(\mathrm{FeO} / \mathrm{Al}_{2} \mathrm{O}_{3}\right)\right]-5.062 \times[\log (\mathrm{CaO} /$

$$
\left.\left.\mathrm{Al}_{2} \mathrm{O}_{3}\right)\right]-11.267 \times\left[\log \left(\mathrm{K}_{2} \mathrm{O} / \mathrm{Al}_{2} \mathrm{O}_{3}\right)\right]-6.562 \times\left[\log \left(\mathrm{MnO} / \mathrm{Al}_{2} \mathrm{O}_{3}\right)\right]
$$

and the mean scores for the two formations are -1.739 for Hanford and 1.145 for Ringold.

In summary:

- Discriminant functions were derived for all three sets of measurements based on 200 West Area samples. The classification of the two geological formations is good for all three sets of measurements.

- The discriminant functions are applicable to the 200 West Area, but generalization to the 200 East Area should be done cautiously due to spatial variability in the EM data, and the lack of samples in the 200 East Area to allow verification of the applicability of the discriminant functions to that area.

\subsection{Classification Rules from Machine Learning Algorithms}

In addition to the use of discriminant function analysis for classification, we used the machine learning package $W e k a$ to examine the performance of machine learning methods to classify samples using the EM, Petro, and XRF datasets. Specifically, two machine learning approaches, C4.5 and OneR, were applied. Training was conducted on data from the 200 West Area, and the decision rules were evaluated by cross-validation. The results are tabulated in Table 4.11.

The classification rates for the training data themselves and those from 10 -fold cross validation suggest that the $\mathrm{C} 4.5$ models are quite good for classifying the Hanford and Ringold formations for the training data for all three sets of variables. For the EM data, we found that the C4.5 decision rule starts with Sphene, a minor component, as the most informative variable because none of the Ringold samples from the 200 West Area contain sphene. However, the generalization of that is questionable because sphene does occur in Ringold samples from the 200 East Area. Given the lack of Petro data from the 200 East Area, it was not possible to evaluate the applicability of the Petro classification rules to that area. 
Table 4.11. Classification Rules from Machine Learning Methods for EM, Petro, and XRF Data (by column from left to right)

\begin{tabular}{|c|c|c|c|c|c|c|c|c|c|c|c|c|c|c|}
\hline \multicolumn{5}{|c|}{ C4.5 } & \multicolumn{5}{|c|}{ C4.5 } & \multicolumn{5}{|c|}{ C4.5 } \\
\hline \multicolumn{5}{|c|}{\begin{tabular}{||l} 
EPIDOTE $<=0$ \\
$\mid$ CALCITE $<=6.5$ \\
|| ILMENITE $<=4.2$ : Hanfor \\
$\mid$ ILMENITE $>4.2$ : Ringold \\
| CALCITE $>6.5:$ Ringold $(5.0$ \\
EPIDOTE $>0$ : Ringold $(9.0)$ \\
SPHENE $>0$ : Hanford $(5.0)$
\end{tabular}} & \multicolumn{5}{|c|}{$\begin{array}{l}\text { Pyroxene }<=1.3: \text { Ringold }(16.0 / 1.0) \\
\text { Pyroxene }>1.3: \text { Hanford }(6.0)\end{array}$} & \multicolumn{5}{|c|}{$\begin{array}{l}\mathrm{SiO} 2<=0.73: \text { Hanford }(25.0 / 3.0) \\
\mathrm{SiO} 2>0.73 \\
\mathrm{~K} 2 \mathrm{O}<=-0.71: \text { Ringold }(38.0 / 1.0) \\
\mathrm{K} 2 \mathrm{O}>-0.71: \text { Hanford }(5.0 / 1.0)\end{array}$} \\
\hline 200 West & Hanford & Ringold & & & 200 West & Hanford & Ringold & & & 200 West & Hanford & Ringold & & \\
\hline Hanford & 17 & 0 & 17 & 100.00 & Hanford & 6 & 1 & 7 & 85.71 & Hanford & 26 & 1 & 27 & 96.30 \\
\hline Ringold & 0 & 18 & 18 & 100.00 & Ringold & 0 & 15 & 15 & 100.00 & Ringold & 4 & 37 & 41 & 90.24 \\
\hline & 17 & 18 & 35 & 100.00 & & 6 & 16 & 22 & 95.45 & & 30 & 38 & 68 & 92.65 \\
\hline 200 West CV & Hanford & Ringold & & & 200 West CV & Hanford & Ringold & & & 200 West CV & Hanford & Ringold & & \\
\hline Hanford & 12 & 5 & 17 & 70.59 & Hanford & 6 & 1 & 7 & 85.71 & Hanford & 23 & 4 & 27 & 85.19 \\
\hline Ringold & 4 & 14 & 18 & 77.78 & Ringold & 2 & 13 & 15 & 86.67 & Ringold & 8 & 33 & 41 & 80.49 \\
\hline & 16 & 19 & 35 & 74.29 & & 8 & 14 & 22 & 86.36 & & 31 & 37 & 68 & 82.35 \\
\hline \multicolumn{5}{|c|}{ OneR } & \multicolumn{5}{|c|}{ OneR } & \multicolumn{5}{|c|}{ OneR } \\
\hline \multicolumn{5}{|c|}{ 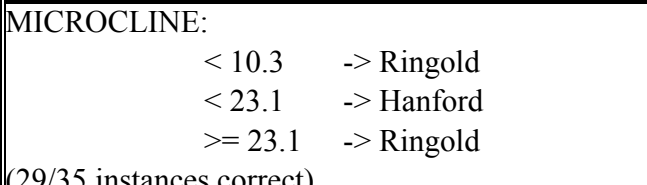 } & \multicolumn{5}{|c|}{$\begin{aligned} & \text { QUARTZ: } \\
&<27.8 \\
&>=27.8 \\
&\text { (21/22 instances } \text { correct })\end{aligned}$} & \multicolumn{5}{|c|}{$\begin{aligned} & \mathrm{SiO} 2: \\
&<0.735 \\
&>=0.735 \\
& \text { (60/68 instances correct) }\end{aligned}$} \\
\hline 200 West & Hanford & Ringold & & & 200 West & Hanford & Ringold & & & 200 West & Hanford & Ringold & & \\
\hline Hanford & 16 & 1 & 17 & 94.12 & \multirow{3}{*}{$\begin{array}{l}\text { Hanford } \\
\text { Ringold }\end{array}$} & 7 & 0 & 7 & 100.00 & \multirow{2}{*}{$\begin{array}{l}\text { Hanford } \\
\text { Ringold }\end{array}$} & 22 & 5 & 27 & 81.48 \\
\hline \multirow[t]{2}{*}{ Ringold } & 5 & 13 & 18 & 72.22 & & 1 & 14 & 15 & 93.33 & & 3 & 38 & 41 & 92.68 \\
\hline & 21 & 14 & 35 & 82.86 & & 8 & 14 & 22 & 95.45 & & 25 & 43 & 68 & 88.24 \\
\hline 200 West CV & Hanford & Ringold & & & \multirow{4}{*}{\begin{tabular}{|l|}
200 West CV \\
Hanford \\
Ringold \\
\end{tabular}} & Hanford & Ringold & & & \multirow{4}{*}{\begin{tabular}{|l}
200 West CV \\
Hanford \\
Ringold \\
\end{tabular}} & Hanford & Ringold & & \\
\hline Hanford & 10 & 7 & 17 & 58.82 & & 6 & 1 & 7 & 85.71 & & 20 & 7 & 27 & 74.07 \\
\hline Ringold & 10 & 8 & 18 & 44.44 & & 1 & 14 & 15 & 93.33 & & 4 & 37 & 41 & 90.24 \\
\hline & 20 & 15 & 35 & 51.43 & & 7 & 15 & 22 & 90.91 & & 24 & 44 & 68 & 83.82 \\
\hline
\end{tabular}


The C4.5 models from the XRF data at the 200 West Area had good cross-validation scores for the training samples. The classification rules developed from the $\mathrm{C} 4.5$ algorithm based on XRF data indicate that if the logratio of $\mathrm{SiO}_{2} / \mathrm{Al}_{2} \mathrm{O}_{3} \leq 0.73$, then the sample should be classified as Hanford formation. This leads to a $93 \%$ correct rate and an $82 \%$ cross-validation score for the 200 West Area samples (Table 4.11). In addition, all Hanford samples would be classified correctly if the rule is applied on the 200 East Area data. However, the lack of any XRF data for the Ringold Formation in the 200 East Area makes the reliability of the rules uncertain in the 200 East Area.

The decision rules from the OneR approach are listed in the bottom half of Table 4.11. OneR does not lead to a good classification model for the EM data as judged by the cross-validation of the training data. This suggests that no single variable from the EM dataset can be used to distinguish between the two geological formations. For the Petro data, quartz has been identified as the best single variable to distinguish between the two geological formations. With a threshold of quartz content equal to $27.8 \%$, the two formations are separated quite well, as indicated by cross-validation of the training data. Confirming the importance of the quartz content, $\mathrm{SiO}_{2}$ was identified as the best variable to separate the two formations for the XRF data, classifying about $90 \%$ of the samples correctly with an $84 \%$ crossvalidation score. The rules from $\mathrm{C} 4.5$ and OneR for the XRF data are similar. They select quartz or $\mathrm{SiO}_{2}$ as the primary distinguishable variable with a similar threshold. For the three datasets studied, all the classification methods present good classification models for the two geological formations for the 200 West Area data. The results for the Petro and XRF classification are consistent in identifying either quartz or $\mathrm{SiO}_{2}$ as the primary variable for classifying samples from the two formations. This is consistent with previous results found by Bjornstad (1990).

In summary:

- Although we found a good performance of the rules on the 200 West Area EM and Petro data, the spatial variability of the variables for those two datasets and the selection of minor variables sensitive to spatial location suggests caution about the goodness of the rules outside the 200 West Area. The consistency of rules from both machine learning methods for the XRF data and the spatial consistency of that data suggests the rules developed using XRF data should be more generally reliable. 


\subsection{Conclusions and Recommendations}

Visual examinations of Hanford and Ringold formation sediment samples do not always conclusively identify the geologic formation to which a sample belongs. Previous studies have indicated that there are differences in mineralogy and bulk-rock geochemical compositions between the Ringold and Hanford units that might be used to differentiate the two formations. We determined that the differences in mineralogy and geochemistry data are significant enough that statistical methods can be used to classify sediment samples belonging to the Hanford and Ringold formations.

EM and Petro data measured on the 200 West Area samples show significant differences between the Hanford and Ringold formation. However, significant spatial variability between data from the 200 West and 200 East Areas for the EM dataset causes the variable differences to be inconsistent when pooling samples from the two areas. XRF variables measured on 200 West Area samples also show significant differences between the two geological formations; those differences do not change much when pooling samples from the 200 East Area because of the greater consistency of the XRF data from the two locations. The compositional differences indicate that mineralogical and geochemical data can be used to quantitatively identify and classify samples from the Hanford and Ringold formations. The compositional differences, which reflect both depositional and diagenetic differences between the Hanford and Ringold, also suggest that distribution coefficient $\left(\mathrm{K}_{\mathrm{d}}\right)$ values for contaminant transport may be different for the two formations.

Principal component analysis supports the use of the mineralogical and geochemical data for classifycation of Hanford and Ringold formation samples. For the Petro data, separation of samples from the two formations measured in the 200 West Area seen in the PC space indicates a good classifier could be built for the two formations. More separation of samples from the two geological formations appears in the PC space of the XRF data. Pooling 200 East and 200 West Area samples does not significantly change the data structure, which confirms the consistency of the XRF measurements from the two locations. This suggests that the XRF data should be most useful in classifying samples from the Hanford and Ringold formations.

We were able to use several statistical techniques to generate effective classifiers for distinguishing between Hanford and Ringold formation samples using mineralogical and geochemical data. Classifiers for the 200 West Area that were generated using discriminant function analysis show good performance for the EM, Petro, and XRF datasets. The generalization of the discriminant functions to other locations like the 200 East Area should proceed with caution, however, because of the lack of stringent validation of the classifiers for the Petro and XRF measurements. In addition to discriminant function analysis, two different machine learning methods, $\mathrm{C} 4.5$ and One R, also provided useful and consistent classification rules for classifying samples as belonging to either the Hanford or Ringold formations based on mineralogical and geochemical data. Those classification rules can be used to classify new samples in the 200 West Area as belonging to either the Hanford or Ringold formations.

Based on the results of this study, we make the following recommendations: 
- We recommend that mineralogical and geochemical data continue to be gathered on a routine basis at the Hanford Site.

- We recommend that sodium be included in the XRF measurement suite. New capabilities in XRF measurements should now make that possible (R. J. Serne, PNNL, personal comm., 2002).

- We recommend that routine trace element analysis be performed on sediment samples at the Hanford Site. Preliminary studies by Bjornstad (1990) indicate that the trace elements Rb, Zn, Zr, and Ba can be used to differentiate between the Hanford and Ringold formations.

- To address some of concerns with grain size variation, it has been suggested that the Petro and XRF measurements be performed on just the fine sand fraction $(0.125-0.25 \mathrm{~mm})$ of the samples $(\mathrm{B} . \mathrm{N}$. Bjornstad, PNNL, personal comm., 2002). Much of the scatter in the data seen in this study may be the result of grain size variations between samples. In particular, basalt content is expected to increase with grain size in the Hanford formation, because the basalt grains settle out and get deposited more quickly under traction than do the finer felsic particles, which remain in suspension longer.

- An alternative possibility would be to include grain size statistics (e.g., mean grain size, sorting, and skewness) as additional variables in the multivariate analysis. This would require care in selection of the samples so that they were only obtained from core barrel or splitspoon drilling, because of the tendency of hard-tool drilling to pulverize the sample and alter the apparent grain size distribution.

- To test the power of the overall classification approach, it would be beneficial to conduct a future field sampling campaign where common mineralogical and geochemical analyses can be conducted on the same samples to allow the use of joint information from the two different kinds of measurements to determine the best variables for distinguishing between the two geological formations. This sampling campaign should include representative samples from all post-basalt units and facies, including the Cold Creek unit.

In conclusion, principal component analysis, discriminant function analyses, and machine learning methods all proved to be valuable additions to the standard toolbox in quantifying the explanatory value of mineral and element variables and determining which are most effective in distinguishing between the Ringold and Hanford stratigraphic units. Future work should build on these datasets with new data from a broader geographic area and all suprabasalt sediments, making it possible to classify samples taken from uncertain stratigraphic units with a high level of confidence. Given the differences in chemical and mineralogical composition for the Hanford and Ringold formations identified in this study, and the control that compositional differences often exert on $\mathrm{K}_{\mathrm{d}}$ 's for different contaminants, it appears that routine measurement of chemical and mineralogical composition of samples from new Hanford boreholes would make it easier to classify Hanford and Ringold sediments, and also provide data that would be useful for predicting the $\mathrm{K}_{\mathrm{d}}$ values for the sediments. 


\subsection{References}

Aitchison J. 1981. “A New Approach To Null Correlations of Proportions.” J. Math. Geol. 13:175-189.

Aitchison J. 1986. The Statistical Analysis of Compositional Data. John Wiley \& Sons, Inc., New York.

Baker VR. 1973. Paleohydrology and Sedimentology of Lake Missoula Flooding in Eastern Washington. Special Paper \#144, Geological Society of America, Boulder, Colorado.

Bjornstad BN. 1990. Geohydrology of the 218-W-5 Burial Ground, 200 West Area, Hanford Site. PNL7336, Pacific Northwest Laboratory, Richland, Washington.

Chapman RP. 1976. "Some Consequences of Applying Lognormal Theory to Pseudonormal Distributions, Discussion. J. Math. Geol. 8:209-214.

Cullers RL. 2000. "The Geochemistry of Shales, Siltstones and Sandstones of Pennsylvanian-Permian Age, Colorado, USA: Implications for Provenance and Metamorphic Studies.” Lithos 51:181-203.

Davis JC. 2002. Statistics and Data Analysis in Geology. $3^{\mathrm{RD}}$ Edition, John Wiley \& Sons, Inc., New York.

Golub GH, and CF Van Loan. 1983. Matrix Computations. Johns Hopkins University Press, Baltimore.

Holte RC. 1993. "Very Simple Classification Rules Perform Well on Most Commonly Used Datasets." Machine Learning 11:63-91.

Horton DG, GV Last, TJ Gilmore, and BN Bjornstad. 2001. A Catalog of Geologic Data for the Hanford Site. PNNL-13653, Pacific Northwest National Laboratory, Richland, Washington.

Johnson RA, and DW Wichern. 1988. Applied Multivariate Statistical Analysis. Prentice Hall, Englewood Cliffs, New Jersey.

Pearson K. 1897. "Mathematical Contributions to The Theory of Evolution: On a Form of Spurious Correlation Which May Arise When Indices Are Used in The Measurements of Organs." Proceedings of the Royal Society 60:489-498.

Quinlan JR. 1992. C4.5: Programs for Machine Learning. Morgan Kaufmann Publishers, San Francisco.

Rencher AC. 1995. Methods of Multivariate Analysis. John Wiley \& Sons, New York.

Reyment RA, and E Savazzi. 1999. Aspects of Multivariate Statistical Analysis in Geology. Elsevier Press, New York. 
Rietjens M. 1995. "Reduction of Error Propagation Due To Normalization: Effect of Error Propagation and Closure on Spurious Correlations." Analytica Chemica Acta 316:205-215.

Rock NMS. 1988. Numerical Geology. Springer-Verlag, Berlin.

SYSTAT $^{\circledR}$. 2000. Statistics I. SPSS Inc, Chicago, Illinois.

Tallman AM, KR Fecht, MC Marratt, and GV Last. 1979. Geology of the Separation Areas, Hanford Site, South-Central Washington. RHO-ST-23, Rockwell Hanford Operations, Richland, Washington.

U.S. Department of Energy (DOE). 2002. Standardized Stratigraphic Nomenclature for Post-RingoldFormation Sediments Within the Central Pasco Basin. DOE/RL-2002-39, Rev. 0, DOE-RL, Richland, Washington.

Verrucchi C, and A Minissale. 1995. "Multivariate Statistical Comparison of Northern Apennines Paleozoic Sequences: A Case Study For the Formation of Monti Romani (Southern Tuscany-Northern Latium, Italy)." Applied Geochemistry 10:581-598.

von Eynatten H, C Barcelo-Vidal, and V Pawlowsky-Glahn. 2003. "Composition and discrimination of sandstones: A statistical evaluation of different analytical methods." J. Sed. Research 73(1):47-57.

Witten IH, and E Frank. 1999. Data Mining: Practical Machine Learning Tools and Techniques with Java Implementations. Morgan Kaufmann Publishers, San Francisco.

Zhang C, W Lijun, L Guosheng, D Shuangshuang, Y Jingrong, and W Xiuli. 2002. "Grain Size Effect on Multi-Element Concentrations in Sediments from the Intertidal Flats of Bohai Bay, China." Applied Geochemistry 17:59-68. 


\title{
Appendix A
}

\author{
Data Tables
}


Table A.1. Electron Microprobe Data

\begin{tabular}{|c|c|c|c|c|c|c|c|c|c|c|c|c|c|c|c|c|c|c|c|c|c|}
\hline \begin{tabular}{l}
$\#$ \\
\multirow{0}{*}{} \\
$\tilde{z}$ \\
$\tilde{z}$
\end{tabular} & 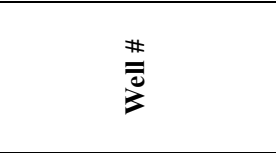 & 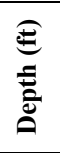 & 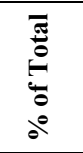 & 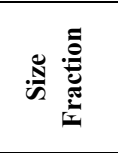 & 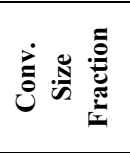 & 泀竞 & 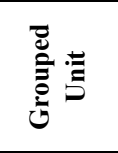 & $\stackrel{N}{\tilde{\Xi}}$ & 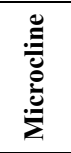 & 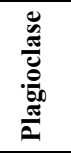 & 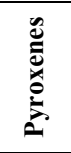 & 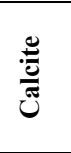 & 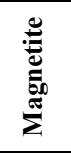 & 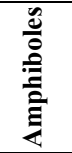 & 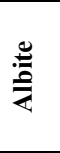 & 莺 & 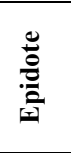 & $\frac{\mathscr{E}}{\ddot{E}}$ & 䒿 & 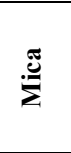 & 苍 \\
\hline 1 & 241-A Tank Farm (C) & - & 100.0 & bulk & bulk & Hanford & Hanford & 32.1 & 14.8 & 17.4 & 0.0 & 6.5 & 14.4 & 12.2 & 0.0 & 0.0 & 0.0 & 0.0 & 0.0 & 2.6 & $\mathrm{~m}$ \\
\hline 2 & 241-SY Tank Farm (C) & 25 & 17.8 & $200-270$ & $.075-.053$ & Hanford & Hanford & 21.6 & 10.4 & 23.3 & 27.5 & 1.6 & 6.2 & 0.0 & 0.0 & 2.4 & 0.0 & 0.0 & 0.8 & 6.1 & $\mathrm{~m}$ \\
\hline 3 & 241-SY Tank Farm (C) & 30 & 3.6 & $200-270$ & $.075-.053$ & Hanford & Hanford & 23.5 & 4.1 & 36.1 & 19.3 & 3.3 & 3.1 & 0.0 & 0.0 & 1.1 & 0.0 & 1.1 & 1.0 & 7.2 & $\mathrm{~m}$ \\
\hline 4 & 299-W10-148 & 80 & 53.1 & $40-200$ & $.425-.075$ & Hanford & Hanford & 47.2 & 21.7 & 15.2 & 8.7 & 0.0 & 0.0 & 5.5 & 0.0 & 0.0 & 0.0 & 0.0 & 0.2 & 1.5 & $\mathrm{~m}$ \\
\hline 5 & 299-W10-148 & 80 & 33.1 & $40-200$ & $.425-.075$ & Hanford & Hanford & 31.5 & 13.0 & 24.7 & 0.4 & 1.8 & 2.9 & 0.9 & 0.0 & 0.0 & 10.3 & 1.0 & 0.5 & 13.1 & $\mathrm{~m}$ \\
\hline 6 & 299-W10-148 & 80 & 86.3 & $10-200$ & $2.0-.075$ & Hanford & Hanford & 41.1 & 18.4 & 18.9 & 5.5 & 0.7 & 1.1 & 3.7 & 0.0 & 0.0 & 4.0 & 0.4 & 0.3 & 5.9 & $\mathrm{~m}$ \\
\hline 7 & 299-W10-148 & 80 & 53.1 & $10-40$ & $2.0-.425$ & Hanford & Hanford & 47.9 & 22.1 & 15.4 & 8.8 & 0.0 & 0.0 & 5.6 & 0.0 & 0.0 & 0.0 & 0.0 & 0.2 & 0.0 & $\mathrm{j}$ \\
\hline 8 & 299-W10-148 & 80 & 33.1 & $40-200$ & $.425-.075$ & Hanford & Hanford & 36.2 & 14.9 & 28.4 & 0.5 & 2.1 & 3.3 & 1.0 & 0.0 & 0.0 & 11.8 & 1.1 & 0.6 & 0.0 & $\mathrm{j}$ \\
\hline 9 & 299-W10-148 & 80 & 86.2 & bulk & bulk & Hanford & Hanford & 42.3 & 18.9 & 19.4 & 8.9 & 0.7 & 1.2 & 3.8 & 0.0 & 0.0 & 4.1 & 0.4 & 0.4 & 0.0 & $\mathrm{j}$ \\
\hline 10 & 299-W11-10 & 90 & 79.82 & $10-200$ & $2.0-.075$ & Hanford & Hanford & 67.1 & 11.3 & 5.4 & 0.0 & 3.3 & 3.6 & 4.5 & 0.0 & 0.0 & 0.0 & 0.0 & 0.0 & 4.7 & $\mathrm{~m}$ \\
\hline 11 & 299-W14-8 & 100 & 9.04 & $10-200$ & $2.0-.075$ & Hanford & Hanford & 54.1 & 16.8 & 18.0 & 0.0 & 0.8 & 4.6 & 2.1 & 0.0 & 3.6 & 0.0 & 0.0 & 0.0 & 0.0 & $\mathrm{~m}$ \\
\hline 12 & 299-W23-108 & 105 & 100.0 & bulk & bulk & Hanford & Hanford & 38.1 & 11.7 & 22.2 & 0.0 & 2.3 & 1.9 & 17.9 & 2.7 & 1.9 & 0.0 & 0.0 & 1.1 & 0.1 & $\mathrm{~m}$ \\
\hline 13 & 299-W23-108 & 105 & 100.0 & bulk & bulk & Hanford & Hanford & 47.0 & 18.9 & 22.8 & 0.0 & 0.5 & 1.9 & 8.9 & 0.0 & 0.0 & 0.0 & 0.0 & 0.0 & 0.0 & $\mathrm{j}$ \\
\hline 14 & 299-W23-52 & 100 & 100.0 & bulk & bulk & Hanford & Hanford & 41.2 & 16.1 & 24.6 & 0.0 & 0.0 & 11.1 & 0.0 & 0.0 & 3.1 & 0.0 & 0.0 & 3.8 & 0.0 & $\mathrm{~m}$ \\
\hline 15 & 299-W23-52 & 100 & 100.0 & bulk & bulk & Hanford & Hanford & 41.2 & 16.1 & 24.6 & 0.0 & 3.8 & 11.1 & 0.0 & 0.0 & 3.1 & 0.0 & 0.0 & 0.0 & 0.0 & $\mathrm{j}$ \\
\hline 16 & 299-W23-72 & 100 & 100.0 & bulk & bulk & Hanford & Hanford & 20.2 & 15.4 & 30.3 & 2.8 & 2.5 & 4.7 & 13.3 & 6.8 & 3.3 & 0.0 & 0.0 & 0.0 & 0.6 & $\mathrm{~m}$ \\
\hline 17 & 299-W23-72 & 100 & 100.0 & bulk & bulk & Hanford & Hanford & 20.3 & 15.5 & 30.4 & 2.8 & 2.6 & 4.7 & 13.4 & 6.8 & 3.3 & 0.0 & 0.0 & 0.0 & 0.0 & $\mathrm{j}$ \\
\hline 18 & 299-W11-26 & 203 & 9.7 & $40-200$ & $.425-.075$ & Middle R. & Ringold & 34.2 & 24.1 & 20.9 & 0.0 & 2.3 & 8.1 & 1.9 & 0.0 & 1.3 & 7.3 & 0.0 & 0.0 & 0.0 & $\mathrm{~m}$ \\
\hline 19 & 299-W11-26 & 293 & 16.4 & $40-200$ & $.425-.075$ & Middle R. & Ringold & 34.8 & 26.8 & 19.7 & 0.0 & 0.0 & 4.9 & 4.0 & 0.0 & 5.5 & 0.0 & 0.0 & 4.4 & 0.0 & $\mathrm{~m}$ \\
\hline 20 & 299-W11-26 & 390 & 18.3 & $40-200$ & $.425-.075$ & Middle R. & Ringold & 47.0 & 28.8 & 9.2 & 0.0 & 12.3 & 2.7 & 0.0 & 0.0 & 0.0 & 0.0 & 0.0 & 0.0 & 0.0 & $\mathrm{~m}$ \\
\hline 21 & 299-W19-10 & 181 & 5.9 & $<40$ & $<0.425$ & Middle R. & Ringold & 19.7 & 10.2 & 18.4 & 3.4 & 13.2 & 11.6 & 15.7 & 3.3 & 3.5 & 0.0 & 0.0 & 0.1 & 0.9 & $\mathrm{~m}$ \\
\hline 22 & 299-W19-10 & 181 & 3.9 & -200 & 0.075 & Middle R. & Ringold & 18.3 & 7.4 & 13.9 & 0.0 & 15.7 & 17.6 & 22.9 & 0.0 & 4.2 & 0.0 & 0.0 & 0.0 & 0.0 & $\mathrm{j}$ \\
\hline 23 & 299-W19-10 & 181 & 2.0 & $40-200$ & $.425-.075$ & Middle R. & Ringold & 23.2 & 16.1 & 27.8 & 10.2 & 8.5 & 0.2 & 1.9 & 9.9 & 1.9 & 0.0 & 0.0 & 0.2 & 0.0 & $\mathrm{j}$ \\
\hline 24 & 299-W19-10 & 181 & 5.9 & bulk & bulk & Middle R. & Ringold & 20.3 & 10.2 & 16.9 & 3.4 & 13.6 & 11.9 & 15.3 & 3.4 & 3.4 & 0.0 & 0.0 & 1.7 & 0.0 & $\mathrm{j}$ \\
\hline 25 & 299-W19-10 & 234 & 7.6 & $<40$ & $<0.425$ & Middle R. & Ringold & 38.3 & 24.3 & 14.9 & 0.8 & 1.3 & 4.2 & 1.7 & 0.0 & 5.9 & 0.5 & 0.0 & 1.3 & 6.8 & $\mathrm{~m}$ \\
\hline 26 & 299-W19-10 & 234 & 2.6 & -200 & 0.075 & Middle R. & Ringold & 46.5 & 17.5 & 12.9 & 0.0 & 0.0 & 7.1 & 4.8 & 0.0 & 7.5 & 1.5 & 0.0 & 2.1 & 0.0 & $\mathrm{j}$ \\
\hline 27 & 299-W19-10 & 234 & 5.0 & $40-200$ & $.425-.075$ & Middle R. & Ringold & 37.9 & 31.1 & 17.8 & 1.4 & 2.3 & 3.0 & 0.0 & 0.0 & 5.6 & 0.0 & 0.0 & 0.9 & 0.0 & $\mathrm{j}$ \\
\hline 28 & 299-W19-10 & 234 & 7.6 & bulk & bulk & Middle R. & Ringold & 40.6 & 26.1 & 15.9 & 1.4 & 1.4 & 4.3 & 1.4 & 0.0 & 5.8 & 1.4 & 0.0 & 1.4 & 0.0 & $\mathrm{j}$ \\
\hline 29 & 299-W19-10 & 275 & 100.0 & bulk & bulk & Middle R. & Ringold & 53.4 & 20.1 & 1.1 & 0.0 & 0.0 & 2.3 & 0.0 & 0.0 & 0.0 & 1.8 & 0.0 & 0.0 & 21.3 & $\mathrm{~m}$ \\
\hline 30 & 299-W19-10 & 275 & 100.0 & bulk & bulk & Middle R. & Ringold & 67.9 & 25.5 & 1.4 & 0.0 & 0.0 & 2.9 & 0.0 & 0.0 & 0.0 & 2.3 & 0.0 & 0.0 & 0.0 & $\mathrm{j}$ \\
\hline 31 & 299-W19-10 & 285 & 100.0 & bulk & bulk & Middle R. & Ringold & 40.8 & 21.1 & 22.8 & 0.0 & 0.0 & 0.0 & 4.6 & 0.0 & 8.8 & 0.0 & 0.0 & 0.0 & 1.8 & $\mathrm{~m}$ \\
\hline 32 & 299-W19-10 & 285 & 100.0 & bulk & bulk & Middle R. & Ringold & 41.6 & 21.5 & 23.2 & 0.0 & 0.0 & 0.0 & 4.7 & 0.0 & 9.0 & 0.0 & 0.0 & 0.0 & 0.0 & $\mathrm{j}$ \\
\hline 33 & 299-W19-10 & 365 & 23.7 & $40-200$ & $.425-.075$ & Middle R. & Ringold & 34.0 & 8.4 & 13.8 & 0.0 & 23.5 & 7.2 & 7.6 & 0.0 & 1.3 & 4.2 & 0.0 & 0.0 & 0.0 & $\mathrm{~m}$ \\
\hline 34 & 299-W19-10 & 365 & 23.7 & $40-200$ & $.425-.075$ & Middle R. & Ringold & 34.1 & 8.3 & 13.8 & 0.0 & 23.8 & 7.2 & 7.4 & 0.0 & 1.1 & 4.2 & 0.0 & 0.0 & 0.0 & $\mathrm{j}$ \\
\hline 35 & 299-W19-10 & 365 & 23.7 & bulk & bulk & Middle R. & Ringold & 34.0 & 8.4 & 13.9 & 0.0 & 23.5 & 7.1 & 7.6 & 0.0 & 1.3 & 4.2 & 0.0 & 0.0 & 0.0 & $\mathrm{j}$ \\
\hline 36 & 299-E19-1 & 426 & $46-61$ & $10-200$ & - & Basal R. & Ringold & 32.3 & 8.5 & 10.1 & 0.0 & 0.9 & 4.2 & 16.8 & 0.0 & 0.0 & 0.0 & 0.0 & 0.0 & 6.6 & $\mathrm{~m}$ \\
\hline 37 & 299-E19-1 & 450 & 10.0 & $40-200$ & - & Basal R. & Ringold & 62.6 & 7.9 & 9.6 & 0.0 & 0.0 & 5.1 & 6.2 & 0.0 & 0.0 & 0.0 & 0.0 & 0.0 & 8.6 & $\mathrm{~m}$ \\
\hline 38 & 299-E19-1 & 488 & 5.9 & $40-200$ & - & Basal R. & Ringold & 44.8 & 37.1 & 8.5 & 0.0 & 0.0 & 0.0 & 0.0 & 0.0 & 4.0 & 0.0 & 2.8 & 0.0 & 2.8 & $\mathrm{~m}$ \\
\hline 39 & 299-E19-1 & 511 & 3.9 & $40-200$ & - & Basal R. & Ringold & 57.9 & 25.1 & 7.7 & 0.0 & 0.0 & 0.0 & 7.7 & 0.0 & 1.6 & 0.0 & 0.0 & 0.0 & 0.0 & $\mathrm{~m}$ \\
\hline
\end{tabular}


Table A.1. (contd.)

\begin{tabular}{|c|c|c|c|c|c|c|c|c|c|c|c|c|c|c|c|c|c|c|c|c|c|}
\hline $\begin{array}{l}\# \\
0 \\
\tilde{z} \\
\tilde{z} \\
\tilde{u}\end{array}$ & $\begin{array}{l}\text { \# } \\
\bar{\equiv} \\
\bar{z}\end{array}$ & 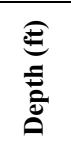 & 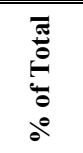 & 疋 & 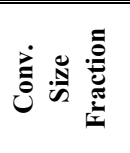 & 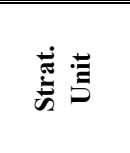 & 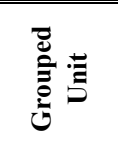 & 离 & 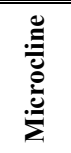 & 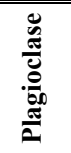 & 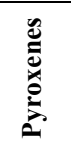 & 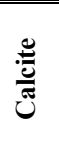 & 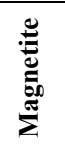 & 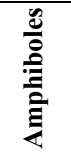 & 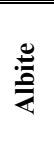 & $\begin{array}{l}\stackrel{\Xi}{\Xi} \\
\stackrel{\Xi}{\Xi}\end{array}$ & $\frac{\stackrel{0}{0}}{\stackrel{0}{0}}$ & $\frac{\mathscr{\Xi}}{\tilde{E}}$ & & $\stackrel{\mathscr{J}}{\stackrel{\Xi}{\Sigma}}$ & 苋 \\
\hline 40 & 299-E13-5 & 185 & 85.7 & $10-200$ & - & Hanford & Hanford & 29.6 & 10.1 & 9.7 & 0.0 & 2.9 & 5.1 & 11.9 & 0.0 & 10.1 & 0.0 & 0.0 & 0.0 & 9.4 & $\mathrm{~m}$ \\
\hline 41 & 299-E13-8 & 70 & 83.9 & $10-200$ & - & Hanford & Hanford & 34.3 & 6.6 & 0.0 & 0.0 & 0.0 & 15.0 & 10.7 & 0.0 & 6.0 & 0.0 & 0.0 & 4.1 & 11.3 & $\mathrm{~m}$ \\
\hline 42 & 299-E16-1 & 60 & 95.34 & $10-200$ & - & Hanford & Hanford & 22.5 & 1.8 & 34.0 & 0.0 & 0.0 & 2.8 & 36.3 & 0.0 & 2.7 & 0.0 & 0.0 & 0.0 & 0.0 & $\mathrm{~m}$ \\
\hline 43 & 299-E16-1 & 125 & 36.27 & $10-200$ & - & Hanford & Hanford & 50.4 & 6.5 & 14.0 & 0.0 & 0.0 & 7.7 & 3.1 & 0.0 & 0.0 & 0.0 & 0.0 & 0.0 & 4.1 & $\mathrm{~m}$ \\
\hline 44 & 299-E25-15 & 100 & 100.0 & bulk & - & Hanford & Hanford & 38.1 & 11.7 & 22.2 & 17.9 & 2.3 & 1.9 & 17.9 & 2.7 & 1.9 & 0.0 & 0.0 & 1.1 & 0.1 & $\mathrm{~m}$ \\
\hline 45 & 299-E25-15 & 100 & 100.0 & bulk & - & Hanford & Hanford & 38.1 & 11.7 & 22.2 & 0.0 & 2.3 & 1.9 & 17.9 & 2.7 & 1.9 & 0.0 & 0.0 & 1.1 & 0.1 & $\mathrm{j}$ \\
\hline 46 & 299-E27-6 & 198 & 11.2 & $40-200$ & - & Hanford & Hanford & 34.8 & 19.6 & 23.5 & 0.0 & 0.0 & 0.0 & 14.7 & 0.0 & 0.0 & 0.0 & 0.0 & 0.0 & 7.4 & $\mathrm{~m}$ \\
\hline 47 & 299-E27-6 & 264 & 8.3 & $40-200$ & - & Hanford & Hanford & 41.4 & 9.0 & 8.3 & 0.0 & 2.1 & 2.1 & 12.4 & 0.0 & 0.0 & 0.0 & 0.0 & 0.0 & 10.3 & $\mathrm{~m}$ \\
\hline 48 & 299-E28-22 & 207 & 22.1 & $40-200$ & - & Hanford & Hanford & 43.9 & 30.1 & 12.2 & 0.0 & 2.6 & 0.0 & 10.1 & 0.0 & 0.0 & 0.0 & 0.0 & 1.1 & 0.0 & $\mathrm{~m}$ \\
\hline 49 & 299-E33-201 & 50 & 78.2 & $40-200$ & - & Hanford & Hanford & 39.0 & 19.2 & 19.1 & 3.3 & 0.2 & 4.5 & 0.1 & 0.0 & 2.4 & 1.3 & 0.1 & 0.1 & 1.7 & $\mathrm{~m}$ \\
\hline 50 & 299-E33-201 & 50 & 78.2 & $10-40$ & - & Hanford & Hanford & 44.9 & 22.5 & 20.3 & 4.1 & 0.0 & 5.2 & 0.0 & 0.0 & 3.1 & 0.0 & 0.0 & 0.0 & 0.0 & $\mathrm{j}$ \\
\hline 51 & 299-E33-201 & 50 & 78.2 & bulk & - & Hanford & Hanford & 39.0 & 19.2 & 19.1 & 3.3 & 0.2 & 4.5 & 0.1 & 0.0 & 2.4 & 1.3 & 0.1 & 0.1 & 1.7 & $\mathrm{j}$ \\
\hline 52 & 299-E33-244 & 70 & 100.0 & bulk & - & Hanford & Hanford & 21.8 & 27.1 & 26.2 & 6.1 & 0.0 & 7.6 & 0.4 & 5.5 & 5.2 & 0.0 & 0.0 & 0.0 & 0.0 & $\mathrm{~m}$ \\
\hline 53 & 299-E33-244 & 70 & 100.0 & bulk & - & Hanford & Hanford & 21.8 & 27.1 & 26.2 & 6.1 & 0.0 & 7.6 & 5.6 & 0.0 & 5.2 & 0.0 & 0.0 & 0.4 & 0.0 & $\mathrm{j}$ \\
\hline 54 & 299-E19-1 & 385 & 6.7 & $40-200$ & - & Lower R. & Ringold & 45.6 & 4.3 & 0.0 & 0.0 & 0.0 & 0.0 & 4.9 & 0.0 & 0.0 & 0.0 & 0.0 & 0.0 & 15.0 & $\mathrm{~m}$ \\
\hline 55 & 299-E27-6 & 293 & 3.6 & $40-200$ & - & Middle R. & Ringold & 68.9 & 12.0 & 10.8 & 0.0 & 0.0 & 8.4 & 0.0 & 0.0 & 0.0 & 0.0 & 0.0 & 0.0 & 0.0 & $\mathrm{~m}$ \\
\hline & 299-E33-244 & 80 & 100.0 & bulk & - & - & & 21.8 & 27.1 & 26.2 & 6.1 & 0.0 & 7.6 & 5.6 & 0.0 & 5.2 & 0.0 & 0.0 & 0.4 & 0.0 & $\bar{j}$ \\
\hline & 299-W19-10 & 519 & 14.1 & $10-40$ & $2.0-.425$ & - & & 46.6 & 29.1 & 22.5 & 0.0 & 0.0 & 0.0 & 1.8 & 0.0 & 0.0 & 0.0 & 0.0 & 0.0 & 0.0 & $\mathrm{j}$ \\
\hline & 299-W19-10 & 519 & 12.9 & $40-200$ & $.425-.075$ & - & & 71.4 & 17.7 & 1.7 & 0.0 & 0.0 & 0.9 & 0.0 & 0.0 & 3.7 & 4.6 & 0.0 & 0.0 & 0.0 & $\mathrm{j}$ \\
\hline & 299-W19-10 & 519 & 27.0 & bulk & bulk & - & & 58.6 & 23.5 & 12.4 & 0.0 & 0.0 & 0.4 & 0.8 & 0.0 & 2.0 & 2.4 & 0.0 & 0.0 & 0.0 & $\mathrm{j}$ \\
\hline
\end{tabular}


Table A.2. Petrographic Data

\begin{tabular}{|c|c|c|c|c|c|c|c|c|c|c|c|c|c|c|c|c|c|c|c|c|}
\hline 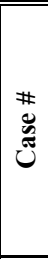 & & $\frac{\#}{\bar{\sigma}}$ & 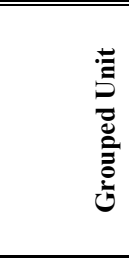 & 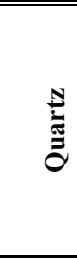 & 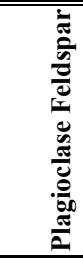 & 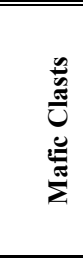 & 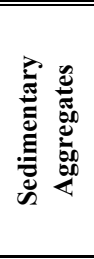 & 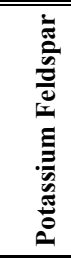 & 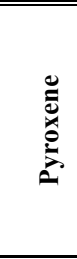 & 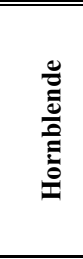 & 苛 & 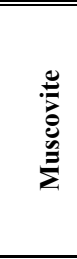 & $\frac{\mathscr{E}}{\tilde{E}}$ & 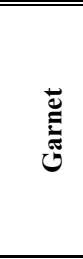 & 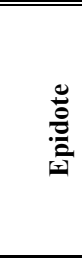 & 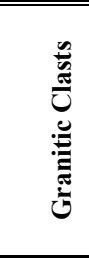 & 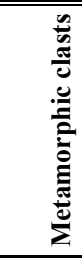 & 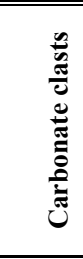 & 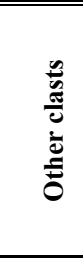 & 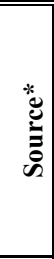 \\
\hline 1 & "299-W10-13 & & "Hanford & 27.1 & 24.9 & "6.9 & 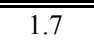 & $\bar{~} 5.5$ & 0.5 & 1.7 & 6.2 & 0.3 & 1.1 & 0.0 & 0.0 & 111.9 & 1.4 & 2.2 & 8.6 & $\overline{\mathrm{a}}$ \\
\hline 2 & 299-W15-16 & & Hanford & 21.4 & 21.1 & 32.6 & 1.5 & 3.5 & 2.6 & 1.2 & 1.5 & 1.2 & 2.4 & 0.3 & 0.0 & 3.5 & 1.2 & 0.3 & 5.9 & $\mathrm{a}$ \\
\hline 3 & 299-W15-16 & & Hanford & 11.2 & 1.5 & 65.2 & 3.4 & 0.0 & 1.5 & 0.0 & 0.7 & 0.0 & 0.0 & 0.0 & 0.0 & 7.5 & 0.0 & 0.0 & 9.0 & $\mathrm{a}$ \\
\hline 4 & 299-W18-21 & & Hanford & 15.2 & 19.4 & 33.9 & 2.3 & 4.7 & 2.6 & 1.6 & 4.7 & 0.8 & 1.6 & 0.0 & 0.0 & 5.4 & 0.5 & 1.6 & 5.9 & $\mathrm{a}$ \\
\hline 5 & 299-W18-21 & & Hanford & 26.8 & 27.5 & 11.3 & 1.4 & 5.4 & 2.6 & 1.2 & 2.3 & 0.2 & 2.6 & 0.9 & 0.2 & 9.6 & 1.4 & 0.2 & 6.3 & $\mathrm{a}$ \\
\hline 6 & 299-W7-5 & & Hanford & 22.1 & 21.3 & 29.4 & 1.4 & 4.5 & 2.0 & 1.1 & 3.1 & 0.0 & 2.0 & 0.0 & 0.0 & 2.8 & 0.6 & 1.1 & 8.7 & $\mathrm{a}$ \\
\hline 7 & 299-W10-13 & & Ringold & 51.5 & 14.6 & 3.9 & 3.6 & 7.1 & 0.6 & 0.3 & 2.7 & 0.3 & 0.0 & 0.6 & 0.0 & 10.7 & 0.3 & 0.0 & 3.9 & $\mathrm{a}$ \\
\hline 8 & 299-W10-13 & & Ringold & 18.5 & 7.8 & 27.0 & 23.1 & 1.3 & 1.0 & 0.0 & 1.0 & 0.3 & 1.0 & 0.3 & 0.0 & 9.4 & 1.9 & 1.9 & 5.5 & $\mathrm{a}$ \\
\hline 9 & 299-W10-13 & & Ringold & 33.2 & 24.6 & 10.7 & 0.6 & 4.4 & 1.0 & 0.6 & 2.2 & 0.3 & 2.2 & 0.0 & 0.3 & 12.6 & 2.5 & 0.3 & 4.3 & $\mathrm{a}$ \\
\hline 10 & 299-W10-13 & & Ringold & 30.9 & 17.8 & 19.0 & 3.0 & 3.9 & 1.2 & 0.6 & 0.6 & 0.3 & 0.9 & 0.0 & 0.0 & 11.9 & 1.2 & 1.2 & 7.7 & $\mathrm{a}$ \\
\hline 11 & 299-W10-13 & & Ringold & 28.5 & 23.0 & 8.4 & 4.7 & 4.2 & 1.3 & 1.1 & 1.8 & 0.0 & 0.5 & 0.0 & 0.3 & 20.3 & 1.1 & 0.0 & 4.7 & $\mathrm{a}$ \\
\hline 12 & 299-W10-14 & & Ringold & 31.9 & 4.8 & 23.2 & 16.5 & 3.9 & 0.3 & 0.0 & 0.3 & 0.7 & 0.0 & 0.0 & 0.0 & 9.7 & 3.2 & 0.0 & 5.5 & $\mathrm{a}$ \\
\hline 13 & 299-W10-14 & & Ringold & 45.3 & 11.7 & 10.6 & 10.3 & 2.8 & 1.1 & 0.9 & 1.1 & 0.9 & 0.9 & 0.9 & 0.0 & 6.0 & 2.6 & 0.3 & 4.8 & $\mathrm{a}$ \\
\hline 14 & 299-W15-16 & & Ringold & 37.6 & 14.7 & 12.8 & 2.9 & 3.6 & 0.8 & 0.8 & 0.5 & 0.3 & 1.1 & 0.3 & 0.0 & 13.6 & 5.3 & 0.0 & 5.6 & $\mathrm{a}$ \\
\hline 15 & 299-W15-16 & & Ringold & 29.3 & 10.5 & 18.8 & 8.6 & 1.3 & 0.6 & 0.3 & 0.6 & 0.3 & 0.6 & 0.0 & 0.0 & 11.1 & 2.5 & 0.0 & 15.3 & $\mathrm{a}$ \\
\hline 16 & 299-W15-17 & & Ringold & 52.6 & 7.5 & 8.4 & 11.8 & 3.8 & 0.9 & 0.3 & 0.6 & 0.0 & 0.3 & 0.0 & 0.3 & 8.7 & 1.2 & 0.3 & 3.5 & $\mathrm{a}$ \\
\hline 17 & 299-W15-17 & & Ringold & 45.4 & 11.6 & 6.2 & 11.3 & 4.8 & 0.6 & 0.6 & 1.8 & 0.0 & 0.6 & 0.3 & 0.3 & 9.2 & 2.7 & 0.3 & 4.4 & $\mathrm{a}$ \\
\hline 18 & 299-W18-21 & & Ringold & 22.9 & 12.6 & 39.2 & 1.5 & 2.8 & 4.3 & 0.2 & 0.8 & 0.0 & 2.0 & 0.0 & 0.5 & 6.0 & 0.0 & 0.0 & 7.3 & $\mathrm{a}$ \\
\hline 19 & 299-W18-22 & & Ringold & 42.3 & 15.3 & 7.5 & 11.4 & 4.1 & 0.0 & 1.0 & 1.5 & 0.0 & 0.7 & 0.7 & 0.0 & 11.0 & 1.7 & 0.0 & 2.7 & $\mathrm{a}$ \\
\hline 20 & 299-W7-2 & & Ringold & 37.3 & 19.5 & 9.7 & 1.0 & 4.1 & 0.8 & 0.3 & 1.3 & 0.8 & 0.8 & 0.3 & 0.3 & 16.2 & 0.3 & 0.0 & 7.6 & $\mathrm{a}$ \\
\hline 21 & 299-W7-2 & & Ringold & 34.6 & 11.3 & 13.6 & 3.9 & 7.8 & 0.3 & 0.3 & 0.6 & 0.0 & 0.0 & 0.0 & 0.0 & 18.4 & 4.2 & 0.0 & 4.9 & $\mathrm{a}$ \\
\hline 22 & 299-W7-3 & & Ringold & 47.5 & 20.1 & 8.0 & 1.6 & 5.9 & 0.3 & 0.8 & 2.1 & 0.3 & 0.8 & 0.3 & 0.0 & 7.0 & 1.3 & 0.3 & 3.8 & $\mathrm{a}$ \\
\hline
\end{tabular}


Table A.3. XRF Data

\begin{tabular}{|c|c|c|c|c|c|c|c|c|c|c|c|c|c|c|c|c|c|c|c|c|c|}
\hline $\begin{array}{l}\text { \# } \\
0 \\
\tilde{N} \\
\tilde{N}\end{array}$ & $\begin{array}{l}\text { \# } \\
\overline{\bar{\sigma}} \\
\bar{z}\end{array}$ & 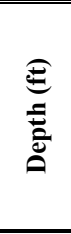 & 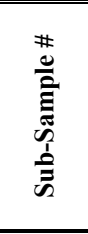 & 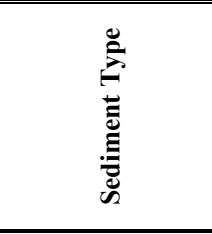 & 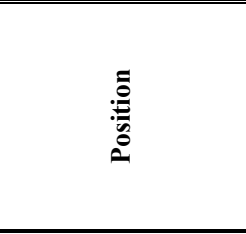 & 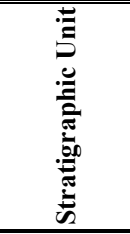 & 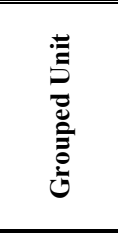 & 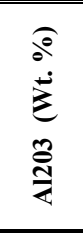 & 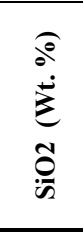 & 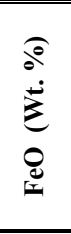 & 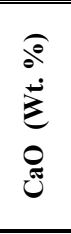 & 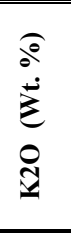 & 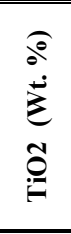 & $\begin{array}{l}\stackrel{\rho}{e} \\
\dot{j} \\
\dot{j}\end{array}$ & 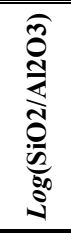 & 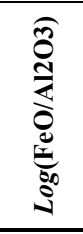 & 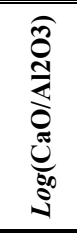 & 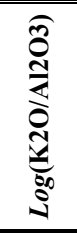 & 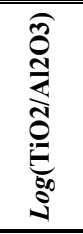 & 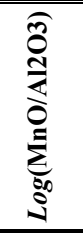 & 苋 \\
\hline 1 & 299-W22-48 & 47 & - & - & - & H1 & Hanford & 15.83 & 67.61 & 4.72 & 8.40 & 1.62 & 1.66 & 0.15 & 0.63 & -0.53 & -0.28 & -0.99 & -0.98 & -2.02 & $\mathrm{~b}$ \\
\hline 2 & $299-W 22-50$ & 60 & - & - & - & H1 & Hanford & 14.55 & 71.85 & 3.67 & 6.63 & 1.97 & 1.22 & 0.11 & 0.69 & -0.60 & -0.34 & -0.87 & -1.08 & -2.12 & $\mathrm{~b}$ \\
\hline 3 & 299-W22-48 & 39.5 & - & - & - & H1a & Hanford & 15.34 & 75.84 & 1.95 & 3.42 & 2.72 & 0.66 & 0.08 & 0.69 & -0.90 & -0.65 & -0.75 & -1.37 & -2.31 & $\mathrm{~b}$ \\
\hline 4 & $299-W 22-50$ & 51 & - & - & - & H1a & Hanford & 13.74 & 72.57 & 4.09 & 6.02 & 2.03 & 1.41 & 0.14 & 0.72 & -0.53 & -0.36 & -0.83 & -0.99 & -2.00 & b \\
\hline 5 & 299-W22-48 & 91.5 & - & - & - & $\mathrm{H} 2$ & Hanford & 14.08 & 77.44 & 1.67 & 3.39 & 2.80 & 0.56 & 0.06 & 0.74 & -0.93 & -0.62 & -0.70 & -1.40 & -2.34 & $\mathrm{~b}$ \\
\hline 6 & 299-W22-48 & 102 & - & - & - & $\mathrm{H} 2$ & Hanford & 14.24 & 77.06 & 1.87 & 3.45 & 2.69 & 0.63 & 0.06 & 0.73 & -0.88 & -0.62 & -0.72 & -1.35 & -2.35 & $\mathrm{~b}$ \\
\hline 7 & $299-W 22-50$ & 116 & - & - & - & $\mathrm{H} 2$ & Hanford & 14.90 & 75.51 & 2.02 & 4.11 & 2.68 & 0.71 & 0.08 & 0.70 & -0.87 & -0.56 & -0.75 & -1.32 & -2.29 & $\mathrm{~b}$ \\
\hline 8 & 299-W23-19 & 88.1 & $22 \mathrm{D}$ & - & - & H1 & Hanford & 12.19 & 78.52 & 2.08 & 3.81 & 2.57 & 0.76 & 0.08 & 0.81 & -0.77 & -0.50 & -0.68 & -1.21 & -2.20 & e \\
\hline 9 & 299-W23-19 & 64.8 & $17 \mathrm{DE}$ & - & - & H1a & Hanford & 12.43 & 74.68 & 3.27 & 6.19 & 2.15 & 1.17 & 0.12 & 0.78 & -0.58 & -0.30 & -0.76 & -1.03 & -2.02 & $\mathrm{e}$ \\
\hline 10 & 299-W23-19 & 73.8 & $19 \mathrm{G}$ & - & - & H1a & Hanford & 12.51 & 77.62 & 2.34 & 3.89 & 2.65 & 0.90 & 0.09 & 0.79 & -0.73 & -0.51 & -0.67 & -1.14 & -2.17 & e \\
\hline 11 & 299-W23-19 & 105 & $26 \mathrm{~A}$ & - & - & $\mathrm{H} 2$ & Hanford & 13.14 & 77.62 & 2.00 & 3.79 & 2.66 & 0.70 & 0.09 & 0.77 & -0.82 & -0.54 & -0.69 & -1.27 & -2.18 & e \\
\hline 12 & 299-W7-5 & 10 & - & Med. Sand & crs. Grained & Hanford & Hanford & 14.56 & 65.77 & 9.25 & 6.66 & 1.75 & 1.85 & 0.16 & 0.65 & -0.20 & -0.34 & -0.92 & -0.90 & -1.96 & $\mathrm{c}$ \\
\hline 13 & 299-W7-5 & 10 & - & Med. Sand & crs. Grained & Hanford & Hanford & 15.09 & 64.19 & 9.73 & 6.96 & 2.09 & 1.81 & 0.13 & 0.63 & -0.19 & -0.34 & -0.86 & -0.92 & -2.06 & $\mathrm{c}$ \\
\hline 14 & 299-W15-16 & 110 & - & V. crs. Sand & Lower crs. Grained & Hanford & Hanford & 14.11 & 65.13 & 9.57 & 7.71 & 1.56 & 1.77 & 0.16 & 0.66 & -0.17 & -0.26 & -0.96 & -0.90 & -1.94 & $\mathrm{c}$ \\
\hline 15 & 299-W15-16 & 110 & - & V. crs. Sand & Lower crs. Grained & Hanford & Hanford & 15.17 & 64.25 & 9.62 & 7.41 & 1.80 & 1.62 & 0.13 & 0.63 & -0.20 & -0.31 & -0.93 & -0.97 & -2.07 & $\mathrm{c}$ \\
\hline 16 & 299-W10-13 & 80 & - & & middle & Hanford & Hanford & 14.07 & 70.33 & 6.98 & 5.48 & 1.78 & 1.24 & 0.12 & 0.70 & -0.30 & -0.41 & -0.90 & -1.05 & -2.07 & $\mathrm{c}$ \\
\hline 17 & 299-W10-13 & 45 & - & Med sand & Middle crs. Grained & Hanford & Hanford & 14.63 & 75.26 & 3.64 & 3.49 & 2.34 & 0.57 & 0.07 & 0.71 & -0.60 & -0.62 & -0.80 & -1.41 & -2.32 & $\mathrm{c}$ \\
\hline 18 & 299-W10-13 & 45 & - & Med sand & Middle crs. Grained & Hanford & Hanford & 14.90 & 72.49 & 4.95 & 4.21 & 2.62 & 0.76 & 0.07 & 0.69 & -0.48 & -0.55 & -0.75 & -1.29 & -2.33 & $\mathrm{c}$ \\
\hline 19 & 299-W15-16 & 40 & - & Med sand & Upper & Hanford & Hanford & 14.23 & 67.45 & 8.60 & 6.07 & 1.88 & 1.62 & 0.15 & 0.68 & -0.22 & -0.37 & -0.88 & -0.94 & -1.98 & $\mathrm{c}$ \\
\hline 20 & 299-W15-16 & 40 & - & Med sand & Upper & Hanford & Hanford & 14.77 & 66.49 & 8.83 & 6.20 & 2.00 & 1.59 & 0.12 & 0.65 & -0.22 & -0.38 & -0.87 & -0.97 & -2.09 & $\mathrm{c}$ \\
\hline 21 & 299-W18-21 & 25 & - & Crs. Sand & Upper crs. grained & Hanford & Hanford & 14.92 & 66.78 & 8.53 & 6.05 & 1.91 & 1.67 & 0.15 & 0.65 & -0.24 & -0.39 & -0.89 & -0.95 & -2.00 & $\mathrm{c}$ \\
\hline 22 & 299-W18-21 & 40 & - & Med. Sand & Upper crs. Grained & Hanford & Hanford & 14.29 & 71.69 & 6.42 & 4.34 & 2.11 & 1.04 & 0.11 & 0.70 & -0.35 & -0.52 & -0.83 & -1.14 & -2.11 & $\mathrm{c}$ \\
\hline 23 & 299-W18-21 & 40 & - & Med. Sand & Upper crs. Grained & Hanford & Hanford & 14.73 & 71.30 & 6.34 & 4.31 & 2.23 & 1.01 & 0.08 & 0.68 & -0.37 & -0.53 & -0.82 & -1.16 & -2.27 & $\mathrm{c}$ \\
\hline 24 & 299-W10-13 & 160 & - & & upper & Middle R. & Ringold & 13.22 & 74.24 & 5.32 & 4.34 & 1.92 & 0.87 & 0.09 & 0.75 & -0.40 & -0.48 & -0.84 & -1.18 & -2.17 & $\mathrm{c}$ \\
\hline 25 & 299-W10-13 & 160 & - & & upper & Middle R. & Ringold & 13.96 & 72.58 & 5.67 & 4.88 & 1.97 & 0.86 & 0.07 & 0.72 & -0.39 & -0.46 & -0.85 & -1.21 & -2.30 & $\mathrm{c}$ \\
\hline 26 & 299-W10-13 & 160 & - & silty clayey sand & Upper & Middle R. & Ringold & 13.71 & 76.34 & 3.72 & 3.41 & 2.18 & 0.57 & 0.07 & 0.75 & -0.57 & -0.60 & -0.80 & -1.38 & -2.29 & $\mathrm{c}$ \\
\hline 27 & 299-W10-13 & 160 & - & silty clayey sand & Upper & Middle R. & Ringold & 13.61 & 76.48 & 3.96 & 3.29 & 2.06 & 0.54 & 0.06 & 0.75 & -0.54 & -0.62 & -0.82 & -1.40 & -2.36 & $\mathrm{c}$ \\
\hline 28 & 299-W10-13 & 240 & - & silty sand & middle & Middle R. & Ringold & 10.17 & 82.65 & 2.72 & 2.05 & 1.88 & 0.48 & 0.05 & 0.91 & -0.57 & -0.70 & -0.73 & -1.33 & -2.31 & $\mathrm{c}$ \\
\hline 29 & 299-W10-13 & 240 & - & silty sand & middle & Middle R. & Ringold & 11.13 & 80.04 & 3.85 & 2.35 & 1.97 & 0.61 & 0.05 & 0.86 & -0.46 & -0.68 & -0.75 & -1.26 & -2.35 & $\mathrm{c}$ \\
\hline
\end{tabular}


Table A.3. (contd.)

\begin{tabular}{|c|c|c|c|c|c|c|c|c|c|c|c|c|c|c|c|c|c|c|c|c|c|}
\hline 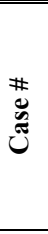 & $\begin{array}{l}\# \\
\bar{\sigma} \\
\bar{z}\end{array}$ & 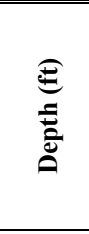 & 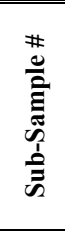 & 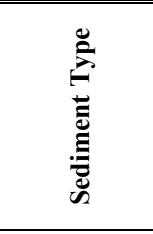 & 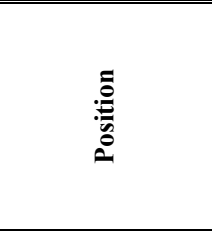 & 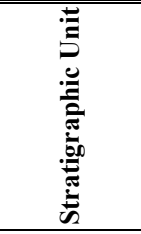 & 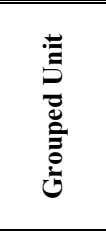 & 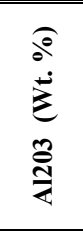 & 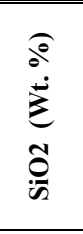 & $\underbrace{e}_{0}$ & 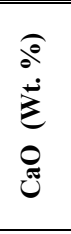 & 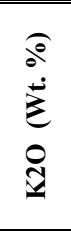 & 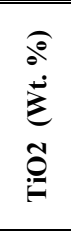 & $\begin{array}{l}\stackrel{e}{e} \\
\dot{z} \\
\dot{z}\end{array}$ & 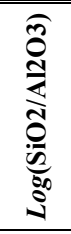 & 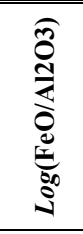 & 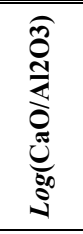 & 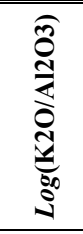 & 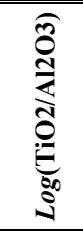 & 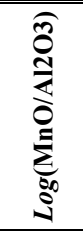 & 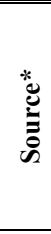 \\
\hline 30 & 299-W10-14 & 440 & - & Med sand & $\begin{array}{l}0 \text { ' above lower } \\
\text { Ringold }\end{array}$ & Middle R. & Ringold & 10.86 & 80.93 & 3.33 & 2.41 & 1.84 & 0.57 & 0.06 & 0.87 & -0.51 & -0.65 & -0.77 & -1.28 & -2.26 & $\mathrm{c}$ \\
\hline 31 & 299-W10-14 & 440 & - & Med sand & $\begin{array}{c}0 \text { ' above lower } \\
\text { Ringold }\end{array}$ & Middle R. & Ringold & 11.09 & 79.81 & 3.98 & 2.65 & 1.80 & 0.62 & 0.05 & 0.86 & -0.45 & -0.62 & -0.79 & -1.25 & -2.35 & $\mathrm{c}$ \\
\hline 32 & 299-W10-14 & $340 \# 1$ & - & Crs. Sand & Middle & Middle R. & Ringold & 11.49 & 79.06 & 3.82 & 3.13 & 1.77 & 0.66 & 0.07 & 0.84 & -0.48 & -0.56 & -0.81 & -1.24 & -2.22 & $\mathrm{c}$ \\
\hline 33 & 299-W10-14 & $340 \# 2$ & - & Crs. Sand & Middle & Middle R. & Ringold & 11.62 & 78.23 & 4.26 & 3.42 & 1.69 & 0.71 & 0.07 & 0.83 & -0.44 & -0.53 & -0.84 & -1.21 & -2.22 & $\mathrm{c}$ \\
\hline 34 & 299-W15-16 & 190 & - & V. crs. sand & Upper & Middle R. & Ringold & 13.54 & 73.73 & 5.49 & 4.55 & 1.77 & 0.82 & 0.10 & 0.74 & -0.39 & -0.47 & -0.88 & -1.22 & -2.13 & $\mathrm{c}$ \\
\hline 35 & 299-W15-16 & 225 & - & Crs. Sand & Upper & Middle R. & Ringold & 10.77 & 80.38 & 3.74 & 2.73 & 1.69 & 0.61 & 0.08 & 0.87 & -0.46 & -0.60 & -0.80 & -1.25 & -2.13 & $\mathrm{c}$ \\
\hline 36 & 299-W15-16 & 225 & - & Crs. Sand & Upper & Middle R. & Ringold & 11.06 & 78.67 & 4.49 & 3.29 & 1.78 & 0.64 & 0.07 & 0.85 & -0.39 & -0.53 & -0.79 & -1.24 & -2.20 & $\mathrm{c}$ \\
\hline 37 & 299-W15-17 & 425 & - & Med sand & $20^{\prime}$ above basalt & Middle R. & Ringold & 10.55 & 80.95 & 3.47 & 2.60 & 1.73 & 0.63 & 0.07 & 0.88 & -0.48 & -0.61 & -0.79 & -1.22 & -2.18 & $\mathrm{c}$ \\
\hline 38 & 299-W15-17 & 425 & - & Med sand & 20 ' above basalt & Middle R. & Ringold & 10.88 & 79.49 & 4.05 & 3.06 & 1.82 & 0.63 & 0.07 & 0.86 & -0.43 & -0.55 & -0.78 & -1.24 & -2.19 & $\mathrm{c}$ \\
\hline 39 & 299-W15-17 & $335 \# 1$ & - & & Middle & Middle R. & Ringold & 10.24 & 81.70 & 3.31 & 2.51 & 1.62 & 0.56 & 0.06 & 0.90 & -0.49 & -0.61 & -0.80 & -1.26 & -2.23 & $\mathrm{c}$ \\
\hline 40 & 299-W15-17 & $335 \# 2$ & - & & Middle & Middle R. & Ringold & 10.83 & 80.48 & 3.58 & 2.81 & 1.62 & 0.62 & 0.06 & 0.87 & -0.48 & -0.59 & -0.83 & -1.24 & -2.26 & $\mathrm{c}$ \\
\hline 41 & 299-W18-21 & 170 & - & Crs. Sand & Upper & Middle R. & Ringold & 14.03 & 69.14 & 8.01 & 5.75 & 1.63 & 1.31 & 0.13 & 0.69 & -0.24 & -0.39 & -0.93 & -1.03 & -2.03 & $\mathrm{c}$ \\
\hline 42 & 299-W18-21 & 210 & - & & Upper & Middle R. & Ringold & 11.39 & 79.86 & 3.59 & 2.68 & 1.82 & 0.60 & 0.06 & 0.85 & -0.50 & -0.63 & -0.80 & -1.28 & -2.28 & $\mathrm{c}$ \\
\hline 43 & 299-W18-21 & 210 & - & & Upper & Middle R. & Ringold & 12.86 & 75.12 & 5.61 & 3.60 & 1.92 & 0.82 & 0.07 & 0.77 & -0.36 & -0.55 & -0.83 & -1.20 & -2.26 & $\mathrm{c}$ \\
\hline 44 & 299-W18-22 & 431 & - & Med. Sand & Middle Ringold & Middle R. & Ringold & 10.35 & 82.07 & 3.10 & 2.17 & 1.75 & 0.51 & 0.05 & 0.90 & -0.52 & -0.68 & -0.77 & -1.31 & -2.32 & $\mathrm{c}$ \\
\hline 45 & 299-W18-22 & 431 & - & Med. Sand & Middle Ringold & Middle R. & Ringold & 10.87 & 79.88 & 4.09 & 2.67 & 1.86 & 0.58 & 0.05 & 0.87 & -0.42 & -0.61 & -0.77 & -1.27 & -2.34 & $\mathrm{c}$ \\
\hline 46 & 299-W18-22 & $320 \# 1$ & - & & Middle & Middle R. & Ringold & 11.20 & 79.88 & 3.75 & 2.92 & 1.56 & 0.62 & 0.07 & 0.85 & -0.48 & -0.58 & -0.86 & -1.26 & -2.20 & $\mathrm{c}$ \\
\hline 47 & 299-W18-22 & $320 \# 2$ & - & & Middle & Middle R. & Ringold & 11.14 & 79.92 & 3.78 & 2.90 & 1.55 & 0.64 & 0.07 & 0.86 & -0.47 & -0.58 & -0.86 & -1.24 & -2.20 & $\mathrm{c}$ \\
\hline 48 & 299-W7-2 & 155 & - & Med. sand & Upper & Middle R. & Ringold & 13.41 & 75.22 & 4.99 & 3.77 & 1.86 & 0.67 & 0.08 & 0.75 & -0.43 & -0.55 & -0.86 & -1.30 & -2.22 & $\mathrm{c}$ \\
\hline 49 & 299-W7-2 & 155 & - & Med. sand & Upper & Middle R. & Ringold & 13.15 & 75.71 & 4.44 & 3.68 & 2.27 & 0.68 & 0.07 & 0.76 & -0.47 & -0.55 & -0.76 & -1.29 & -2.27 & $\mathrm{c}$ \\
\hline 50 & 299-W7-2 & 220 & - & Crs. sand & Middle & Middle R. & Ringold & 10.38 & 81.37 & 3.14 & 2.83 & 1.71 & 0.51 & 0.06 & 0.89 & -0.52 & -0.56 & -0.78 & -1.31 & -2.24 & $\mathrm{c}$ \\
\hline 51 & 299-W7-2 & 220 & - & Crs. sand & Middle & Middle R. & Ringold & 9.92 & 80.89 & 3.63 & 3.13 & 1.87 & 0.51 & 0.05 & 0.91 & -0.44 & -0.50 & -0.72 & -1.29 & -2.30 & $\mathrm{c}$ \\
\hline 52 & 299-W7-3 & 320 & - & Med. Sand & Lower? & Middle R. & Ringold & 12.27 & 77.34 & 4.51 & 3.18 & 1.85 & 0.77 & 0.08 & 0.80 & -0.43 & -0.59 & -0.82 & -1.20 & -2.19 & $\mathrm{c}$ \\
\hline 53 & 299-W22-48 & 164 & - & - & - & Rtf & Ringold & 13.93 & 78.54 & 1.61 & 2.21 & 3.08 & 0.57 & 0.05 & 0.75 & -0.94 & -0.80 & -0.66 & -1.39 & -2.42 & $\mathrm{~b}$ \\
\hline 54 & 299-W22-50 & 161 & - & - & - & Rtf & Ringold & 12.94 & 78.11 & 2.30 & 3.82 & 1.94 & 0.79 & 0.09 & 0.78 & -0.75 & -0.53 & -0.82 & -1.21 & -2.15 & $\mathrm{~b}$ \\
\hline 55 & 299-W23-19 & 205 & $43 B$ & - & - & Rwi(e) & Ringold & 12.83 & 80.24 & 1.47 & 2.39 & 2.52 & 0.47 & 0.07 & 0.80 & -0.94 & -0.73 & -0.71 & -1.44 & -2.28 & $\mathrm{e}$ \\
\hline 56 & 299-W7-2 & 95 & - & Crs. Sand & Middle & Upper R. & Ringold & 12.92 & 76.05 & 4.58 & 3.63 & 2.01 & 0.73 & 0.08 & 0.77 & -0.45 & -0.55 & -0.81 & -1.25 & -2.21 & $\mathrm{c}$ \\
\hline 57 & 299-W7-2 & 95 & - & Crs. Sand & Middle & Upper R. & Ringold & 13.58 & 74.99 & 4.64 & 3.90 & 2.11 & 0.72 & 0.06 & 0.74 & -0.47 & -0.54 & -0.81 & -1.28 & -2.35 & $\mathrm{c}$ \\
\hline
\end{tabular}


Table A.3. (contd.)

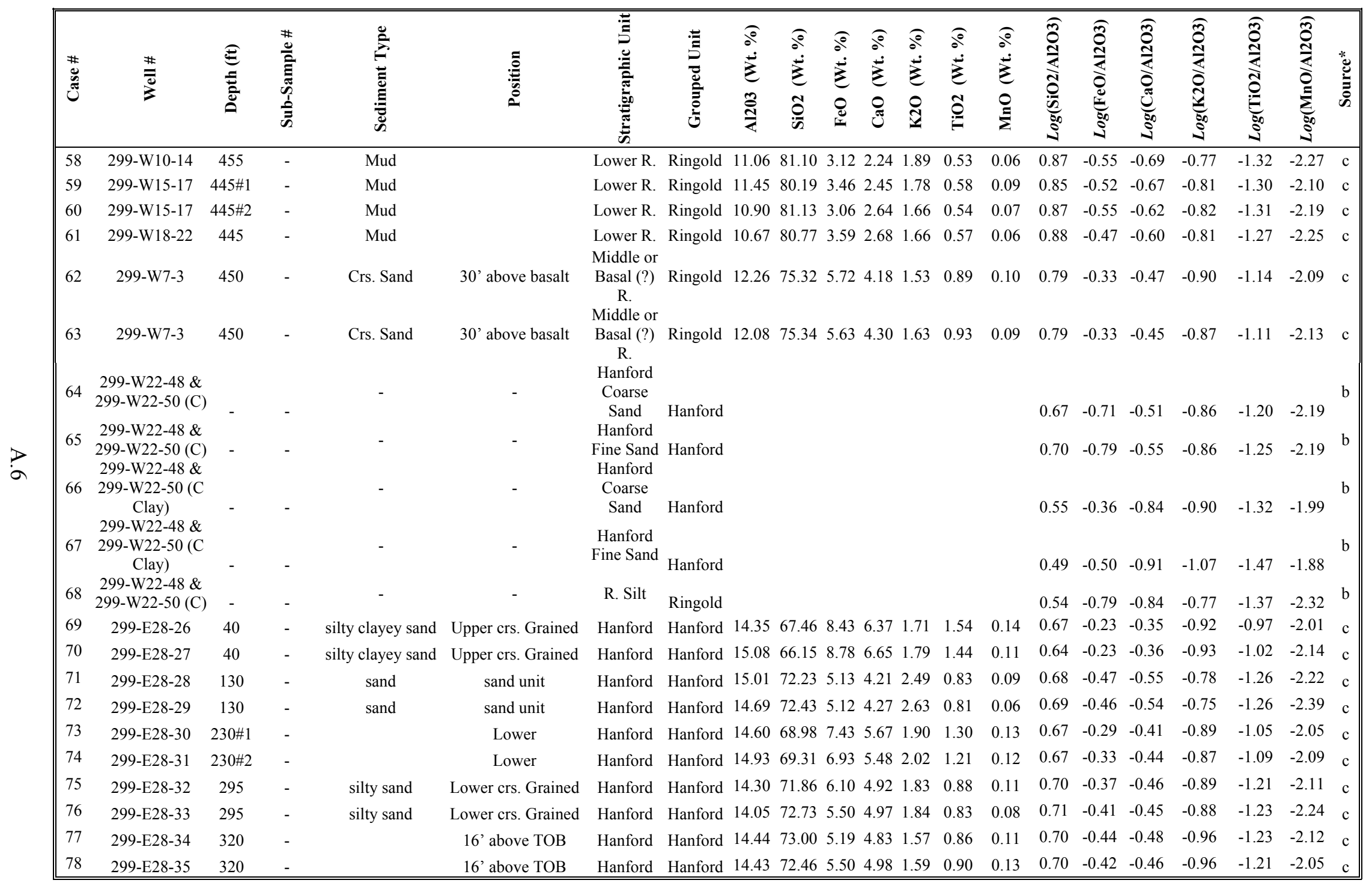


Table A.3. (contd.)

\begin{tabular}{|c|c|c|c|c|c|c|c|c|c|c|c|c|c|c|c|c|c|c|c|c|c|}
\hline 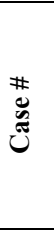 & $\begin{array}{l}\text { \# } \\
\bar{\Xi} \\
\bar{z}\end{array}$ & 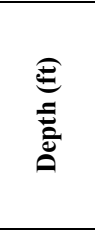 & 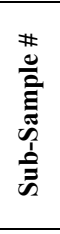 & 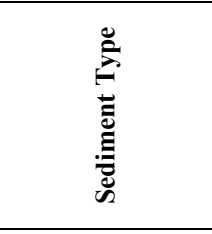 & 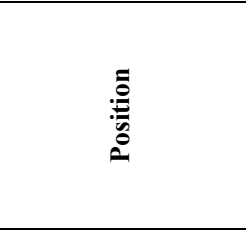 & 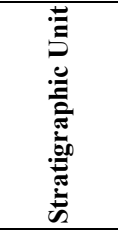 & 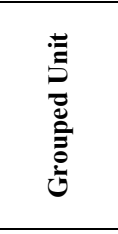 & 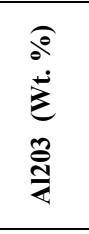 & 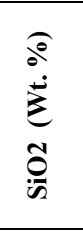 & $\underset{0}{\stackrel{0}{0}}$ & 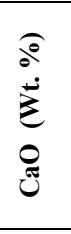 & 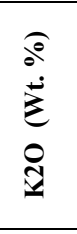 & 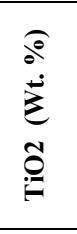 & 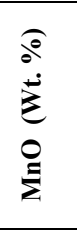 & 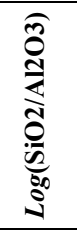 & 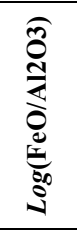 & 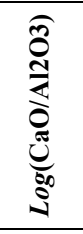 & 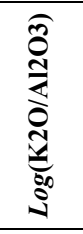 & 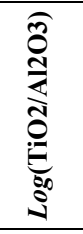 & 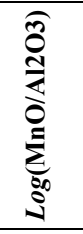 & 苋 \\
\hline 79 & 299-E33-30 & 40 & - & silty sand & Upper crs. Grained & Hanford & Hanford & 14.00 & 73.08 & 5.35 & 4.32 & 2.24 & 0.93 & 0.09 & 0.72 & -0.42 & -0.51 & -0.80 & -1.18 & -2.19 & $\mathrm{c}$ \\
\hline 80 & 299-E33-30 & 40 & - & silty sand & Upper crs. Grained & Hanford & Hanford & 14.75 & 70.47 & 6.34 & 4.89 & 2.40 & 1.06 & 0.08 & 0.68 & -0.37 & -0.48 & -0.79 & -1.14 & -2.27 & $\mathrm{c}$ \\
\hline 81 & 299-E33-30 & 140 & - & & Middle of sand unit & Hanford & Hanford & 14.31 & 74.46 & 4.33 & 3.88 & 2.24 & 0.71 & 0.08 & 0.72 & -0.52 & -0.57 & -0.81 & -1.30 & -2.25 & c \\
\hline 82 & 299-E33-30 & 140 & - & & Middle of sand unit & Hanford & Hanford & 14.36 & 72.91 & 5.21 & 4.27 & 2.38 & 0.80 & 0.07 & 0.71 & -0.44 & -0.53 & -0.78 & -1.25 & -2.31 & $\mathrm{c}$ \\
\hline 83 & 299-E33-30 & 240 & - & & $\sim 40$ above TOB & Hanford & Hanford & 14.72 & 69.88 & 6.77 & 5.22 & 2.05 & 1.24 & 0.11 & 0.68 & -0.34 & -0.45 & -0.86 & -1.07 & -2.13 & $\mathrm{c}$ \\
\hline 84 & 299-E34-2 & 50 & - & silty sand & Upper & Hanford & Hanford & 14.53 & 70.53 & 6.55 & 5.15 & 1.97 & 1.17 & 0.11 & 0.69 & -0.35 & -0.45 & -0.87 & -1.09 & -2.12 & $\mathrm{c}$ \\
\hline 85 & 299-E34-2 & 50 & - & silty sand & Upper & Hanford & Hanford & 14.66 & 68.13 & 7.89 & 5.91 & 2.07 & 1.24 & 0.10 & 0.67 & -0.27 & -0.39 & -0.85 & -1.07 & -2.17 & $\mathrm{c}$ \\
\hline 86 & 299-E34-2 & 150 & - & sand & Middle & Hanford & Hanford & 14.21 & 74.89 & 4.06 & 3.77 & 2.33 & 0.67 & 0.07 & 0.72 & -0.54 & -0.58 & -0.79 & -1.33 & -2.31 & $\mathrm{c}$ \\
\hline 87 & 299-E34-2 & 150 & - & sand & Middle & Hanford & Hanford & 14.18 & 73.83 & 4.57 & 4.29 & 2.41 & 0.66 & 0.07 & 0.72 & -0.49 & -0.52 & -0.77 & -1.33 & -2.31 & c \\
\hline 88 & 299-E34-2 & 230 & - & silty clayey sand & $\sim 10$ ' above basalt & Hanford & Hanford & 13.65 & 71.89 & 6.55 & 4.90 & 1.82 & 1.07 & 0.11 & 0.72 & -0.32 & -0.44 & -0.88 & -1.11 & -2.09 & $\mathrm{c}$ \\
\hline 89 & 299-E34-2 & 230 & - & silty clayey sand & $\sim 10^{\prime}$ above basalt & Hanford & Hanford & 13.81 & 70.75 & 7.25 & 5.00 & 2.02 & 1.07 & 0.09 & 0.71 & -0.28 & -0.44 & -0.83 & -1.11 & -2.19 & c \\
\hline 90 & 299-E34-2 & $215 \# 1$ & - & & & Hanford & Hanford & 14.59 & 72.39 & 5.47 & 4.54 & 2.01 & 0.91 & 0.10 & 0.70 & -0.43 & -0.51 & -0.86 & -1.21 & -2.16 & $\mathrm{c}$ \\
\hline 91 & 299-E34-2 & $215 \# 2$ & - & & & Hanford & Hanford & 14.36 & 73.75 & 4.81 & 4.12 & 2.10 & 0.77 & 0.08 & 0.71 & -0.48 & -0.54 & -0.83 & -1.27 & -2.25 & $\mathrm{c}$ \\
\hline 92 & 299-E34-3 & 50 & - & silty sand & Upper & Hanford & Hanford & 15.18 & 69.64 & 6.67 & 5.36 & 1.88 & 1.15 & 0.11 & 0.66 & -0.36 & -0.45 & -0.91 & -1.12 & -2.14 & $\mathrm{c}$ \\
\hline 93 & 299-E34-3 & 50 & - & silty sand & Upper & Hanford & Hanford & 16.18 & 66.52 & 8.00 & 5.92 & 1.95 & 1.33 & 0.10 & 0.61 & -0.31 & -0.44 & -0.92 & -1.09 & -2.21 & $\mathrm{c}$ \\
\hline 94 & 299-E34-3 & 120 & - & sand & Middle & Hanford & Hanford & 14.59 & 74.46 & 4.06 & 3.72 & 2.43 & 0.67 & 0.07 & 0.71 & -0.56 & -0.59 & -0.78 & -1.34 & -2.32 & $\mathrm{c}$ \\
\hline 95 & 299-E34-3 & 120 & - & sand & Middle & Hanford & Hanford & 14.11 & 73.45 & 4.80 & 4.32 & 2.49 & 0.77 & 0.06 & 0.72 & -0.47 & -0.51 & -0.75 & -1.26 & -2.37 & $\mathrm{c}$ \\
\hline 96 & 299-E34-3 & 165 & - & silty sand & Lower & Hanford & Hanford & 14.20 & 69.63 & 7.34 & 5.45 & 1.97 & 1.29 & 0.12 & 0.69 & -0.29 & -0.42 & -0.86 & -1.04 & -2.07 & $\mathrm{c}$ \\
\hline 97 & 299-E34-3 & 165 & - & silty sand & Lower & Hanford & Hanford & 14.89 & 68.32 & 7.74 & 5.49 & 2.22 & 1.24 & 0.10 & 0.66 & -0.28 & -0.43 & -0.83 & -1.08 & -2.17 & $\mathrm{c}$ \\
\hline 98 & 299-E34-3 & 210 & - & & 5 ' above basalt & Hanford & Hanford & 14.63 & 69.61 & 7.13 & 5.42 & 1.81 & 1.18 & 0.12 & 0.68 & -0.31 & -0.43 & -0.91 & -1.09 & -2.09 & $\mathrm{c}$ \\
\hline 99 & 299-E34-3 & 210 & - & & 5 ' above basalt & Hanford & Hanford & 14.07 & 69.59 & 7.67 & 5.42 & 1.94 & 1.20 & 0.10 & 0.69 & -0.26 & -0.41 & -0.86 & -1.07 & -2.15 & $\mathrm{c}$ \\
\hline \multicolumn{22}{|c|}{$\begin{array}{l}\text { * Note that stratigraphic unit designations are taken from source documents, and may not follow current standardized nomenclature. } \\
\text { ' Serne R, BN Bjornstad, HT Schaef, BA Williams, DC Lanigan, DG Horton, RE Clayton, AV Mitroshkov, VL Legore, MJ O'Hara, CF Brown, KE Parker, IV Kutnyakov, JN Serne, GV Last, SC } \\
\text { Smith, CW Lindenmeier, JM Zachara, and D Burke. 2002. Characterization of Vadose Zone Sediment: Uncontaminated RCRA Borehole Core Samples and Composite Samples. PNNL-13757- } \\
\text { 1, Pacific Northwest National Laboratory, Richland, WA } \\
\text { c Unpublished data, files of B.N. Bjornstad, Pacific Northwest National Laboratory. } \\
\text { 'Serne R, HT Schaef, BN Bjornstad, DC Lanigan, GW Gee, CW Lindenmeier, RE Clayton, VL Legore, RD Orr, MJ O'Hara, CF Brown, GV Last, IV Kutnyakov, D Burke, TC Wilson, and BA } \\
\text { Williams. 2002. Characterization of Vadose Zone Sediment: Borehole 299-W23-19 [SX-115] in the S-SX Waste Management Area. PNNL-13757-2, Pacific Northwest National Laboratory, } \\
\text { Richland, WA. }\end{array}$} \\
\hline
\end{tabular}




\section{Appendix B}

Supporting Data Analysis and Figures 
Table B.1. Statistics of EM Data

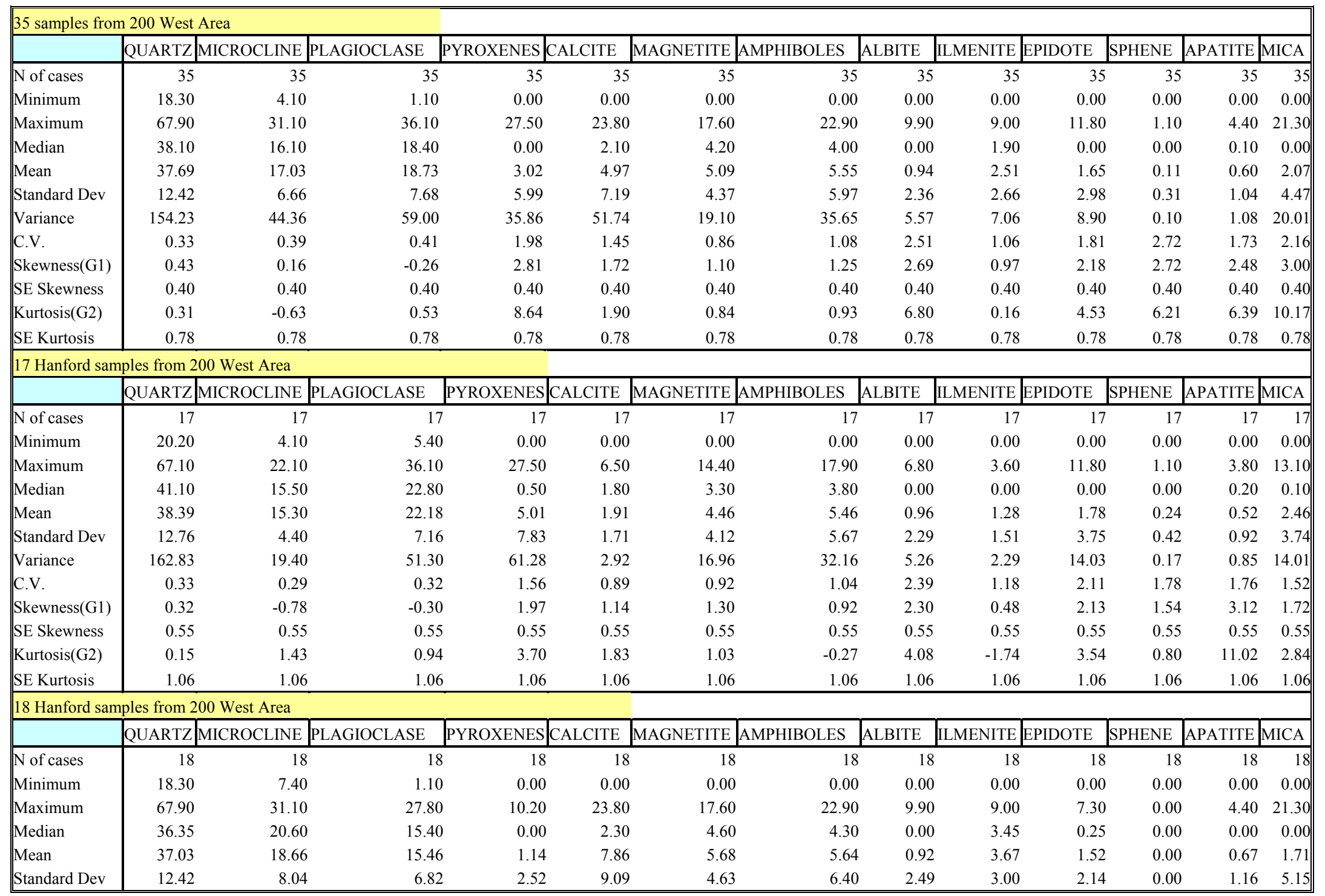


Table B.1. (contd.)

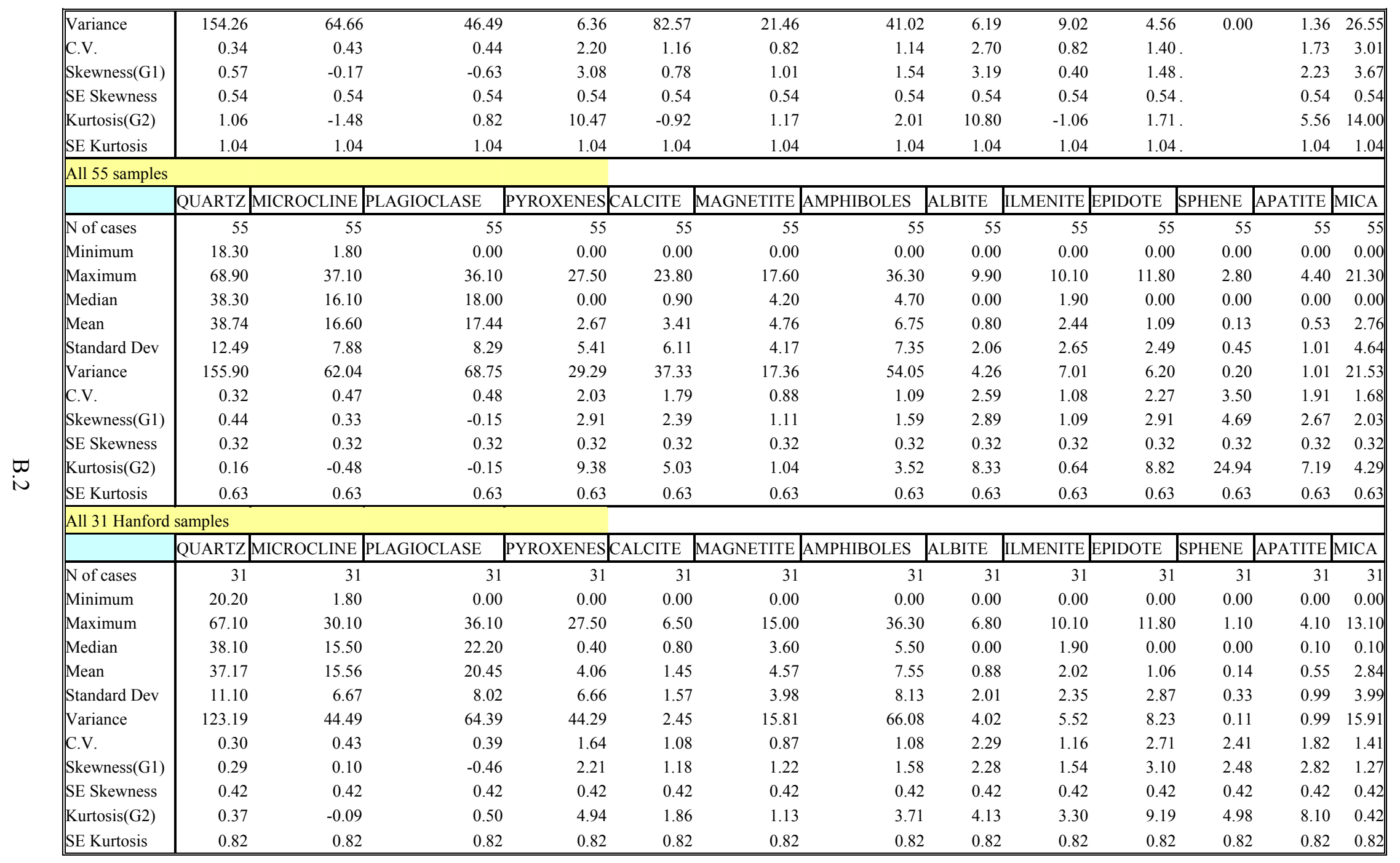


Table B.1. (contd.)

\begin{tabular}{|c|c|c|c|c|c|c|c|c|c|c|c|c|c|}
\hline \\
\hline \multicolumn{14}{|c|}{\begin{tabular}{|l|l|l|l|l}
\multicolumn{1}{|l|}{ All 24 Hanford samples } \\
\end{tabular}} \\
\hline $\mathrm{N}$ of cases & 24 & 24 & 24 & 24 & 24 & 24 & 24 & 24 & 24 & 24 & 24 & 24 & 24 \\
\hline Minimum & 18.30 & 4.30 & 0.00 & 0.00 & 0.00 & 0.00 & 0.00 & 0.00 & 0.00 & 0.00 & 0.00 & 0.00 & 0.00 \\
\hline Median & 39.45 & 18.80 & 13.85 & 0.00 & 1.10 & 4.25 & 4.65 & 0.00 & 1.75 & 0.00 & 0.00 & 0.00 & 0.00 \\
\hline Mean & 40.78 & 17.95 & 13.54 & 0.86 & 5.93 & 5.00 & 5.71 & 0.69 & 2.99 & 1.14 & 0.12 & 0.50 & 2.66 \\
\hline Standard Dev & 14.06 & 9.18 & 7.02 & 2.23 & 8.52 & 4.47 & 6.22 & 2.18 & 2.95 & 1.96 & 0.57 & 1.04 & 5.4 \\
\hline Variance & 197.67 & 84.27 & 49.33 & 4.96 & 72.67 & 20.02 & 38.71 & 4.74 & 8.72 & 3.82 & 0.33 & 1.09 & 29.77 \\
\hline C.V. & 0.34 & 0.51 & 0.52 & 2.59 & 1.44 & 0.89 & 1.09 & 3.15 & 0.99 & 1.71 & 4.90 & 2.07 & 2.05 \\
\hline Skewness(G1) & 0.40 & 0.23 & -0.17 & 3.60 & 1.22 & 1.03 & 1.37 & 3.73 & 0.70 & 1.90 & 4.90 & 2.67 & 2.45 \\
\hline SE Skewness & 0.47 & 0.47 & 0.47 & 0.47 & 0.47 & 0.47 & 0.47 & 0.47 & 0.47 & 0.47 & 0.47 & 0.47 & 0.47 \\
\hline Kurtosis(G2) & -0.19 & -1.07 & -0.08 & 14.27 & 0.04 & 1.28 & 1.40 & 14.91 & -0.69 & 3.24 & 24.00 & 8.02 & 5.90 \\
\hline
\end{tabular}


Table B.2. Statistics of Petro Data

\begin{tabular}{|c|c|c|c|c|c|c|c|c|c|c|c|c|c|c|c|c|c|}
\hline \multicolumn{18}{|c|}{22 samples from 200 West Area } \\
\hline \multicolumn{2}{|l|}{$\mid \begin{array}{l} \\
N \text { of cases }\end{array}$} & qu & $\mathrm{ma}$ & $\mathrm{se}$ & $\mathrm{k}$ & py & ho & bi & $\mathrm{mu}$ & op & gv & ep & $\mathrm{gr}$ & $\mathrm{me}$ & $\mathrm{ca}$ & ot & \\
\hline \multirow{2}{*}{\multicolumn{2}{|c|}{\begin{tabular}{|l} 
N of cases \\
Minimum
\end{tabular}}} & 22.0 & 22.0 & 22.0 & 22.0 & 22.0 & 22.0 & 22.0 & 22.0 & 22.0 & 22.0 & 22.0 & 22.0 & 22.0 & 22.0 & 22.0 & 22.0 \\
\hline & & 11.2 & 1.5 & 3.9 & 0.6 & 0.0 & 0.0 & 0.0 & 0.3 & 0.0 & 0.0 & 0.0 & 0.0 & 2.8 & 0.0 & 0.0 & 2.7 \\
\hline \multicolumn{2}{|l|}{ Maximum } & 52.6 & 27.5 & 65.2 & 23.1 & 7.8 & 4.3 & 1.7 & 6.2 & 1.2 & 2.6 & 0.9 & 0.5 & 20.3 & 5.3 & 2.2 & 15.3 \\
\hline \multicolumn{2}{|l|}{ Median } & 31.4 & 15.0 & 12.0 & 3.2 & 4.1 & 0.9 & 0.6 & 1.4 & 0.3 & 0.8 & 0.0 & 0.0 & 9.7 & 1.4 & 0.3 & 5.6 \\
\hline \multirow{2}{*}{\multicolumn{2}{|c|}{$\begin{array}{l}\text { Mean } \\
\text { Standard Dev }\end{array}$}} & 32.4 & 15.6 & 18.5 & 5.8 & 4.1 & 1.2 & 0.7 & 1.7 & 0.3 & 1.0 & 0.2 & 0.1 & 10.1 & 1.7 & 0.5 & 6.2 \\
\hline & & 11.6 & 6.9 & 14.6 & 5.9 & 1.8 & 1.0 & 0.5 & 1.4 & 0.3 & 0.8 & 0.3 & 0.2 & 4.4 & 1.4 & 0.7 & 2.7 \\
\hline \multicolumn{2}{|l|}{ Variance } & 134.8 & 48.0 & 214.1 & 35.3 & 3.2 & 1.0 & 0.2 & 2.1 & 0.1 & 0.6 & 0.1 & 0.0 & 19.6 & 1.9 & 0.5 & 7.3 \\
\hline \multicolumn{2}{|l|}{ C.V. } & 0.4 & 0.4 & 0.8 & 1.0 & 0.4 & 0.8 & 0.7 & 0.8 & 1.1 & 0.8 & 1.4 & 1.6 & 0.4 & 0.8 & 1.5 & 0.4 \\
\hline \multicolumn{2}{|l|}{ Skewness(G1) } & 0.1 & -0.2 & 1.8 & 1.5 & -0.2 & 1.5 & 0.4 & 1.8 & 1.1 & 0.6 & 1.3 & 1.3 & 0.6 & 1.1 & 1.6 & 1.9 \\
\hline \multirow{3}{*}{\multicolumn{2}{|c|}{$\begin{array}{l}\text { SE Skewness } \\
\text { Kurtosis(G2) } \\
\text { SE Kurtosis }\end{array}$}} & 0.5 & 0.5 & 0.5 & 0.5 & 0.5 & 0.5 & 0.5 & 0.5 & 0.5 & 0.5 & 0.5 & 0.5 & 0.5 & 0.5 & 0.5 & 0.5 \\
\hline & & -0.8 & -0.7 & 3.7 & 2.1 & 0.8 & 2.5 & -0.7 & 3.7 & 0.6 & -0.6 & 0.6 & 0.4 & 0.4 & 1.2 & 1.5 & 5.3 \\
\hline & & 1.0 & 1.0 & 1.0 & 1.0 & 1.0 & 1.0 & 1.0 & 1.0 & 1.0 & 1.0 & 1.0 & 1.0 & 1.0 & 1.0 & 1.0 & 1.0 \\
\hline \multicolumn{18}{|c|}{ 6 Hanford samples from 200 West Area } \\
\hline & qu & $\mathrm{ma}$ & $\mathrm{se}$ & $\overline{\mathrm{k}}$ & py & ho & bi & $\mathrm{mu}$ & op & gv & ep & gr & $\mathrm{me}$ & $\mathrm{ca}$ & ot & \\
\hline \multicolumn{2}{|l|}{$\mid N$ of cases } & 6.0 & 6.0 & 6.0 & 6.0 & 6.0 & 6.0 & 6.0 & 6.0 & 6.0 & 6.0 & 6.0 & 6.0 & 6.0 & 6.0 & 6.0 & 6.0 \\
\hline \multicolumn{2}{|l|}{ Minimum } & 11.2 & 1.5 & 6.9 & 1.4 & 0.0 & 0.5 & 0.0 & 0.7 & 0.0 & 0.0 & 0.0 & 0.0 & 2.8 & 0.0 & 0.0 & 5.9 \\
\hline \multicolumn{2}{|l|}{ Maximum } & 27.1 & 27.5 & 65.2 & 3.4 & 5.5 & 2.6 & 1.7 & 6.2 & 1.2 & 2.6 & 0.9 & 0.2 & 11.9 & 1.4 & 2.2 & 9.0 \\
\hline \multicolumn{2}{|l|}{ Median } & 21.8 & 21.2 & 31.0 & 1.6 & 4.6 & 2.3 & 1.2 & 2.7 & 0.3 & 1.8 & 0.0 & 0.0 & 6.5 & 0.9 & 0.7 & 7.5 \\
\hline \multicolumn{2}{|l|}{ Mean } & 20.7 & 19.3 & 29.9 & 1.9 & 3.9 & 2.0 & 1.1 & 3.1 & 0.4 & 1.6 & 0.2 & 0.0 & 6.8 & 0.8 & 0.9 & 7.4 \\
\hline Standard Dev & & 6.3 & 9.2 & 20.7 & 0.8 & 2.1 & 0.8 & 0.6 & 2.0 & 0.5 & 0.9 & 0.4 & 0.1 & 3.6 & 0.6 & 0.9 & 1.5 \\
\hline Variance & & 40.0 & 84.4 & 428.5 & 0.6 & 4.2 & 0.7 & 0.3 & 4.1 & 0.2 & 0.9 & 0.1 & 0.0 & 12.6 & 0.3 & 0.8 & 2.2 \\
\hline Skewness(G1) & & -0.6 & -1.9 & 0.9 & 1.6 & -1.8 & -1.2 & -1.7 & 0.6 & 1.0 & -1.0 & 2.0 & 2.4 & 0.4 & -0.4 & 0.6 & 0.0 \\
\hline SE Skewness & & 0.8 & 0.8 & 0.8 & 0.8 & 0.8 & 0.8 & 0.8 & 0.8 & 0.8 & 0.8 & 0.8 & 0.8 & 0.8 & 0.8 & 0.8 & 0.8 \\
\hline Kurtosis(G2) & & -1.1 & 4.1 & 1.2 & 2.0 & 3.5 & 0.5 & 3.4 & -0.7 & -0.3 & 0.6 & 4.0 & 6.0 & -1.3 & -1.4 & -1.3 & -3.1 \\
\hline SE Kurtosis & & 1.7 & 1.7 & 1.7 & 1.7 & 1.7 & 1.7 & 1.7 & 1.7 & 1.7 & 1.7 & 1.7 & 1.7 & 1.7 & 1.7 & 1.7 & 1.7 \\
\hline 16 Ringold samp & les from 2 & 00 West Are & & & & & & & & & & & & & & & \\
\hline & & qu $\mathrm{f}$ & $\mathrm{ma}$ & $\mathrm{se}$ & $\mathrm{k}$ & py & ho & $\mathrm{bi}$ & $\mathrm{mu}$ & op & gv & ep & gr & $\mathrm{me}$ & $\mathrm{ca}$ & ot & \\
\hline$\widehat{N}$ of cases & & 16.0 & 16.0 & 16.0 & 16.0 & 16.0 & 16.0 & 16.0 & 16.0 & 16.0 & 16.0 & 16.0 & 16.0 & 16.0 & 16.0 & 16.0 & 16.0 \\
\hline Minimum & & 18.5 & 4.8 & 3.9 & 0.6 & 1.3 & 0.0 & 0.0 & 0.3 & 0.0 & 0.0 & 0.0 & 0.0 & 6.0 & 0.0 & 0.0 & 2.7 \\
\hline Maximum & & 52.6 & 24.6 & 39.2 & 23.1 & 7.8 & 4.3 & 1.1 & 2.7 & 0.9 & 2.2 & 0.9 & 0.5 & 20.3 & 5.3 & 1.9 & 15.3 \\
\hline Median & & 36.0 & 13.6 & 10.6 & 4.3 & 4.0 & 0.8 & 0.5 & 1.1 & 0.3 & 0.7 & 0.1 & 0.0 & 10.8 & 1.8 & 0.0 & 4.8 \\
\hline Mean & & 36.8 & 14.2 & 14.2 & 7.2 & 4.1 & 0.9 & 0.5 & 1.2 & 0.3 & 0.8 & 0.2 & 0.1 & 11.4 & 2.0 & 0.3 & 5.7 \\
\hline Standard Dev & & 10.0 & 5.6 & 9.2 & 6.4 & 1.8 & 1.0 & 0.3 & 0.7 & 0.3 & 0.6 & 0.3 & 0.2 & 4.1 & 1.4 & 0.5 & 2.9 \\
\hline Variance & & 99.2 & 31.6 & 85.4 & 41.1 & 3.1 & 0.9 & 0.1 & 0.5 & 0.1 & 0.4 & 0.1 & 0.0 & 17.1 & 2.1 & 0.3 & 8.6 \\
\hline C.V. & & 0.3 & 0.4 & 0.7 & 0.9 & 0.4 & 1.0 & 0.7 & 0.6 & 1.0 & 0.8 & 1.3 & 1.4 & 0.4 & 0.7 & 1.9 & 0.5 \\
\hline Skewness(G1) & & 0.0 & 0.3 & 1.5 & 1.1 & 0.5 & 3.0 & 0.1 & 0.6 & 0.9 & 1.1 & 1.1 & 1.0 & 0.8 & 0.7 & 2.5 & 2.5 \\
\hline SE Skewness & & 0.6 & 0.6 & 0.6 & 0.6 & 0.6 & 0.6 & 0.6 & 0.6 & 0.6 & 0.6 & 0.6 & 0.6 & 0.6 & 0.6 & 0.6 & 0.6 \\
\hline Kurtosis(G2) & & -0.7 & -0.6 & 2.4 & 0.9 & 0.6 & 10.9 & -1.1 & -0.8 & -0.1 & 1.3 & 0.3 & -0.3 & 0.2 & 0.5 & 6.3 & 7.8 \\
\hline SE Kurtosis & & 1.1 & 1.1 & 1.1 & 1.1 & 1.1 & 1.1 & 1.1 & 1.1 & 1.1 & 1.1 & 1.1 & 1.1 & 1.1 & 1.1 & 1.1 & 1.1 \\
\hline abbreviation & $\mathrm{qu}$ & & $\mathrm{fe}$ & $\mathrm{ma}$ & & $\mathrm{se}$ & & $\mathrm{k}$ & py & py & & ho & & bi & & & \\
\hline Full name & quartz & & plagfeldspar & MA & FIC & SEDAGGr & egate & $\mathrm{k}$ feldspa & & pyroxene & & HORNBL & ENDE & BIOTITE & & & \\
\hline abbreviation & $\mathrm{mu}$ & & op & gv & & ep & & $\mathrm{gr}$ & $\mathrm{m}$ & ne & & $\mathrm{ca}$ & & ot & & & \\
\hline Full name & MUSCO & VITE & OPAQUES & GA & RNET & EPIDOTE & & GRANITI & & METAMORP & PHIC & CARBON & VATE & OTHER & & & \\
\hline
\end{tabular}


Table B.3. Statistics of XRF Data

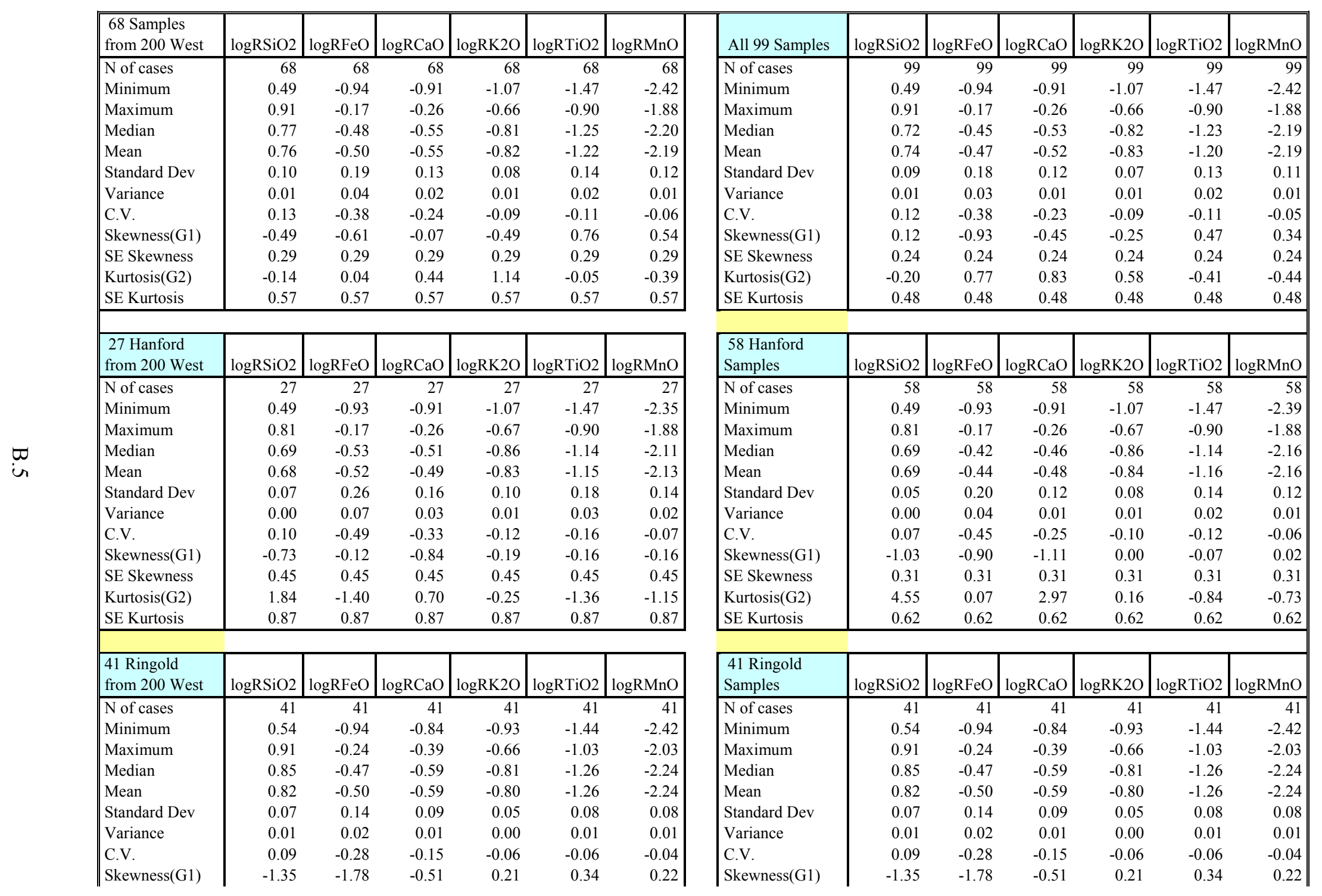


Table B.3. (contd.)

\begin{tabular}{|c|c|c|c|c|c|c|c|c|c|c|c|c|c|}
\hline $\begin{array}{l}41 \text { Ringold } \\
\text { from } 200 \text { West }\end{array}$ & $\log \mathrm{RSiO} 2$ & $|\log \mathrm{RFeO}|$ & $|\log \mathrm{RCaO}|$ & $\log \mathrm{RK} 2 \mathrm{O}$ & $\log \mathrm{RTiO} 2$ & $\log \mathrm{RMnO}$ & \begin{tabular}{|l}
41 Ringold \\
Samples \\
\end{tabular} & $\operatorname{logRSiO} 2$ & $\log \mathrm{RFeO}$ & $\log \mathrm{RCaO}$ & | $\log \mathrm{RK} 2 \mathrm{O}$ & $|\log \mathrm{RTiO} 2|$ & $\log \mathrm{RMnO}$ \\
\hline SE Skewness & 0.37 & 0.37 & 0.37 & 0.37 & 0.37 & 0.37 & SE Skewness & 0.37 & 0.37 & 0.37 & 0.37 & $0.37^{\circ}$ & 0.37 \\
\hline Kurtosis(G2) & 3.11 & 4.09 & 0.94 & 1.02 & 1.69 & -0.10 & Kurtosis(G2) & 3.11 & 4.09 & 0.94 & 1.02 & 1.69 & -0.10 \\
\hline SE Kurtosis & 0.72 & 0.72 & 0.72 & 0.72 & 0.72 & 0.72 & SE Kurtosis & 0.72 & 0.72 & 0.72 & 0.72 & 0.72 & 0.72 \\
\hline
\end{tabular}


Table B.4. Correlation Between XRF Variables (99 samples)

\begin{tabular}{|c|c|c|c|c|c|c|}
\hline 99 samples & (Log(SiO2/A12O3) & "Log(FeO/A12O3) & Log(CaO/Al2O3) & Log(K2O/A12O3) & "Log(TiO2/A12O3) & $\mathrm{L} \log (\mathrm{MnO} / \mathrm{Al} 2 \mathrm{O} 3)$ \\
\hline $\mathrm{Log}(\mathrm{SiO} 2 / \mathrm{A} 12 \mathrm{O} 3)$ & 1 & & & & & \\
\hline $\mathrm{Log}(\mathrm{FeO} / \mathrm{Al} 2 \mathrm{O} 3)$ & -0.24 & 1.00 & & & & \\
\hline $\mathrm{Log}(\mathrm{CaO} / \mathrm{Al} 2 \mathrm{O} 3)$ & -0.29 & 0.57 & 1.00 & & & \\
\hline $\mathrm{Log}(\mathrm{K} 2 \mathrm{O} / \mathrm{A} 12 \mathrm{O} 3)$ & 0.53 & -0.64 & -0.43 & 1.00 & & \\
\hline $\mathrm{Log}(\mathrm{TiO} 2 / \mathrm{Al} 2 \mathrm{O} 3)$ & -0.36 & 0.69 & 0.88 & -0.52 & 1.00 & \\
\hline $\log (\mathrm{MnO} / \mathrm{Al} 2 \mathrm{O} 3)$ & -0.42 & 0.51 & 0.52 & -0.74 & 0.70 & 1.00 \\
\hline $\mathrm{Log}(\mathrm{FeO} / \mathrm{A} 12 \mathrm{O} 3)$ & -0.45 & 1.00 & & & & \\
\hline $\mathrm{Log}(\mathrm{CaO} / \mathrm{Al} 2 \mathrm{O} 3)$ & -0.56 & 0.67 & 1.00 & & & \\
\hline $\mathrm{Log}(\mathrm{K} 2 \mathrm{O} / \mathrm{A} 12 \mathrm{O} 3)$ & 0.57 & -0.67 & -0.61 & 1.00 & & \\
\hline $\mathrm{Log}(\mathrm{TiO} 2 / \mathrm{Al} 2 \mathrm{O} 3)$ & -0.47 & 0.74 & 0.90 & -0.64 & 1.00 & \\
\hline $\log (\mathrm{MnO} / \mathrm{Al} 2 \mathrm{O} 3)$ & -0.44 & 0.55 & 0.66 & -0.75 & 0.73 & 1.00 \\
\hline
\end{tabular}

Table B.5. Correlation Between XRF Variables (68 samples)

\begin{tabular}{|c|c|c|c|c|c|c|}
\hline 68 samples & اLLog(SiO2/Al2O3) & Log(FeO/Al2O3) & $\mathrm{Log}(\mathrm{CaO} / \mathrm{Al} 2 \mathrm{O} 3)$ & "Log(K2O/A12O3) & "Log(TiO2/A12O3) & "Log(MnO/Al2O3) \\
\hline $\mathrm{Log}(\mathrm{SiO} 2 / \mathrm{A} 12 \mathrm{O} 3)$ & 1 & & & & & \\
\hline $\mathrm{Log}(\mathrm{FeO} / \mathrm{Al} 2 \mathrm{O} 3)$ & -0.09 & 1.00 & & & & \\
\hline $\mathrm{Log}(\mathrm{CaO} / \mathrm{Al} 2 \mathrm{O} 3)$ & -0.18 & 0.48 & 1.00 & & & \\
\hline $\mathrm{Log}(\mathrm{K} 2 \mathrm{O} / \mathrm{A} 12 \mathrm{O} 3)$ & 0.52 & -0.64 & -0.36 & 1.00 & & \\
\hline $\mathrm{Log}(\mathrm{TiO} 2 / \mathrm{A} 12 \mathrm{O} 3)$ & -0.29 & 0.63 & 0.88 & -0.49 & 1.00 & \\
\hline $\log (\mathrm{MnO} / \mathrm{Al} 2 \mathrm{O} 3)$ & -0.47 & 0.51 & 0.51 & -0.72 & 0.69 & 1.00 \\
\hline $\mathrm{Log}(\mathrm{SiO} 2 / \mathrm{A} 12 \mathrm{O} 3)$ & 1.00 & & & & & \\
\hline $\mathrm{Log}(\mathrm{FeO} / \mathrm{Al} 2 \mathrm{O} 3)$ & -0.18 & 1.00 & & & & \\
\hline $\mathrm{Log}(\mathrm{CaO} / \mathrm{Al} 2 \mathrm{O} 3)$ & -0.40 & 0.50 & 1.00 & & & \\
\hline $\mathrm{Log}(\mathrm{K} 2 \mathrm{O} / \mathrm{A} 12 \mathrm{O} 3)$ & 0.50 & -0.63 & -0.51 & 1.00 & & \\
\hline $\mathrm{Log}(\mathrm{TiO} 2 / \mathrm{Al} 2 \mathrm{O} 3)$ & -0.29 & 0.62 & 0.87 & -0.58 & 1.00 & \\
\hline $\log (\mathrm{MnO} / \mathrm{Al} 2 \mathrm{O} 3)$ & -0.38 & 0.45 & 0.61 & -0.69 & 0.69 & 1.00 \\
\hline
\end{tabular}



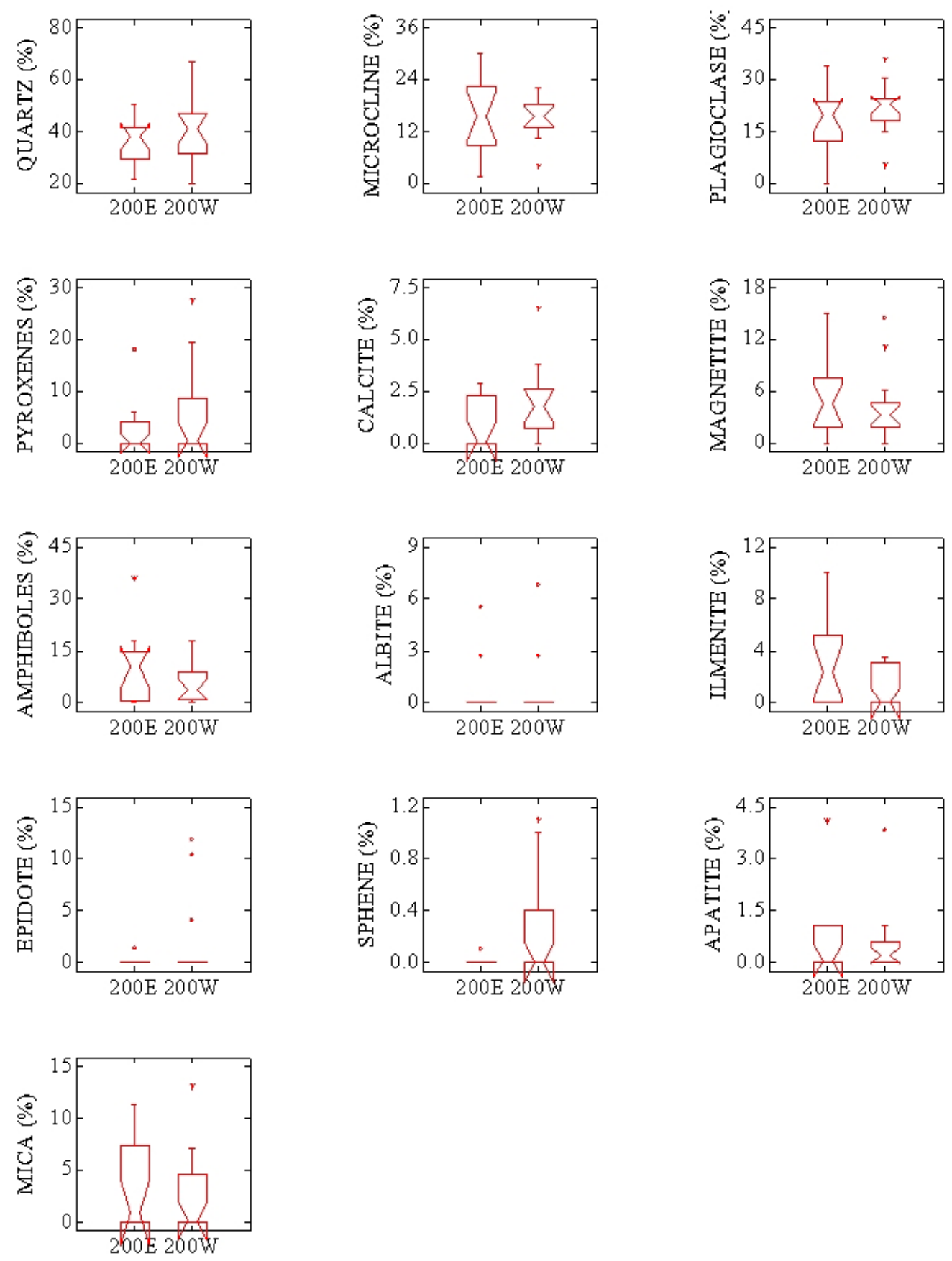

Figure B.1a. Box Plots of EM Variables of Hanford Samples in Terms of 200 West and 200 East Area 

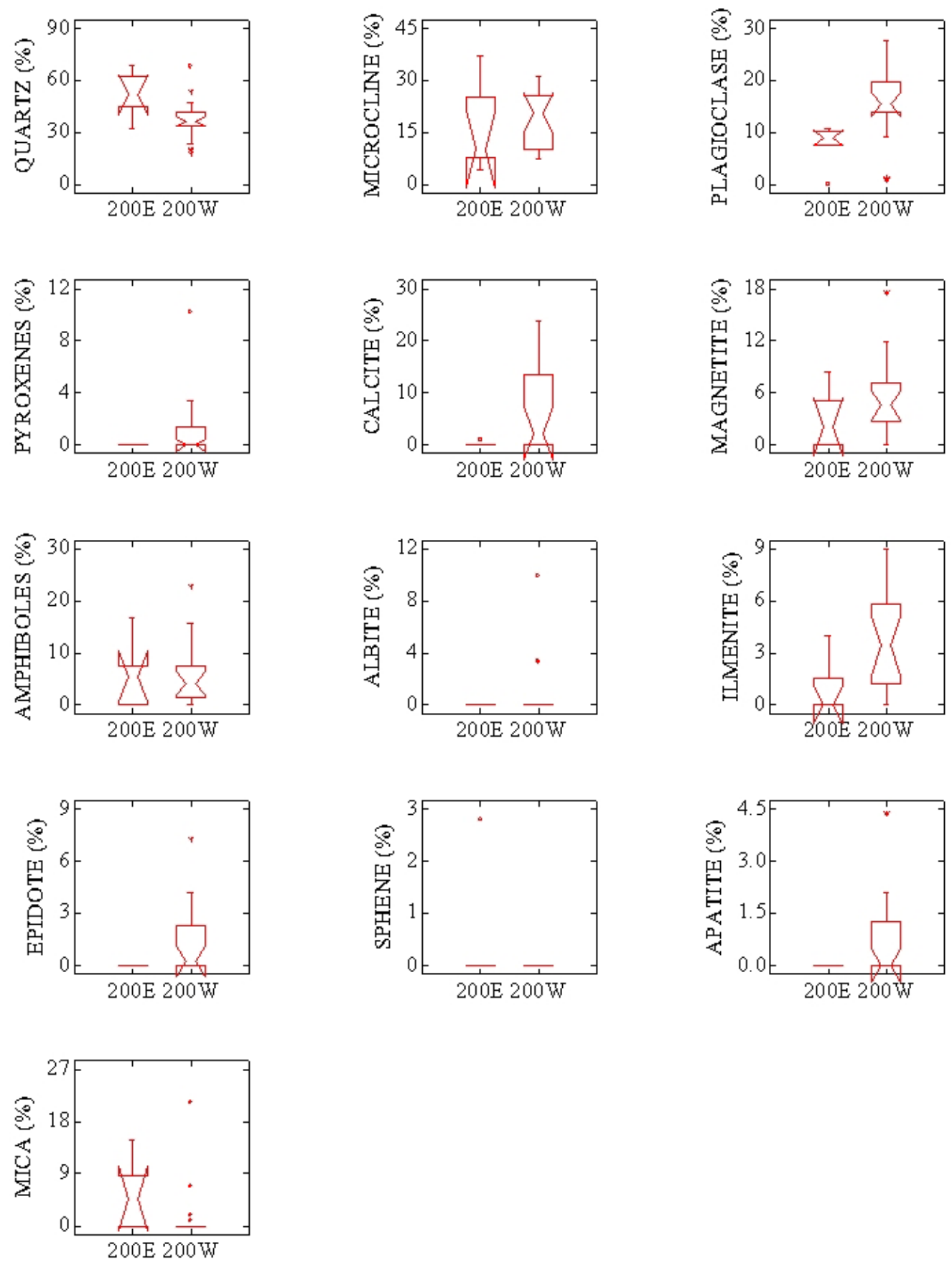

Figure B.1b. Box Plots of EM Variables of Ringold Samples in Terms of 200 West and 200 East Area 

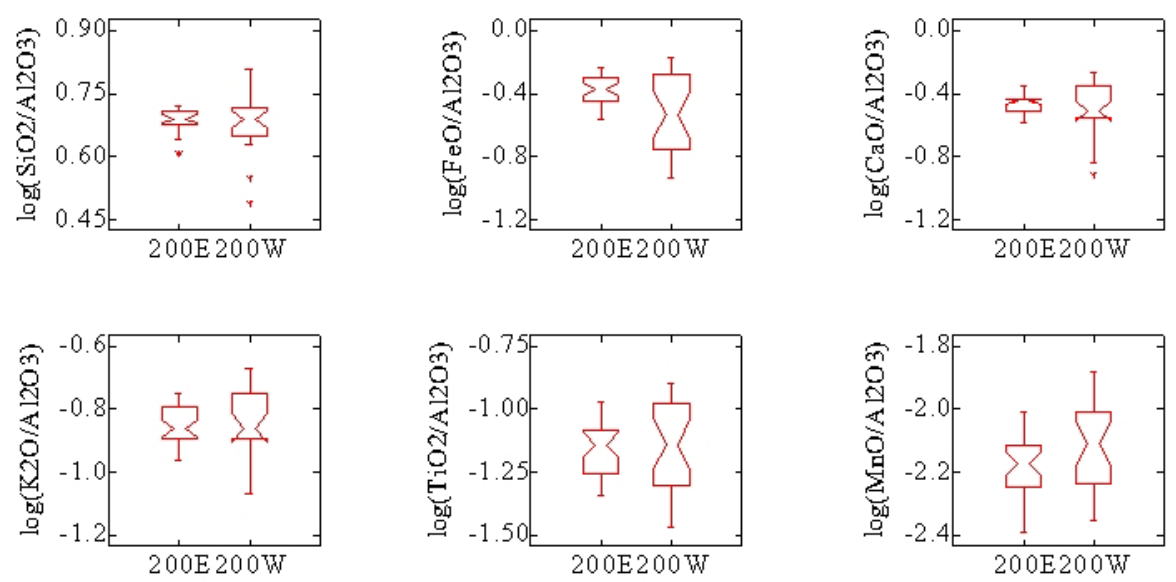

Figure B.2. Box Plots of XRF Variables of Hanford Samples From the 200 West and 200 East Areas
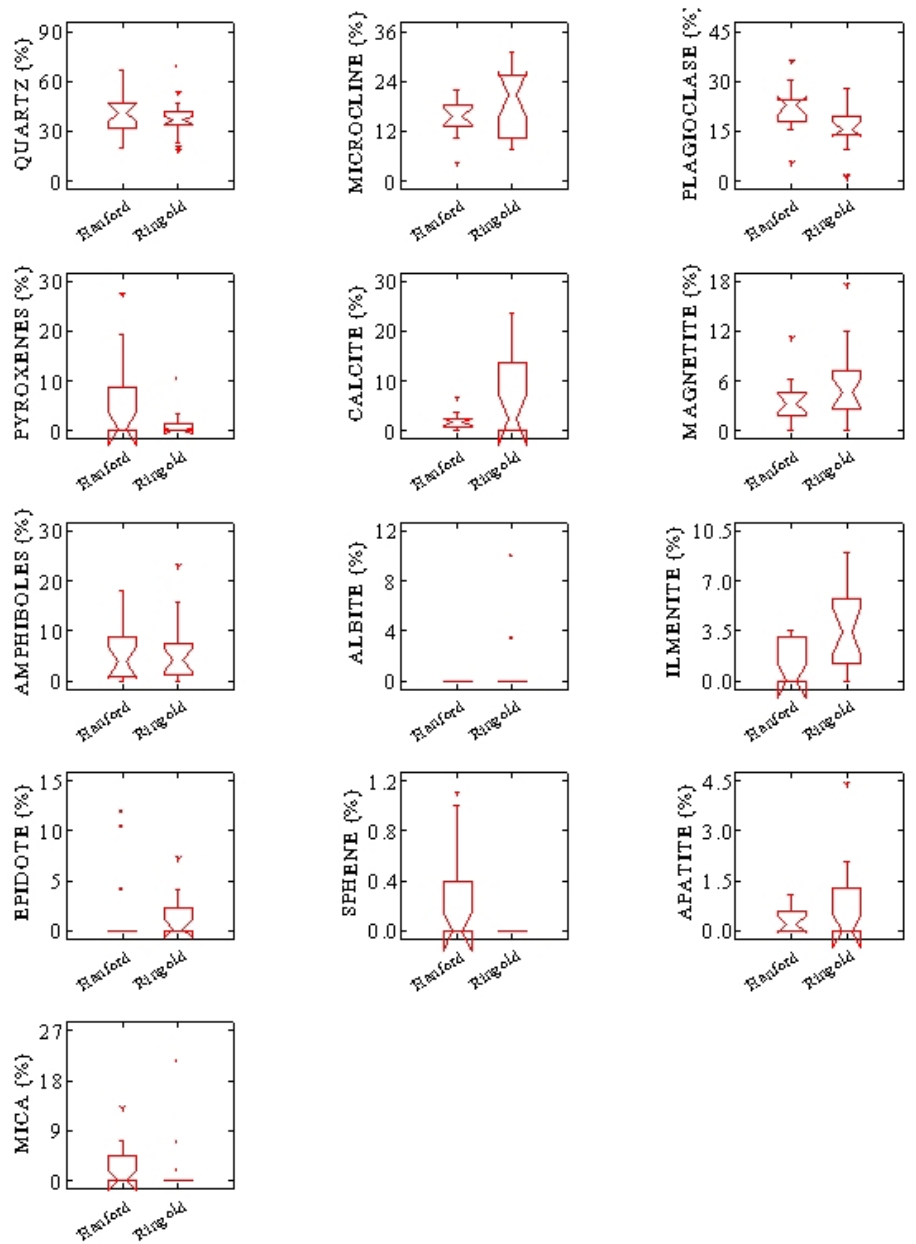

Figure B.3.a. Box Plots of EM Variables of 35 Samples From 200 West in Terms of Hanford and Ringold Formation 

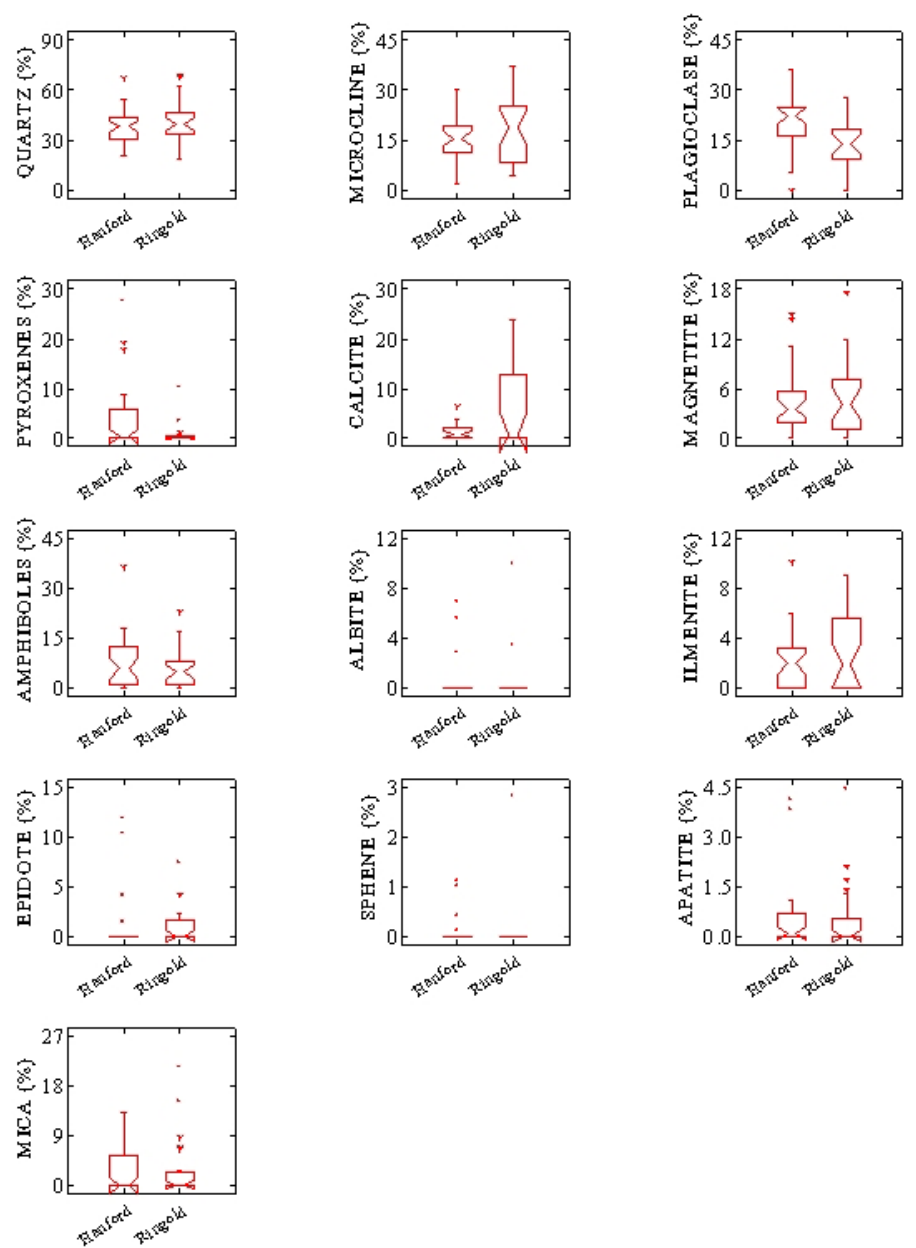

Figure B.3.b. Box Plots of EM Variables of all 55 Samples From Both 200 West and 200 East in Terms of Hanford and Ringold Formation 

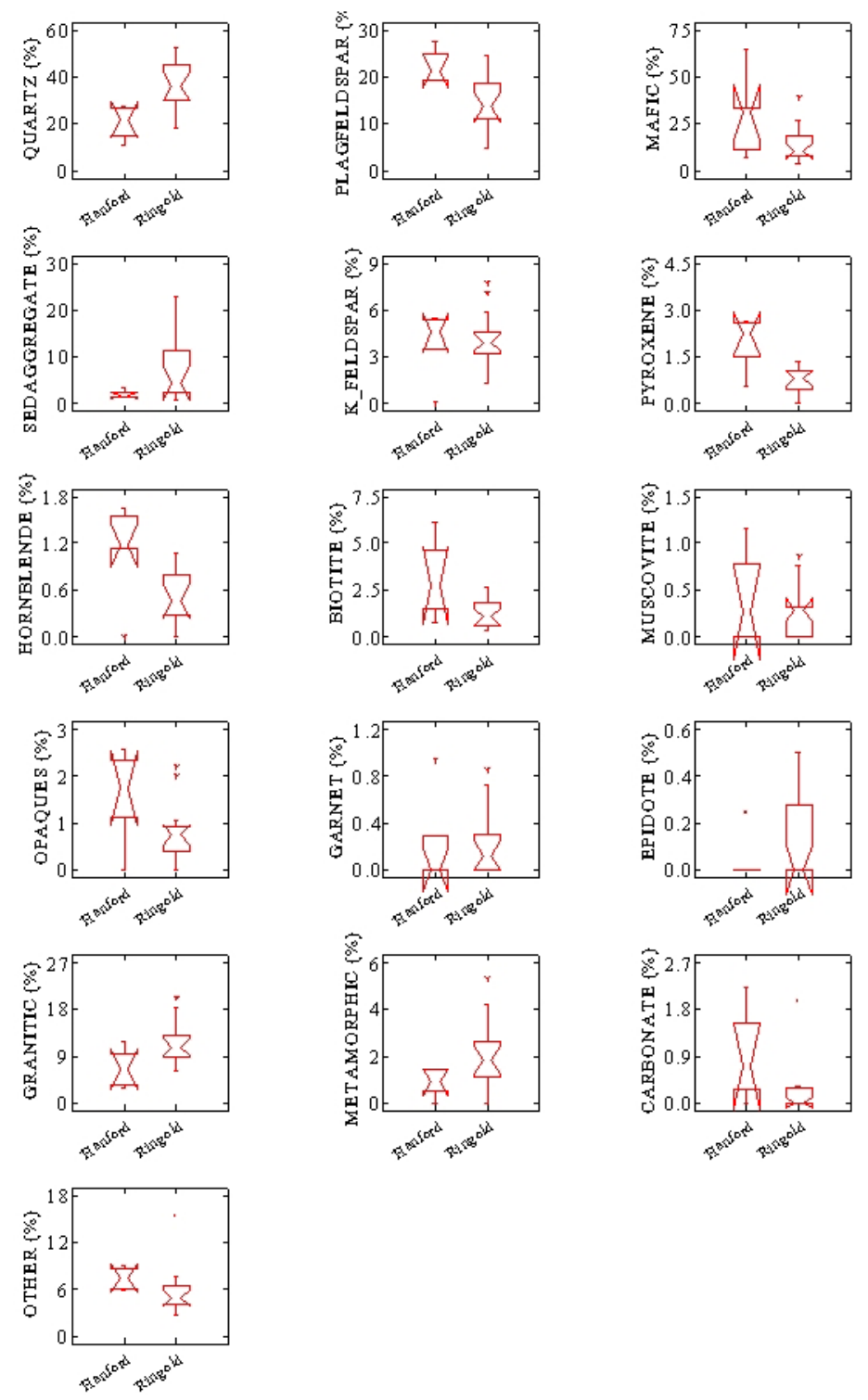

Figure B.4. Box Plots of Petro Variables of 22 Samples From 200 West in Terms of Hanford and Ringold Formation 

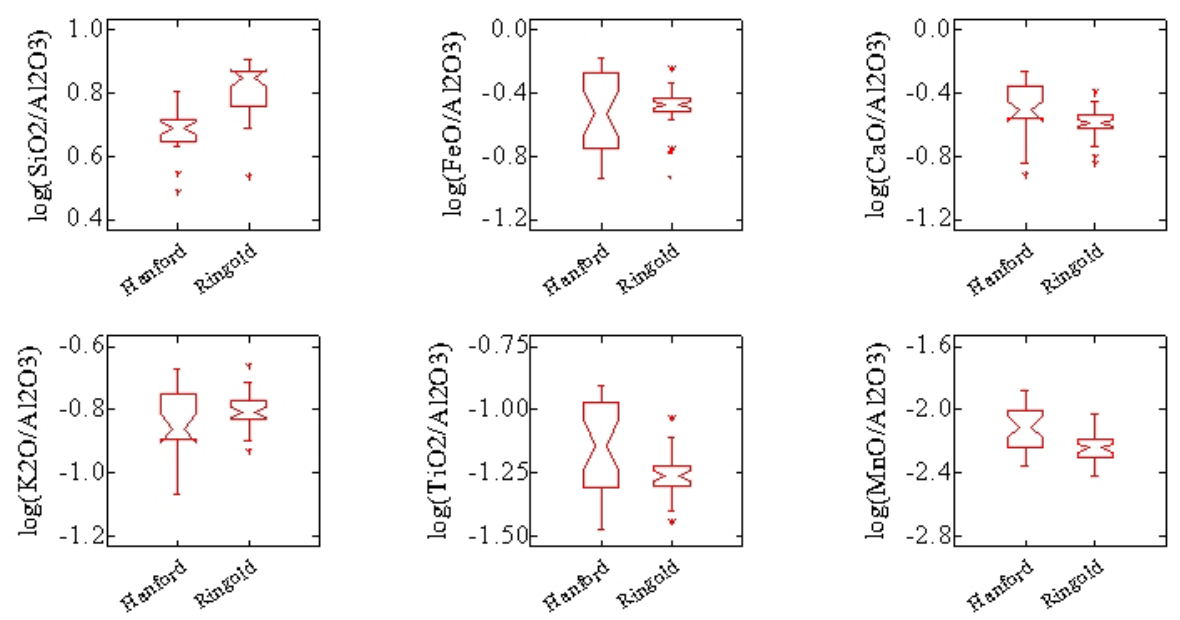

Figure B.5a. Box Plots of XRF Variables of 68 Samples From 200 West in Terms of Hanford and Ringold Formation. Left: and right: all 99 samples from both 200 West and 200 East.
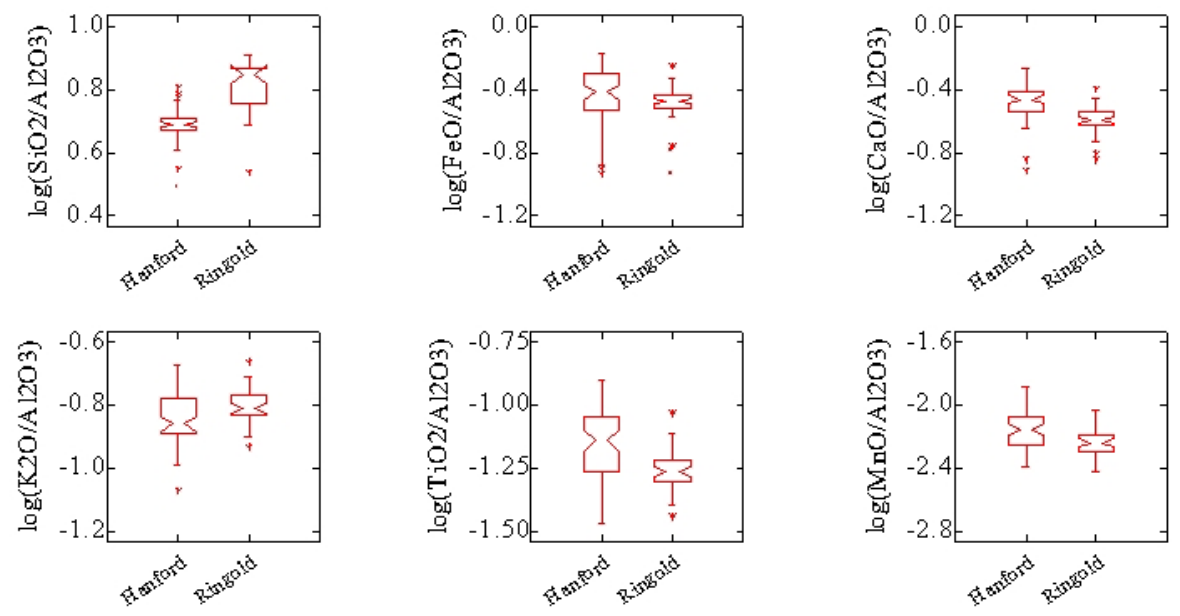

Figure B.5b. Box Plots of XRF Variables of All 99 Samples From Both 200 West and 200 East in Terms of Hanford and Ringold Formation 


\section{Distribution}

No. of

Copies

OFFSITE

R. D. Mackley

121 West 900 North \#2

Logan, UT 84341

\section{ONSITE}

\section{DOE, Richland Operations Office}

D. Hildebrand

J. Morse

K. M. Thompson

Bechtel Hanford, Inc.

K. R. Fecht

7 Fluor Hanford, Inc.

J. V. Borghese

C. W. Connell

F. M. Coony

T. Fogwell

B. H. Ford

L. C. Swanson

R. T. Wilde

4 CH2M Hill Group
H0-02

E6-35

A6-38

A6-38

A6-38

A0-21

E6-35

E6-35

E6-35

E6-35

E6-35
R. W. Bryce

K. Cantrell

W. J. Deutsch

M. Fayer

E. J. Freeman

M. Freshley

G. W. Gee

T. J Gilmore

D. G. Horton

C. T. Kincaid

G. V. Last (5)

C. W. Lindenmeier

W. J. Martin

C. J. Murray (5)

W. Nichols

T. L. Page

S. P. Reidel

H. T. Schaef

T. D. Scheibe

R. J. Serne

B. A. Williams

Y. Xie (5)

J. M. Zachara

Hanford Technical Library (2)

Information Release Office (7)
E6-35

K6-81

K6-81

K9-33

K9-36

K9-33

K9-33

K6-81

K6-81

K9-33

K6-81

P7-25

K6-81

K6-81

K9-33

K9-02

K6-81

K6-81

K9-36

P8-37

K6-81

K6-81

K8-96

P8-55

K1-06
A. Knepp
E6-35
F. Mann
E6-35
D. A. Myers
E6-35
V. J. Rohay
E6-35

\section{Pacific Northwest National Laboratory}

$\begin{array}{ll}\text { B. N. Bjornstad K6-81 } & \text { Ko }\end{array}$

Distr.1 